\title{
Integrating Renewable Energy Technologies in the Electric Supply Industry: A Risk Management Approach
}

T.E. Hoff

Pacific Energy Group Walnut Creek, California

NREL technical monitor: C. Herig

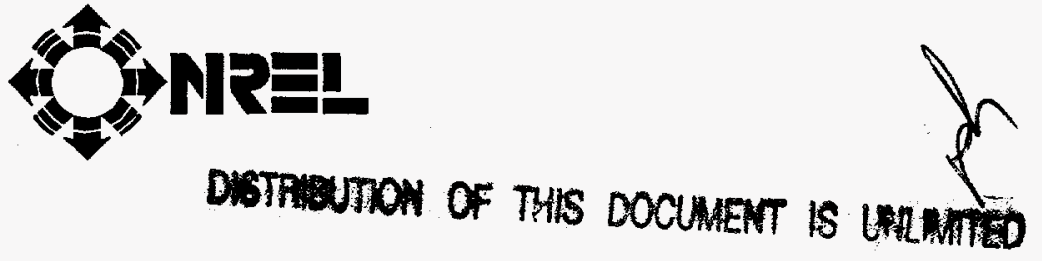

National Renewable Energy Laboratory 1617 Cole Boulevard Golden, Colorado 80401-3393

A national laboratory of the U.S. Department of Energy Managed by Midwest Research Institute for the U.S. Department of Energy under Contract No. DE-AC36-83CH10093

Prepared under Subcontract No. XAX-6-16817-01

July 1997 
This publication was reproduced from the best available camera-ready copy submitted by the subcontractor and received no editorial review at NREL.

\section{NOTICE}

This report was prepared as an account of work sponsored by an agency of the United States government. Neither the United States government nor any agency thereoi, nor any of their employees, makes any warranty, express or implied, or assumes any legal liability or responsibility for the accuracy, completeness, or usefulness of any information, apparatus, product, or process disclosed, or represents that its use would not infringe privately owned rights. Reference herein to any specific commercial product, process, or service by trade name, trademark, manufacturer, or otherwise does not necessarily constitute or imply its endorsement, recommendation, or favoring by the United States govemment or any agency thereot. The views and opinions of authors expressed herein do not necessarily state or reflect those of the United States government or any agency thereof.

Available to DOE and DOE contractors from:

Office of Scientific and Technical Information (OSTI)

P.O. Box 62

Oak Ridge, TN 37831

Prices available by calling (423) $576-8401$

Available to the public from:

National Technical Information Service (NTIS)

U.S. Department of Commerce

5285 Port Royal Road

Springfield, VA 22161

(703) $487-4650$ 


\section{DISCLAIMER}

Portions of this document may be illegible electronic image products. Images are produced from the best available original document. 


\section{EXECUTIVE SUMMARY}

Regulatory and technical forces are causing electric utilities to move from a natural monopoly to a more competitive environment. Associated with this movement is an increasing concern about how to manage the risks associated with the electric supply business. One approach to managing risks is to purchase financial instruments such as options and futures contracts. Another approach is to own physical assets that have low risk attributes or characteristics.

This research evaluates how investments in renewable energy technologies can mitigate risks in the electric supply industry. It identifies risks that are known to be of concern to utilities and other power producers. These risks include uncertainty in fuel prices, demand, environmental regulations, capital cost, supply, and market structure. The research then determines how investments in renewables can mitigate these risks. Methods are developed to calculate the value of renewables in terms of their attributes of fuel costs, environmental costs, lead-time, modularity, availability, initial capital costs, and investment reversibility. Examples illustrate how to apply the methods.

\section{RISK-MITIGATING ATTRIBUTES}

\section{Fuel Costs}

A frequently cited attribute of renewables is that they have no fuel costs. As a result, there is no uncertainty associated with future fuel prices. This research estimates the value of eliminating fuel price uncertainty by evaluating what it would have cost to enter into a long-term, fixed price fuel contract such as a natural gas contract. This transaction has a direct cost and an indirect cost. The direct cost is the present value cost of the fuel contract with the discount rate being the firm's debt rate. The indirect cost is the cost associated with changes in the firm's capital structure because such a contract is comparable to taking out a loan and has characteristics that are similar to debt financing.

\section{Environmental costs}

Renewable energy technologies tend to have minimal costs associated with environmental legislation. This results in a benefit of renewables relative to fossil-based plants. Environmental costs incurred by a fossil-based plant owner fall into two categories. First, there is the added cost of building the fossil-based plant to satisfy current environmental standards. Second, there are the potential costs that the fossil-based plant owner might incur in the future due to environmental standards that have not yet been established. While the added cost to satisfy current standards is typically included in the initial capital cost of the fossil-based plant, potential future costs are not. This research suggests how to calculate these potential costs, and thus the relative benefit associated with renewables.

\section{Lead-time}

Utilities are still considered to be regulated natural monopolies. This requires them to serve all customers regardless of whether or not it is profitable to do so. The interaction between demand 
uncertainty, plant lead-time, and capacity additions is of concern to these utilities. A typical approach to incorporating demand uncertainty is to project high, average, and low demand scenarios. An accurate evaluation of the value of technologies with short lead-times, however, requires that the dynamic nature of demand uncertainty be captured because demand can grow at different rates over time. Results indicate that the value of short lead-time technologies greatly increases when demand is uncertain and the dynamic nature of demand uncertainty is considered.

\section{Modularity}

In addition to having short lead-times, a number of renewable technologies provide plant owners with added value because they are modular and have location flexibility. The value of a short lead-time when combined with modularity and location flexibility can be high when the technologies are used to defer long lead-time T\&D system investments.

\section{Availability}

Modular plants are attractive from an availability perspective. First, modular plants can begin operation as each segment of the total plant is completed. Thus, modular plants produce revenue earlier than non-modular plants. Second, the availability of a modular plant is more certain than non-modular plants if equipment failures are independently distributed. This is because a failure in a modular plant only affects a portion of the plant while a failure in a non-modular plant affects the entire plant.

\section{Initial Capital Costs}

Modular plants are attractive from an initial capital cost perspective. First, fewer capital resources are tied up for a shorter period of time in the plant as it is under construction. This reduces the possibility that the firm building the plant will get into financial difficulty and may result in a lower rate of return required by investors. Second, modular plants have off-ramps so that stopping a project is not a total loss.

\section{Investment Reversibility}

Investment reversibility is the degree to which a completed investment is reversible. A reversible plant will have a high salvage value should the plant owner need to remove the plant for some reason (e.g., if the plant's value becomes low in the particular application). Modular plants are likely to be more reversible than non-modular plants because they can be moved to areas of higher value or used in other applications.

\section{EXAMPLES}

Examples are used to illustrate how to apply the methods listed above; the more detailed examples are as follows. 


\section{Municipal Utility Invests in Wind}

This example compares a municipal utility's decision to invest in a wind plant versus a natural gas plant. The wind investment results in a reduction in fuel price uncertainty, a reduction in environmental cost uncertainty, and enables the utility to respond to demand uncertainty using the wind plant's modularity and short lead-time. The example demonstrates that the inclusion of these attributes can make the wind plant an economically attractive investment.

\section{Utility Extends Grid Using PV}

This example describes a utility's use of customer-owned PV to expand its grid to non-gridconnected areas when there is uncertainty about whether there will be sufficient demand to justify an expansion. The modularity of PV enables the utility to change a loss situation with an immediate grid extension to a profitable opportunity.

\section{Utility Delays T\&D Expansion Using Distributed PV}

This example illustrates how a utility can respond to demand uncertainty on the T\&D system level using distributed PV generation. It demonstrates how the PV can be combined with a system upgrade to be economically attractive even when PV costs alone are excessive.

\section{Renewable Aggregator Invests in Wind}

This example demonstrates how a renewable aggregator can use an investment in wind plants in combination with other generation to satisfy the terms of a power delivery contract. The aggregator can benefit from the project off-ramps associated with wind plants.

\section{CONCLUSIONS AND FUTURE WORK}

The general conclusion of this research is that renewables, particularly the modular technologies such as PV and wind, can provide decision-makers with physical risk-management investments. The specific contributions of this research are that it:

- provides an overview of project evaluation methods as background information;

- describes how renewables can be used to manage known risks faced by various types of plant owners in the electric supply industry;

- develops methods to calculate the risk-mitigating value of the various attributes; and

- applies the methods using simple examples.

There are several aspects of future work that can be pursued. First is to apply the methods to actual case studies where decision-makers are contemplating an investment and a renewable technology may be a good alternative. Second is to further develop the methods presented in this report with an emphasis on more effectively incorporating risk attitude into the analysis. Third is to develop software that enables a wider audience to use the methods developed in this research. 


\section{ACKNOWLEDGEMENTS}

Special thanks goes to Christy Herig and Brian Parsons from NREL and Jack Cadogan from the U.S. Department of Energy for their technical and financial support. They helped to formulate the project, commented on each part of this work as it was completed, and provided excellent support from the beginning to the end of the project.

Detailed review was provided that substantially improved the report. Independent Economist Shimon Awerbuch provided an extensive review of the final draft and Howard Wenger from the Pacific Energy Group, Dan Packee, and Karl Knapp provided feedback on earlier versions. Participants at the Virtual Utility Conference, Stanford University's TEERR group, and the Utility, Wind Modeling Planning Meeting (February 22-23, 1996 at NREL) provided feedback during presentations.

Technical assistance was provided by: Leon Brathwaite from California Energy Commission (CEC's valuation of the risk mitigation of renewable energy technologies); Jonanthan Jacobs from Pacific Gas and Electric Company (PG\&E's valuation of fuel diversity); Peter Lilienthan from NREL (attribute definitions); Jonathan Lowell from New England Electric System (NEES's incorporation of option valuation into investment selection and power contracts valuation); Gerry Nix from NREL (project formulation); Ren Orans from Energy and Environmental Economics (transmission cost information); Kevin Porter and Blair Swezey from NREL and Jan Hamrin (definition of the renewable aggregator concept); and Carl Weinberg from Weinberg and Associates (regulatory perspective). 


\section{CONTENTS}

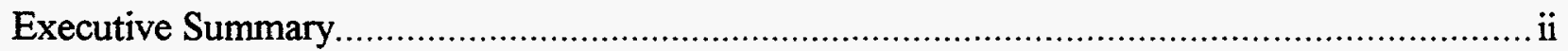

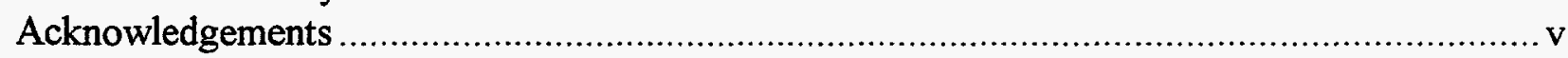

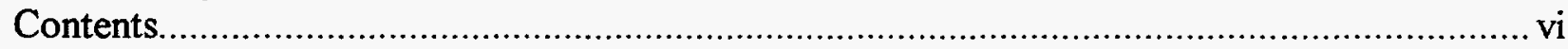

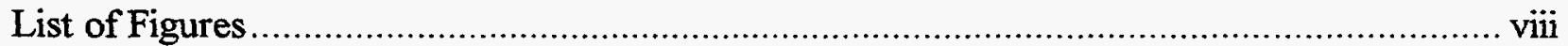

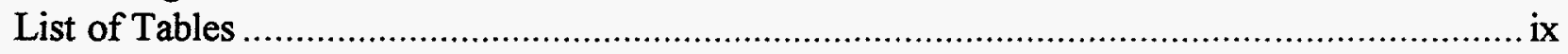

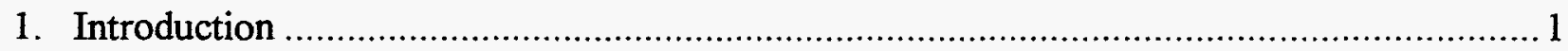

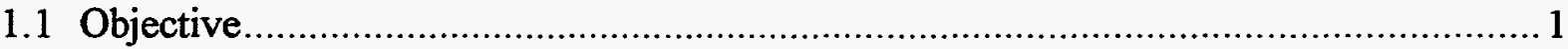

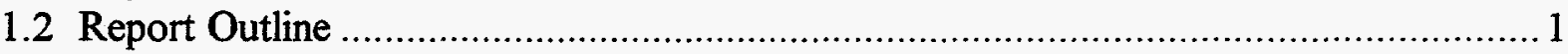

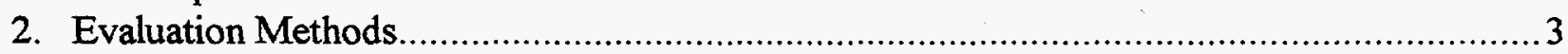

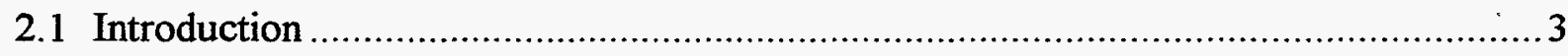

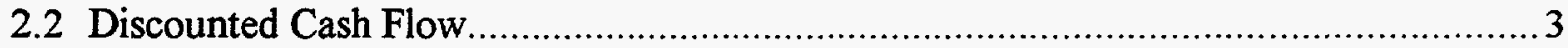

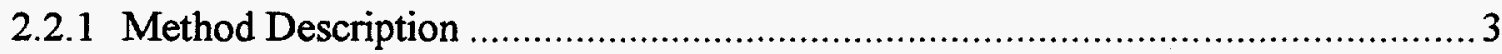

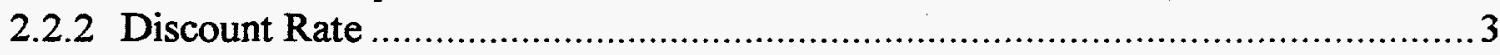

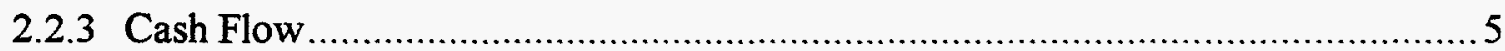

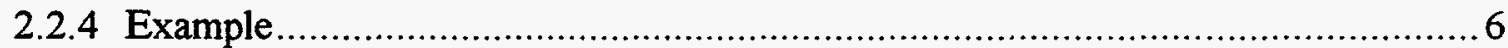

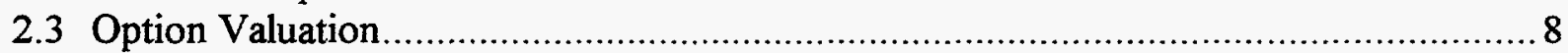

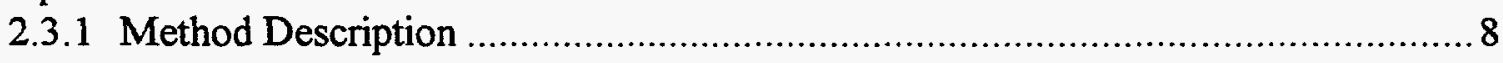

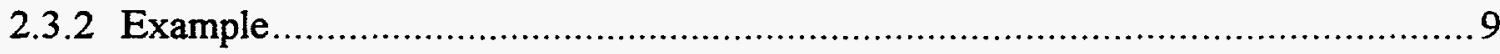

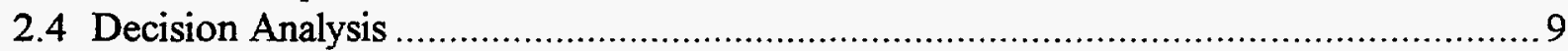

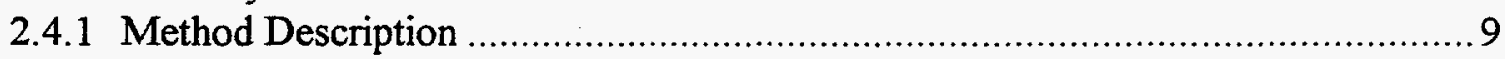

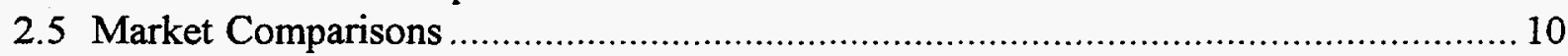

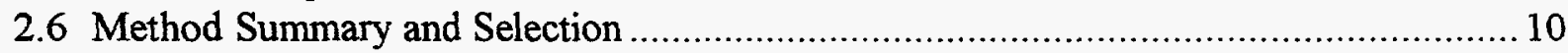

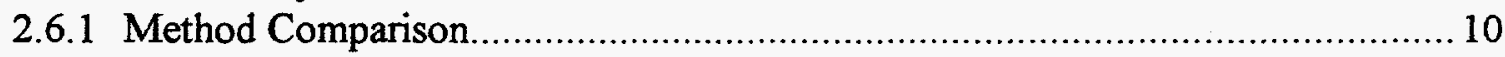

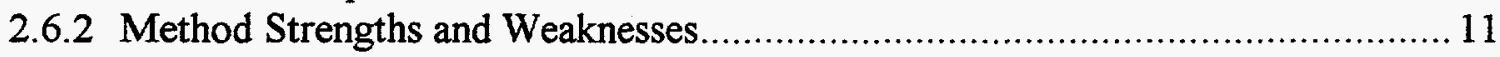

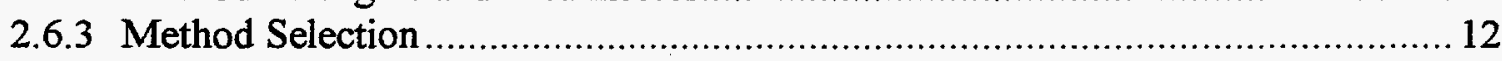

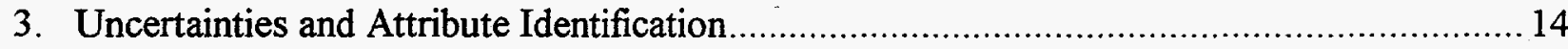

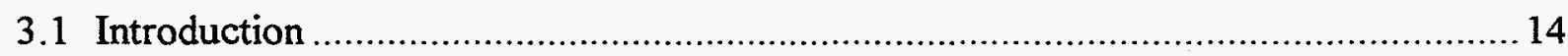

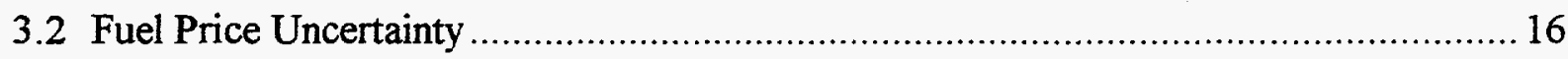

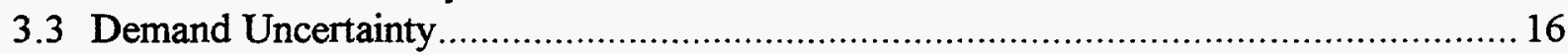

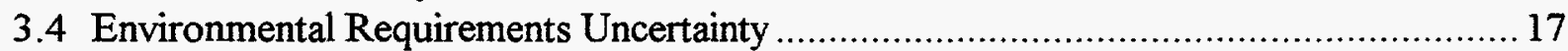

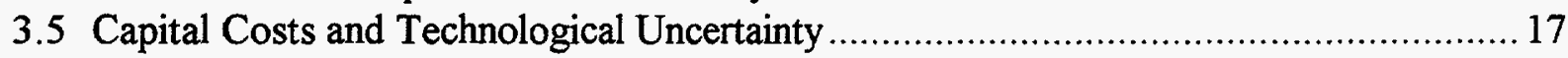

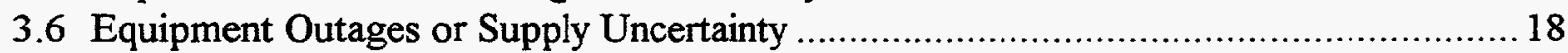

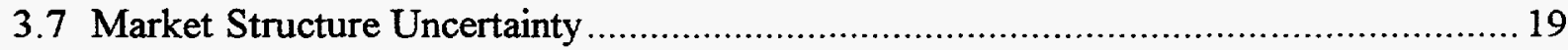

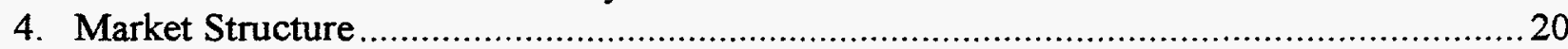

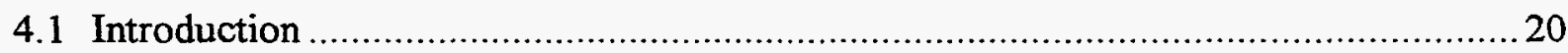

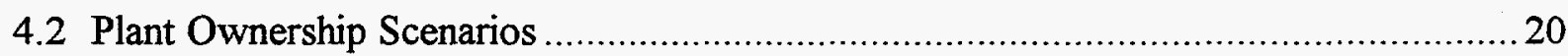

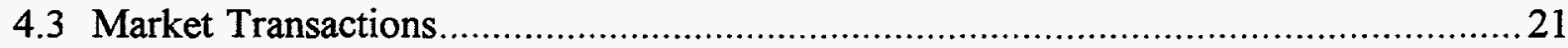

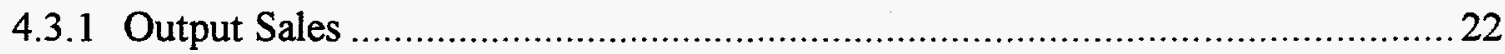

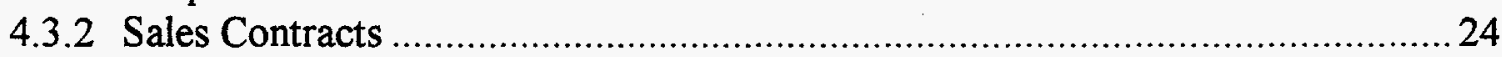

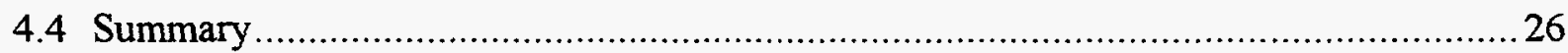

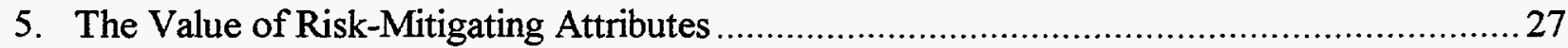

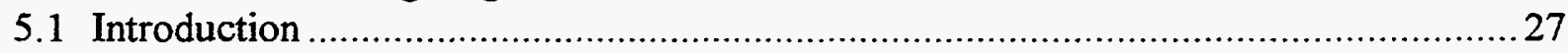

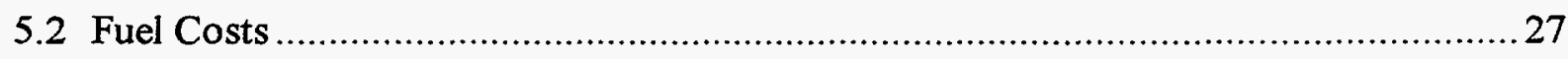




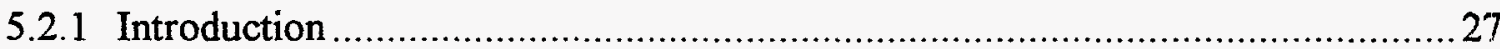

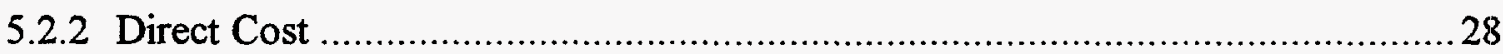

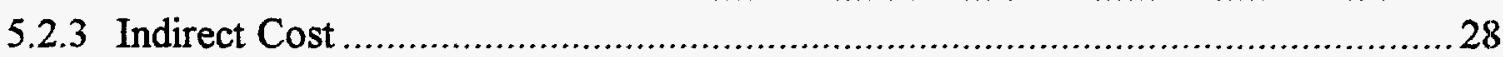

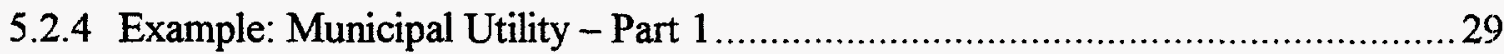

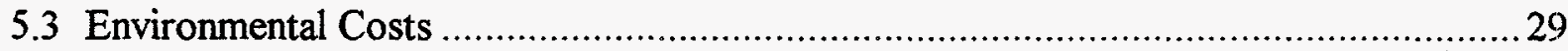

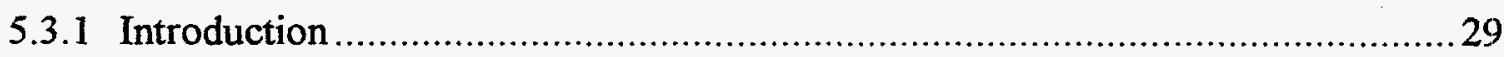

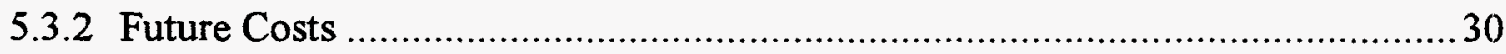

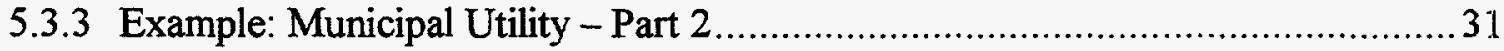

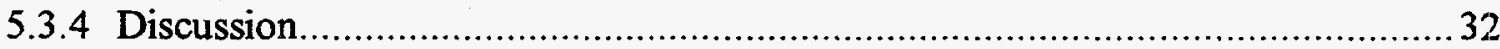

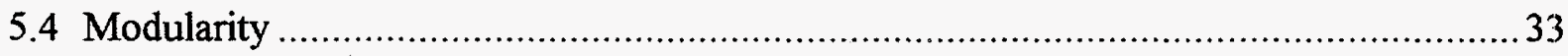

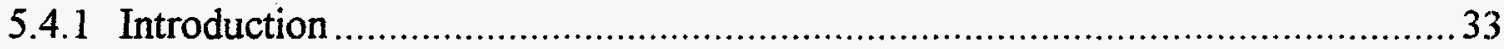

5.4.2 Example: Extending the Utility Grid using PV Generation .................................33

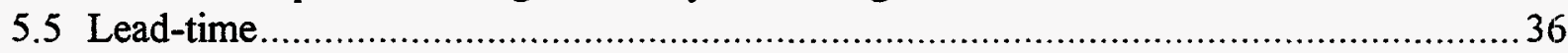

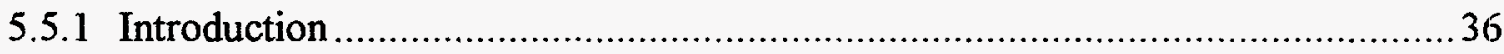

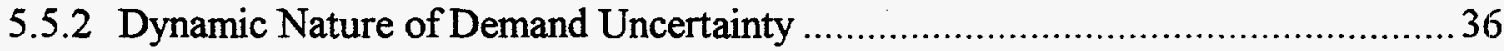

5.5.3 Interaction Between Lead-Time and Demand Uncertainty .................................33

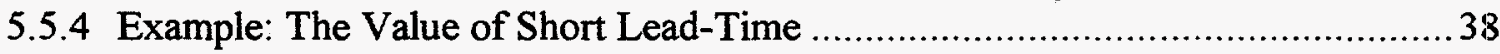

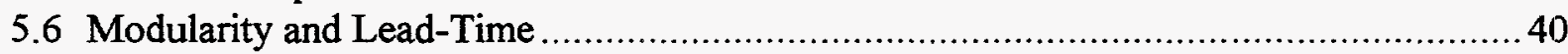

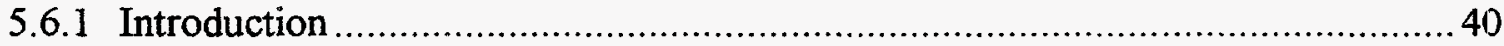

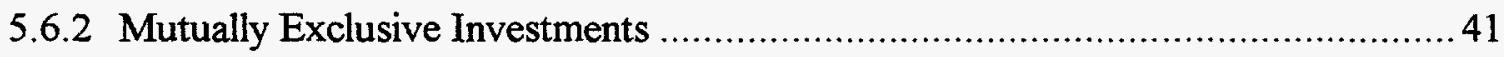

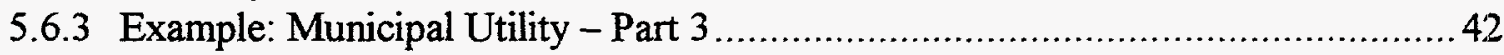

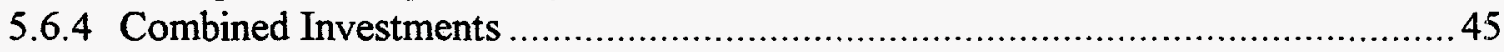

5.6.5 Example: Lead-Time and Modularity for T\&D System with PV ......................45

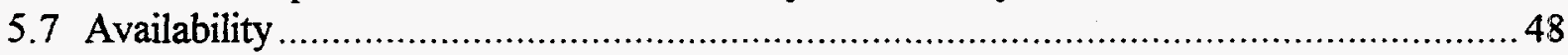

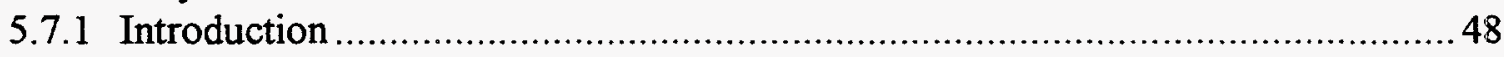

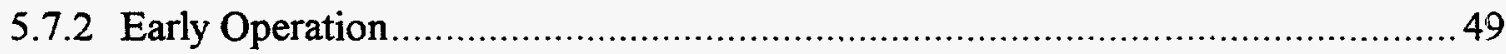

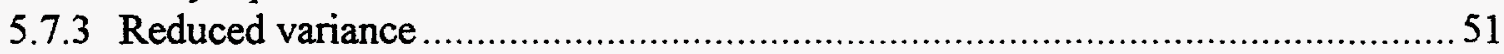

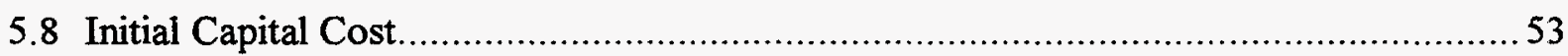

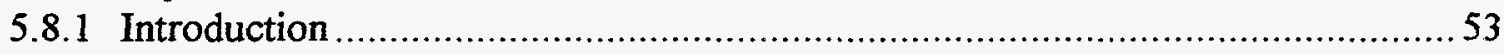

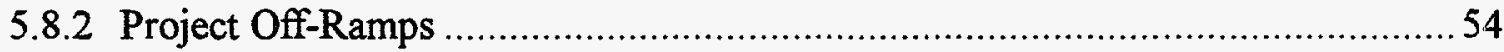

5.8.3 Example: Project Off-Ramps Associated with Wind Project .............................55

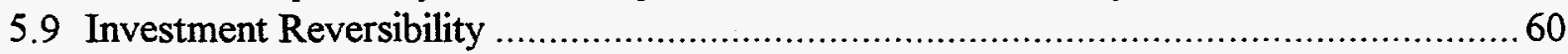

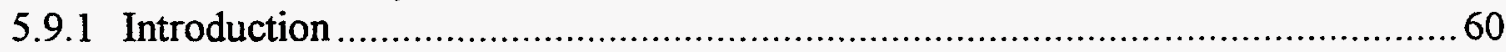

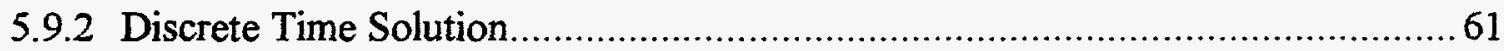

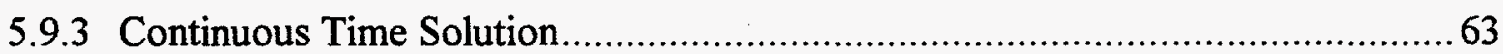

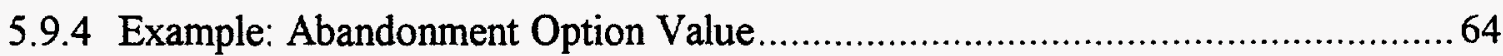

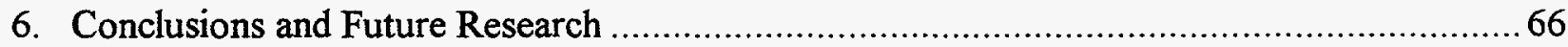

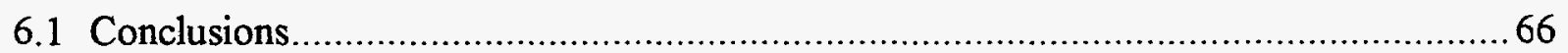

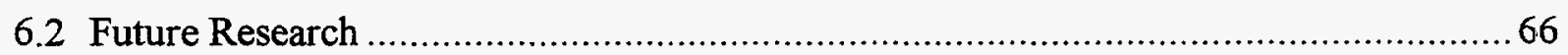

6.2.1 Apply Results to Actual Case Studies ..........................................................66

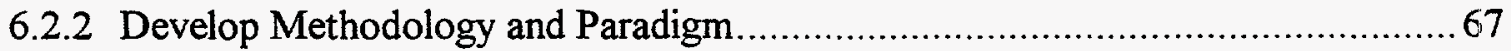

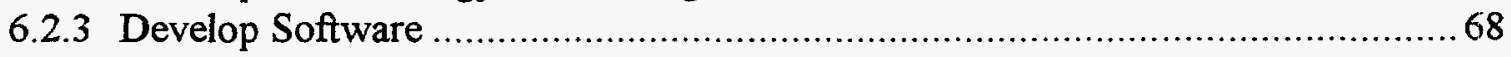

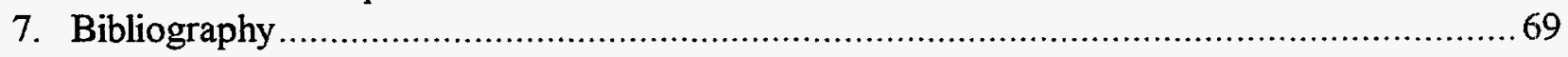




\section{LIST OF FIGURES}

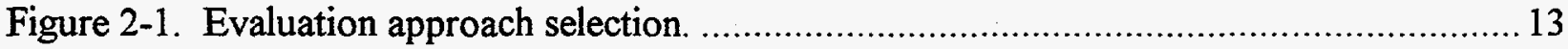

Figure 4-1. Additions to PG\&E's undepreciated assets. ...................................... 21

Figure 4-2. Current electric supply system. ............................................................ 22

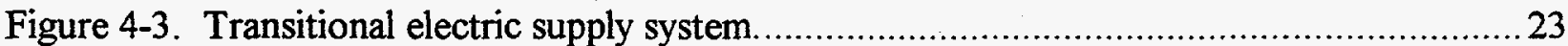

Figure 4-4. Competitive electric supply system. .......................................................... 24

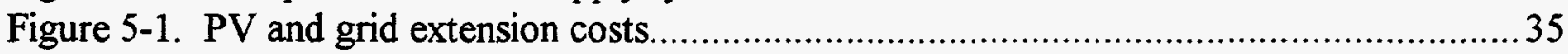

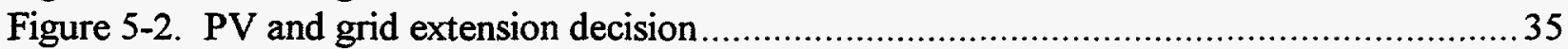

Figure 5-3. Demand growth using a static evaluation approach..................................... 37

Figure 5-4. Demand growth using a dynamic evaluation approach. .................................. 37

Figure 5-5. Value of short lead-time using static and dynamic evaluation approaches............. 39

Figure 5-6. Benefits of distributed generation. ........................................................ 41

Figure 5-7. Municipal utility capacity and peak demand. .............................................44

Figure 5-8. Municipal utility capacity with gas and wind plants. ....................................... 44

Figure 5-9. Cost of using PV and upgrade to satisfy T\&D capacity ................................. 48

Figure 5-10. Modular plant produces revenue earlier than non-modular plant. .......................49

Figure 5-11. Value of early availability increases with construction time. ............................ 51

Figure 5-12. Distribution of plant outages for a two-unit modular plant. .............................552

Figure 5-13. Variance of availability versus number of segments..................................55

Figure 5-14. Modular plants have lower unrecovered costs than non-modular plants.............. 54

Figure 5-15. Project off-ramps associated with modular plants........................................ 56

Figure 5-16. Project off-ramps associated with modular plants - example ............................56

Figure 5-17. Staged wind plant investment ................................................................. 59

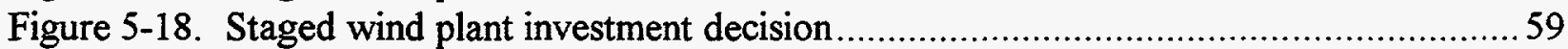

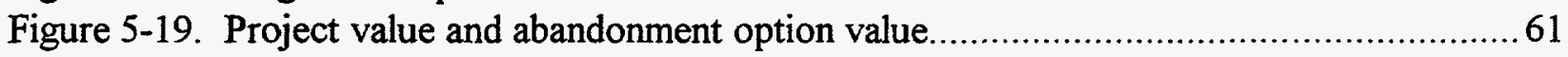

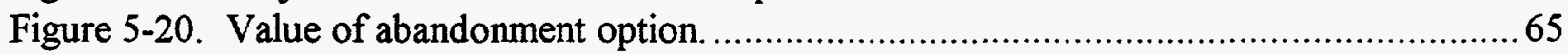




\section{LIST OF TABLES}

Table 2-1. After-tax weighted average cost of capital calculation.................................. 4

Table 2-2. Discounted cash flow example................................................................. 7

Table 2-3. Project evaluation method summary........................................................... 11

Table 3-1. Resource attributes relevant to utility decisions. ............................................. 15

Table 3-2. Interaction between uncertainties and attributes. ............................................ 15

Table 4-1. Important attributes to various decision-makers. ...........................................26

Table 5-1. Municipal utility example........................................................................ 43

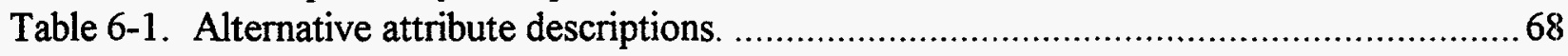




\section{INTRODUCTION}

\subsection{OBJECTIVE}

One of the goals of the U.S. Department of Energy's Division of Conservation and Renewable Energy is to advance the commercial deployment of renewable energy systems. An essential element is to identify markets for renewable energy technologies in the evolving utility industry.

Regulatory and technical forces are causing electric utilities to move from a natural monopoly to a more competitive environment. Associated with this movement is an increasing concern about how to manage the risks associated with the electric supply business, issues that were previously considered to be unimportant in the monopolistic environment. This includes, for example, recognizing hidden costs associated with risk (Brown and Ryngaert 1994, Kolbe, et. al. 1994, Kolbe and Tye 1995, Lively 1994) and effectively using financial risk management tools (Cater 1995, Jones and Felder 1994, Speckman and Schleimer 1995).

One approach to managing risks is to purchase financial instruments such as options and futures contracts. Another approach is to own physical assets that have low risk attributes or characteristics. That is, decision-makers can invest in tangible assets to manage risks rather than using financial instruments. This research takes the second approach and investigates the potential of mitigating risk in the electric supply industry by owning renewable energy technologies. By doing so, it combines the goal of advancing the commercial deployment of renewable energy technologies with the electric supply industry's goal of managing risk.

\subsection{REPORT OUTLINE}

The report is organized as follows. Chapters 2 through 4 lay the foundations necessary to perform the analysis. Chapter 2 describes methods that can be used to evaluate investments when there is uncertainty and managerial flexibility. It compares the methods, summarizes their strengths and weaknesses, and recommends the most appropriate method given the available information. Chapter 3 describes uncertainties that are of concern in the electric supply industry and introduces how renewables can address these uncertainties. Chapter 4 discusses important market structure issues as they apply to this work.

Chapter 5 presents the bulk of the research. It qualitatively discusses the risk-mitigating attributes of renewables, it develops detailed methods to numerically quantify the risk-mitigation value of each of the attributes, and it presents examples of how to apply the methods. Explicit consideration is given to the attributes of fuel costs, environmental costs, lead-time, modularity, location flexibility, availability, initial capital costs, and investment reversibility. While examples are provided for each attribute, the more detailed examples include: 
- a municipal utility's investment in wind; this results in a reduction in fuel price uncertainty (Section 5.2.4), a reduction in environmental cost uncertainty (Section 5.3.3), and enables the utility to respond to demand uncertainty using the wind plant's modularity and short lead-time (Section 5.6.3);

- a utility's expansion of the grid to non-grid-connected areas using customer-owned PV when there is demand uncertainty (Section 5.4.2);

- a utility's use of distributed PV generation to respond to demand uncertainty on the T\&D system (Section 5.6.5); and

- a renewable aggregator's use of wind technologies and the project off-ramps that they provide (Section 5.8.3).

Conclusions and recommendations for future research are presented in Chapter 6 . In general, this research concludes that renewable energy technologies, especially modular technologies such as PV and wind, can provide decision-makers with physical risk-management investments. In particular, it:

- provides an overview of project evaluation methods as background information;

- describes how renewables can be used to manage known risks faced by various types of plant owners in the electric supply industry;

- develops methods to calculate the risk-mitigating value of the various attributes; and

- applies the methods using simple examples.

Future research includes: applying this work to actual case studies where decision-makers are contemplating an investment and a renewable technology may be a good alternative; further developing the evaluation methodology presented in this report and perhaps even constructing a new paradigm; and creating software to facilitate the use of the results presented in this report by others. 


\section{EVALUATION METHODS}

\subsection{INTRODUCTION}

This chapter lays the foundations necessary to calculate the value of mitigating risk in the electric supply industry using renewables. ${ }^{1}$ It reviews methods to evaluate investments when there is uncertainty and managerial flexibility and presents simple examples of how to apply the methods. The methods are discounted cash flow (Section 2.2), option valuation (Section 2.3), decision analysis (Section 2.4), and contract comparisons (Section 2.5). Section 2.6 compares the methods, summarizes their strengths and weaknesses, and suggests which method to use based on the available information and type of project.

\subsection{DISCOUNTED CASH FLOW}

\subsubsection{Method Description}

The discounted cash flow method discounts expected future cash flows at some discount rate and sums the result. This is also called the net present value method.

$$
\text { Value }=C_{0}+\sum_{i=1}^{T} \frac{E\left(C_{t}\right)}{(1+r)^{2}}
$$

where Value is the investment's net present value, $C_{0}$ is the certain after-tax cash flow at time 0 , $E\left(C_{t}\right)$ is the expected after-tax cash flow at time $t, T$ is the investment's life, and $r$ is the riskadjusted discount rate. ${ }^{2}$

Equation (2.1) has two critical inputs: (1) the discount rate; and (2) the probability distribution of the investment's future cash flows. The following subsections consider selection of the discount rate and evaluation of cash flows.

\subsubsection{Discount Rate}

A first approach to selecting the discount rate is an engineering economics approach (e.g., Lang and Merino 1993, Thuesen and Fabrycky 1993). This is the approach most often used by electric utilities. This approach uses the company's after-tax weighted average cost of capital (WACC) as the discount rate. The WACC equals the arithmetic average of the company's source of new capital funds with explicit consideration given to the effect of taxes (Brealey and Myers 1991, p. 465). For example, a utility that has half debt financing (at 8.0 percent), half equity financing (at 12.0 percent), and a combined effective tax rate of 40 percent has an 8.4 percent after-tax WACC as presented in Table 2-1.

Most of the analysis and results apply to demand side management programs as well.

2 While $r$ is specified in Equation (2.1) as a constant, it can be a function of time so that the discount rate changes over the investment's life (Robichek and Myers 1966; Fama 1977; Myers and Turnbull 1977; Hull 1986) 
Table 2-1. After-tax weighted average cost of capital calculation.

\begin{tabular}{|c|c|c|c|c|}
\hline $\begin{array}{l}\text { Capital } \\
\text { Source }\end{array}$ & $\begin{array}{l}\text { Capital } \\
\text { Ratio }\end{array}$ & $\begin{array}{c}\text { Capital } \\
\text { Cost }\end{array}$ & $\begin{array}{l}\text { Adjustment } \\
\text { for Taxes }\end{array}$ & $\begin{array}{l}\text { Weighted } \\
\text { Cost }\end{array}$ \\
\hline Debt & 0.5 & 8.0 & $(1-0.4)$ & 2.4 \\
\hline Equity & 0.5 & 12.0 & 1 & 6 \\
\hline
\end{tabular}

Using the company's WACC as the discount rate is valid in the case where the risk characteristics of the investment under consideration are similar to the company's overall risk characteristics and capital structure (Copeland, Koller, and Murrin 1991) and the analysis focuses on net present value. Incorrect results, however, can occur when this is not the case.

A second approach to selecting the discount rate is to use a corporate finance solution. This approach selects the project-specific WACC or discount rate using market information (Brealey and Myers 1991, chapter 9; Ross, Westerfield, and Jaffe 1993, chapter 12; van Horne 1995, chapter 8). The procedure uses the Capital Asset Pricing Model ${ }^{3}$ to determine the correct discount rate. One selects a publicly traded company whose risk characteristics are similar to the risk characteristics of the project under consideration. The equity beta (a parameter used in the Capital Asset Pricing Model) of this company is determined by looking it up in a financial publication such as Value Line (1995) and adjusted to reflect the differences between the two companies' leveraging policies (i.e., debt to equity ratios). The adjusted beta is used to calculate the equity rate of return associated with the investment using the Capital Asset Pricing Model. Finally, the equity and debt rates are combined to determine the project-specific WACC as was done in Table 2-1.

A third approach is possible when the focus is only on costs rather than the net present value. One example of this is when revenues from two mutually exclusive projects will be identical but the cash outflows will be different (Booth 1982, Copeland and Weston 1986, pp. 414-419). A project's beta (and thus its discount rate) can be estimated as the weighted average of the revenue and cost betas. Copeland and Weston show that this can theoretically result in negative betas for the cash outflows. They caution, however, that it is never advisable to totally ignore revenues or the risk of the revenue stream because this may result in selecting a project that has a negative net present value.

3 The Capital Asset Pricing Model states that a stock's risk-adjusted discount rate is $r=r_{f}+\beta\left(r_{m}-r_{f}\right)$ where $r_{f}$ is the risk-free discount rate, $r_{m}$ is the discount rate for the market portfolio, and $\beta$ is a measure that depicts the sensitivity of the stock's excess rate of return to that of the market portfolio and the risk-free discount rate. A detailed discussion about the Capital Asset Pricing Model and beta can be found in any basic finance textbook (e.g., Brealey and Myers 1991, pp. 161-165 and pp. 181-189). 
Awerbuch and Deehan (1995) and Awerbuch (1995) take this third approach in applications to the electric utility industry. These authors disaggregate projects and examine the various cash outflow components (i.e., fuel cost, fixed cost, variable O\&M costs, etc.). Awerbuch obtains betas specific to the various project components and then uses the Capital Asset Pricing Model to determine the appropriate discount rates. Awerbuch estimates fuel betas by regressing historical fuel prices (rather than historical stock prices) with market performance. ${ }^{4}$

\subsubsection{Cash Flow}

The second critical input required in Equation (2.1) is a probability distribution of the investment's future cash flows. The approach that is most often used by electric utilities is to project a single net cash flow and then discount this at the company's WACC. A more detailed approach is to select several possible scenarios and assign probability distributions to each scenario, calculate the expected cash flow, and discount the expected cash flow at the riskadjusted discount rate. While these approaches are widely used in practice, they can result in inaccurate value if projects have managerial flexibility. Managerial flexibility is the ability to alter a project's direction as uncertainties are resolved.

It is widely accepted that static versions of the discounted cash flow method do not adequately account for operating flexibility and other strategic aspects associated with a project (e.g., Trigeorgis and Mason 1987). This is because decision-makers often have the opportunity to alter a project's direction as new information is revealed over time.

Thus, it must be determined how management can respond as uncertainty is resolved. This is often best accomplished through the drawing of decision trees. After drawing the decision tree and the cash flow for each branch of the tree is determined, one takes the expected value of the cash flows for each time period and discounts the results at the risk-adjusted discount rate.

Smith and Nau (1995) and Hoff (1996) show that selecting the correct discount rate is the most problematic aspect of this approach. One typically selects the discount rate from an asset in the market with the same risk characteristics as the project under consideration. The problem is that there is often no asset that has the same risk characteristics as the project when flexibility is considered. In essence, rather than correlating project cash flows with a stock, one must correlate cash flows with a financial option that has identical characteristics as the project.

4 These efforts are of particular interest because the authors find that the fuel discount rates are lower than the risk-free discount rate. This results in very high present value fuel costs. The authors state that this is due to the fact that fuel prices are negatively correlated with the market.

Several comments are in order. First, while the economy may slow during large oil price shocks, it is not clear that fuel prices are negatively correlated with the market in general (Bernhardt 1994, Bodmer and Waldman 1995). Second, while negative betas (i.e., betas that are less than zero) are theoretically possible, they are rare. For example, the beta for every one of the 1,700 stocks listed in the Value Line Investment Survey (1995) had positive betas. Third, the beta for Enron, a large gas supply company, was 0.80 (Enron has a capital structure similar to many electric utilities - half debt, half equity); this is slightly larger than the betas of many of the electric utilities. Thus, Enron has a higher WACC than most utilities if Enron's cost of debt is the same as the cost of debt for most utilities. These observations suggest that further analysis is needed to confirm whether or not fuel discount rates are as low as Awerbuch finds. 


\subsubsection{Example}

The following example illustrates how the discounted cash flow method can be applied to project evaluation under uncertainty. The example is intended to be simple so that the method can be illustrated. For this reason, it lacks some of the more complicating factors, such as multiple uncertainties and multiple time periods, likely to be encountered in evaluating real projects.

Management may invest in one of two mutually exclusive energy generation projects, each of which will provide revenues only in 1998. As shown in Table 2-2, Project A has a one-year leadtime and requires a $\$ 900$ investment in 1997 to be ready in 1998 . Project $B$ has no lead-time and costs $\$ 1,500$ in 1998. Ignore Project B' for the moment. Revenues are uncertain and will be either $\$ 1,800$ or $\$ 600$ in 1998 .

The net present value of Project $A$ is the 1997 cost of $\$ 900$ plus the expected 1998 revenues of $\$ 1,200$ (50\% chance of $\$ 1,800$ and $50 \%$ chance of $\$ 600$ ) discounted to 1997 . Table $2-2$ provides the market data necessary to select the correct discount rate to discount the revenues to 1997 . It is the same as the stock's discount rate because the revenues can be replicated in each state by purchasing 50 shares of stock. The result, as presented in the Analysis section of Table 2-2, is a net present value of $\$ 100$. Project $B$ has its 1998 cost discounted at the bond rate (because the cost occurs with certainty) and the 1998 revenues discounted at the stock rate. Its net present value is $-\$ 389$. This suggests that Project $A$ is preferred to Project $B$.

This evaluation of Project B, however, fails to account for managerial flexibility. Management will wait until revenue uncertainty is resolved in 1998 to invest in Project B. It will spend \$1,500 if revenues are $\$ 1,800$ but will not make the investment if revenues are $\$ 600$. Thus, a more accurate reflection of management's position is Project B'.

Project $\mathrm{B}^{\prime}$ is more difficult to evaluate using a discounted cash flow analysis because the both the cost and revenue are state dependent. The market data in Table 2-2 do not directly provide the needed discount rate to perform the analysis. As a result, it is not known whether Project A or Project $\mathrm{B}^{\prime}$ is preferred. 
Table 2-2. Discounted cash flow example.

\begin{tabular}{|c|c|c|c|}
\hline \multicolumn{4}{|c|}{ Project Cash Flows } \\
\hline Project & $\begin{array}{c}\text { Project } A \\
1 \text { yr. Lead-time }\end{array}$ & $\begin{array}{c}\text { Project B } \\
\text { (No Lead-time, } \\
\text { Inflexible) }\end{array}$ & $\begin{array}{c}\text { Project B' } \\
\text { (No Lead-time, } \\
\text { Flexible) }\end{array}$ \\
\hline Cost (1997) & $\$ 900$ & - & - \\
\hline Cost (1998) & - & $\$ 1,500$ & $\begin{array}{l}50 \%-\$ 1,500 \text { in } 1998 \\
50 \%-\quad \$ 0 \text { in } 1998\end{array}$ \\
\hline Revenues (1998) & $\begin{array}{l}50 \%-\$ 1,800 \\
50 \%-\quad \$ 600 \\
\end{array}$ & $\begin{array}{l}50 \%-\$ 1,800 \\
50 \%-\quad \$ 600 \\
\end{array}$ & $\begin{array}{l}50 \%-\$ 1,800 \\
50 \%-\quad \$ 0 \\
\end{array}$ \\
\hline \multicolumn{4}{|c|}{ Market Data } \\
\hline Asset & Bond & & Stock \\
\hline Price (1997) & $\$ 100$ & & $\$ 20$ \\
\hline Value (1998) & $\$ 108$ & & $\begin{array}{l}50 \%-\$ 36 \\
50 \%-\$ 12 \\
\end{array}$ \\
\hline Discount Rate ${ }^{5}$ & $8 \%$ & & $20 \%$ \\
\hline \multicolumn{4}{|c|}{ Net Present Value Analysis } \\
\hline & Project A & Project B & Project B' \\
\hline Net Present Value & $\begin{array}{c}-900+ \\
1 / 2\left(\frac{1,800+600}{1+0.2}\right)\end{array}$ & $\begin{array}{c}-\frac{1,500}{1+0.08} \\
1 / 2\left(\frac{1,800+600}{1+0.2}\right)\end{array}$ & $1 / 2\left(\frac{1,800-1,500}{1+r}\right)$ \\
\hline Result & $\$ 100$ & $-\$ 389$ & Unknown \\
\hline \multicolumn{4}{|c|}{ Option Valuation Analysis } \\
\hline & Project A & Project B & Project B' \\
\hline Option Valuation & $\begin{array}{c}-900+ \\
\frac{0.4 \times 1,800+0.6 \times 600}{1+0.08}\end{array}$ & $\begin{array}{c}\frac{0.4 \times(1,800-1,500)}{1+0.08}+ \\
\frac{0.6 \times(600-1,500)}{1+0.08}\end{array}$ & $\begin{array}{c}\frac{0.4 \times(1,800-1,500)}{1+0.08}+ \\
\frac{0.6 \times(0)}{1+0.08}\end{array}$ \\
\hline Result & $\$ 100$ & $-\$ 389$ & $\$ 111$ \\
\hline
\end{tabular}

5 The discount rate equals the expected value in 1998 divided by the price in 1997 minus 1. 


\subsection{OPTION VALUATION}

\subsubsection{Method Description}

Option valuation is an alternative method that can be used to determine a project's value under uncertainty. This method is based on work from option valuation in financial economics, an area that is becoming of greater interest to utilities given the competitive environment (Jones and Felder 1994; Kaslow and Pindyck 1994; Cater 1995). Performing an option valuation requires that the project be spanned by existing traded assets. This means that the project's cash flow is perfectly correlated with some portfolio of traded assets so that the project's cash flow and the portfolio's value are identical in every future state of the world. The requirement, which is called spanning, is more stringent than simply requiring that the investment has the same risk characteristics as a portfolio of market traded assets.

The existence of state prices is the unifying principle in asset pricing in financial markets (Duffie 1992). If they exist, there is one price for each state of the world at each date. State prices take into account uncertainty and discounting over time. A state price is the current price of a security that pays off $\$ 1$ if a particular state occurs in the future and pays off $\$ 0$ in all other states. The price of any security is determined according to these state prices and the security's cash flows. Security price is the state-price weighted sum of its future cash flows.

There are several ways to represent this value mathematically. One way, as described in the previous paragraph, is to multiply the state price times the security's cash flow for each state at each date and then sum the results. Cox and Ross (1976), Constantinides (1978), as well as others, have shown that any contingent, or state-dependent, claim on an asset can be priced in a world with systematic risk by replacing its actual growth rate with its risk-free growth rate and then behaving as if the world were risk neutral. That is, the state prices are the risk-neutral probabilities (rather than the actual probabilities) discounted at the risk-free discount rate. Thus, one way to write the value of the investment is

$$
\text { Value }=C_{0}+\sum_{t=1}^{T} \frac{\hat{E}\left(C_{t}\right)}{\left(1+r_{f}\right)^{2}}
$$

where Value is the investment's current value, $C_{0}$ is the after-tax cash flow at time $0, \hat{E}\left(C_{t}\right)$ is the risk-neutral expectation of the after-tax cash flow at time $t, T$ is the investment's life, and $r_{f}$ is the risk-free discount rate.

There are a number of energy related studies that use option valuation. Teisberg (1993) uses option valuation to evaluate the flexibility to delay or abandon projects and to show why firms prefer to invest in smaller, shorter lead-time plants. Kaslow and Pindyck (1994) and Lowell (1995) demonstrate how to use option valuation to value flexibility of generating plants (or contracts) with shorter lead-times and how to build valuable "buyout" options into a contract so that the utility has capacity available if it needs it while still protecting itself from purchasing capacity it does not need. Hassett and Metcalf (1993) use option valuation to show why 
consumers are less likely to invest in conservation technologies since they have high initial capital costs.

\subsubsection{Example}

Consider the example presented in Table 2-2. The first step of the option valuation method is to determine the set of state prices associated with the existing securities. There should be no arbitrage opportunities since the market is in equilibrium. The absence of arbitrage means that there is no way to lock in a risk-free profit by simultaneously entering into two or more market transactions. In essence, this means that the risk-neutral probabilities discounted at the risk-free discount rate (i.e., the state prices) times the future value of the market assets equals the their current price. The risk-neutral probabilities in this example are 0.4 and 0.6 rather than the actual probabilities of 0.5 and $0.5^{6}$

These state prices are used to perform the option valuation for Projects A, B, and B'. The results are presented in Table 2-2. The table shows that identical results are obtained for Projects $A$ and $\mathrm{B}$ as in the discounted cash flow analysis. In addition, a result of $\$ 111$ is obtained for Project B'. (Note that this implies that the correct discount rate would have to be 35 percent, which is neither the same as the bond or the stock.) This means that Project $\mathrm{B}^{\prime}$ is preferred to Project $\mathrm{A}$.

\subsection{DECISION ANALYSIS}

\subsubsection{Method Description}

Decision analysis is a systematic procedure for assessing the value of a project to a particular decision-maker using certain rules of thought (Howard 1992). Decision analysis structures important uncertainties and future decisions in the form of a decision tree. The decision-maker's time and risk preferences are determined through the utility function. (Note that "utility" as used in "utility function" is an economics term used to measure value or worth. The utility function measures how a decision-maker values wealth or consumption. One should not confuse utility used in this sense with electric utility.) Decision analysis "folds back" the decision tree in order to select the optimal decision. Decision analysis uses expected utility theory from the field of economics to determine the certain equivalent of the uncertain cash flow and then usually discounts the result at the risk-free discount rate.

$$
\text { Value }=C_{0}+\sum_{t=1}^{T} \frac{C E_{t}}{\left(1+r_{f}\right)^{t}}
$$

where Value is the investment's current value, $C_{0}$ is the certain after-tax cash flow at time $0, C E_{t}$ is certain equivalent of the uncertain cash flow $C_{t}$ at time $t, T$ is the investment's life, and $r_{f}$ is the risk-free discount rate. The certain equivalent is the size of the payoff that the decision-maker requires in order to be indifferent between it and the uncertain cash flow.

6 This is because for the bond, $(0.4 / 1.08) * \$ 36+(0.6 / 1.08) * \$ 12=\$ 20$.

$(0.4 / 1.08) * \$ 108+(0.6 / 1.08) * \$ 108=\$ 100$ and for the stock, 
Decision analysis has been used extensively in evaluating uncertainty in the electric utility industry (Hobbs and Maheshwari 1990). There are a number of decision analysis studies that focus specifically on renewable energy technologies. Cadogan, et. al. (1992) use decision analysis to compare a utility's investment in either a gas-fired combined cycle plant or a hybrid wind-gas turbine plant given uncertainties of demand, installed capital cost, fuel cost and fuel escalation. Morris, et. al. (1993) use decision analysis to assess the value of flexibility associated with distributed photovoltaic generation technologies. ${ }^{7}$

\subsection{MARKET COMPARISONS}

A fourth approach, though not specifically a formal method, is to determine the value of a project by examining contracts that are offered in the market. These contracts could include futures or forwards contracts. The approach here is to create a portfolio that contains the renewable energy project so that it looks exactly like a contract that is being offered in the market place. The value of the renewable energy project is the value of the contract that is offered in the market. Awerbuch $(1995$, p. 63) has done some initial work in this area by valuing fuel costs based on long-term gas contracts and Lively (1994) considers the possibility of long-term transmission contracts as being futures contracts.

Care must be exercised in assessing the risk associated with the contract in the discounting process. The value of a long-term contract is only as secure as the risk of default of parties on both sides of the contract. The utility must consider the risk of default of the one providing the services or commodities of the contract and the one offering the contract must consider the risk of default of the utility. Thus, while contracts may be fixed price, they are not necessarily risk-free.

\subsection{METHOD SUMMARY AND SELECTION}

\subsubsection{Method Comparison}

It is helpful to compare the methods before summarizing their strengths and weaknesses. Each of the method's mathematical formulations are restated in Table 2-3 for purposes of convenience. The notation in the table is that $r$ is the risk-adjusted discount rate, $r_{f}$ is the risk-free discount rate, $C_{o}$ is the after-tax cash flow at time $0, E\left(C_{t}\right)$ is the expected after-tax cash flow in a risky world at time $t, \hat{E}\left(C_{t}\right)$ is the expected after-tax cash flow in a risk-neutral world at time $t, C E_{t}$ is certain equivalent of the uncertain cash flow $C_{t}$ in a risky world at time $t$, and $T$ is the investment's life.

7 An example of the application of decision analysis can be found in Hoff (1996). 
Table 2-3. Project evaluation method summary.

\begin{tabular}{|c|c|c|}
\hline Discounted Cash Flow & Option Valuation & Decision Analysis \\
\hline$C_{0}+\sum_{t=1}^{T} \frac{E\left(C_{t}\right)}{(1+r)^{t}}$ & $C_{0}+\sum_{t=1}^{T} \frac{\hat{E}\left(C_{t}\right)}{\left(1+r_{f}\right)^{t}}$ & $C_{0}+\sum_{t=1}^{T} \frac{C E_{t}}{\left(1+r_{f}\right)^{t}}$ \\
\hline$C_{0}=$ cash flow at time 0 & $C_{0}=$ cash flow at time 0 & $C_{0}=$ cash flow at time 0 \\
$C_{t}=$ cash flow at time $\mathrm{t}$ & $C_{t}=$ cash flow at time $\mathrm{t}$ & $C E_{t}=$ certain equivalent \\
$E()=$ expected value & $\hat{E}()=$ expected value & of cash flow $C_{t}$ \\
in risky world & in risk - free world & at time $\mathrm{t}$ \\
$r=$ risk - adjusted & $r_{f}=$ risk -free & $r_{f}=$ risk - free \\
discount rate & discount rate & discount rate \\
$T=$ ending period & $T=$ ending period & $T=$ ending period \\
\hline
\end{tabular}

All three methods are similar in that they calculate a single number for the value of the net cash flow at time $t$ and then discount the result. They are also similar in that they can be used in a dynamic framework to account for managerial flexibility by specifying the state-specific cash flows. That is, each of the methods can accommodate the "option-like" nature of managerial flexibility.

The methods differ, however, in how they deal with risk. The discounted cash flow method takes the risky cash flows, calculates the expected value at each time period, and then discounts the results at the risk-adjusted discount rate. The option valuation method modifies the probability distribution of the cash flows to make it risk-neutral, calculates the expected value of this riskneutral distribution at each time period, and then discounts the results at the risk-free discount rate. The decision analysis approach takes the risky cash flows, determines the certain equivalent at each time period, and then discounts the results at the risk-free discount rate.

\subsubsection{Method Strengths and Weaknesses}

The strengths of the discounted cash flow method are that it is widely used in practice and that market data are readily available that can be used to determine the correct discount rate when there is no managerial flexibility. The weakness of the discounted cash flow method lies in the difficulty associated with selecting the correct risk-adjusted discount rate. Selecting the correct discount rate is straightforward if the project's risk characteristics are the same as the company's average risk and there is no managerial flexibility. Selecting the correct discount rate increases in difficulty if the project's risk differs from the company's overall risk because one must find a traded asset that has the same risk characteristics as the project. The difficulty is that judgment is required. This difficulty further increases when one considers the component cash outflows of the project individually. Finally, it appears that the only way to determine the correct discount rate 
for the net cash flows when managerial flexibility is introduced is to create and value financial options (i.e., to perform an option valuation).

The greatest strength of the option valuation method is that it gives a single, market-based solution to the value of the project. There are several weaknesses of the option valuation method. First, the option valuation method is not currently widely used or well understood in practice. Second (and most critically), the project's uncertainties must be spanned by market traded assets. Spanning requires that, not only does the project and the portfolio of market traded assets have the same risk characteristics, but they must also have identical cash flows in every possible state. Third, the parameters needed to generate the future distribution of the market-traded asset's value are not directly observable in the market and must be estimated.

The strengths of the decision analysis approach is that it can be applied with or without market data and that many in the utility industry are familiar with the approach. The weakness of the decision analysis approach is that one must assess the decision-maker's utility function to determine risk preferences in the process of determining the certain equivalent. ${ }^{8}$

\subsubsection{Method Selection}

These observations lead to the suggestion that all three methods have uses in project evaluation depending upon the available data and type of project. While there are exceptions, Figure 2-1 presents a flow chart that recommends how to select the most appropriate method. The squares in the figure correspond to the questions that need to be answered in selecting the method. The ovals correspond to the recommended evaluation method. ${ }^{9}$ The questions are as follows:

1) Does a market traded asset exists (either the company's stock or some other asset) for the type of risk associated with the project; use decision analysis if there is no such asset else proceed to the next question.

2) Does the project have managerial flexibility; use discounted cash flow if the project has no flexibility else proceed to the next question.

3) Are the project's uncertainties are spanned by market traded assets; use option valuation if they are otherwise use decision analysis.

8 Note that Smith and Nau (1995) and Hoff (1996) have shown that the option valuation and decision analysis approaches have identical results if the market trading opportunities are explicitly considered in addition to the specific project under evaluation.

9 The contracts approach is not included in the flow chart since it is not strictly a method but a comparison of a contract that exists in the market. 


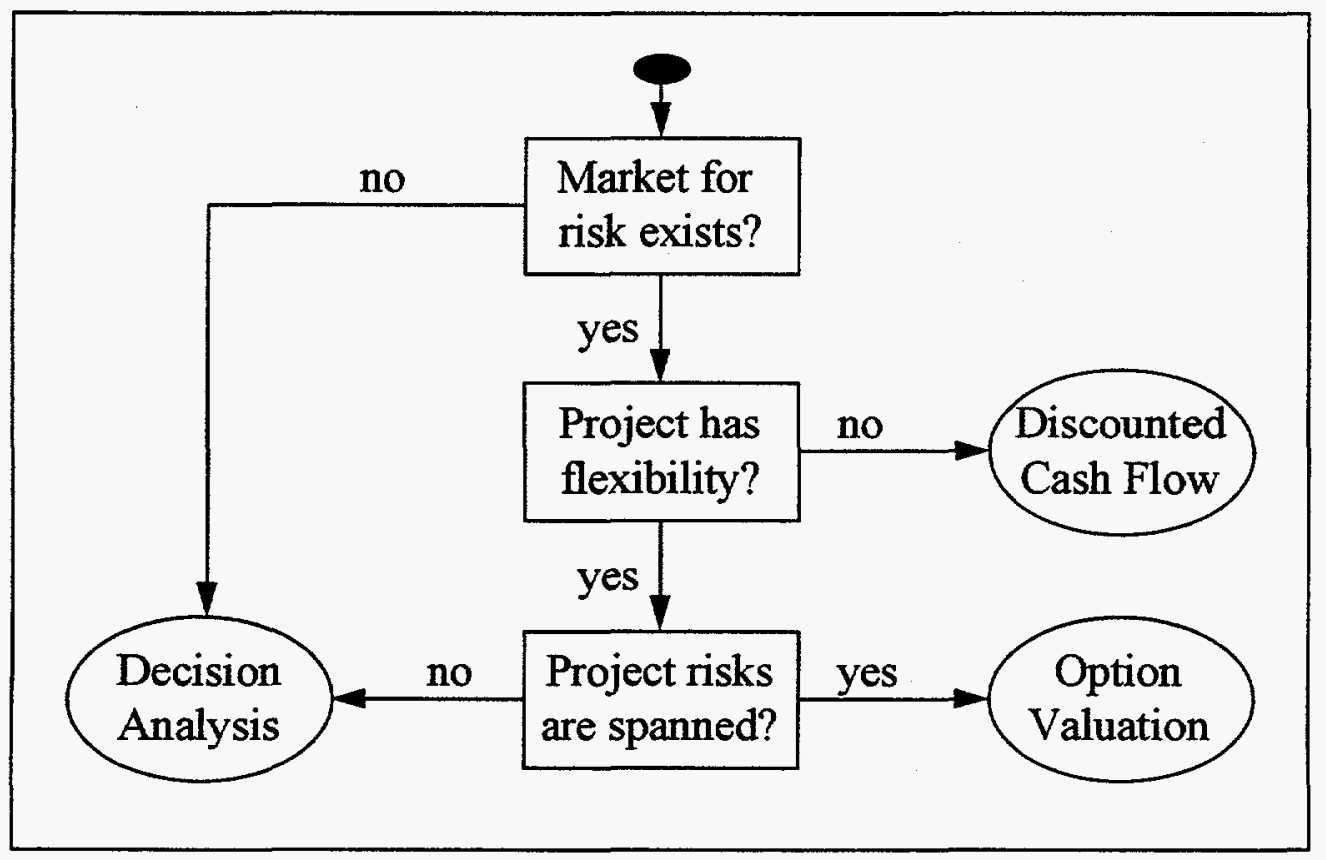

Figure 2-1. Evaluation approach selection. 


\section{UNCERTAINTIES AND ATTRIBUTE IDENTIFICATION}

\subsection{INTRODUCTION}

Evaluating a utility's financial performance has typically focused on the utility's revenues and costs; very little attention has been given to attributes associated with the product that is delivered. For example, Bernt, Doane, and Epstein (1995) point out that many advocates of restructuring in California emphasize that electric rates for the three largest utilities exceed the national average by almost 50 percent. The authors claim, however, that it is dangerous to draw conclusions based on a comparison of rates. They show that comparing electric rates of utilities across the United States is like comparing the price of McDonald's Big Macs: the price of Big Macs depends on where the purchase is made. Prices vary by more than a factor of two around the world but the management of the McDonalds with the highest prices is not necessarily criticized as having poor performance; many other factors are important.

While Bernt, Doane, and Epstein (1995) identify the danger of comparing rates without considering all factors, an identical conclusion is true about comparing the costs of different resource additions or contract additions. The product offered in a bid for power, for example, is a bundle of many characteristics and one cannot simply compare the price of the contract to determine which bid should be selected (Moskovitz and Bradford 1995). As the literature suggests, (e.g., Brown, Lewis, and Ryngaert 1994; Kolbe, et. al. 1994; Kolbe and Tye 1995; Piepmeier 1995) caution must be exercised when selecting a resource or contract to properly account for all of the product's characteristics.

A number of authors have considered the importance of examining the attributes associated with a resource when making acquisition decisions (e.g., Staschus, et. al. 1991). A detailed effort of identifying the attributes of renewable energy technologies in an integrated resource planning context was performed by Logan, Neil, and Taylor (1994) and published in a concise form by Logan, et. al. (1995).

Logan, et. al. (1995) identify ten separate attributes that are of concern in an integrated resource planning process. A modified version of these attributes, with the categorization into System and Financial groupings is presented in Table 3-1. The system attributes (where "system" refers to both the resource and the overall utility system) include capability, availability, dispatchability, location, and modularity. The financial attributes include capital costs, operating costs, external costs, and financial incentives. Logan, et. al. note that there is some degree of risk involved in all of the attributes but they list risk as a separate attribute. 
Table 3-1. Resource attributes relevant to utility decisions.

\begin{tabular}{|l|l|}
\hline Attribute & \multicolumn{1}{|c|}{ Description } \\
\hline System & \\
\hline Capability & Maximum capacity and energy output, including time profile \\
\hline Availability & Planned/unplanned outages and fuel/energy source availability \\
\hline Dispachability & Degree of utility control over output \\
\hline Location & Point where resource is connected to system \\
\hline Modularity & Incremental size and pre-construction/construction lead-time \\
\hline Financial & \\
\hline Capital Costs & Capital and other non-operating costs (e.g., decommissioning) \\
\hline Operating Costs & Fuel costs and operation \& maintenance costs \\
\hline External Costs & Environmental and public safety costs \\
\hline Incentives & Tax credits, shareholder incentives, and emission allowances \\
\hline
\end{tabular}

An alternative to viewing risk as a separate attribute is to evaluate it as if it affects each of the system and financial attributes in Table 3-1. This is accomplished by identifying uncertainties that are of concern to utilities and then describing the interaction between the uncertainties and the relevant attributes.

Kaslow and Pindyck (1994) state that three key uncertainties of concern to utilities are: the electric utility's usual business uncertainties of (1) fuel costs and (2) demand growth; and the uncertainty of (3) new and evolving environmental requirements. Hobbs and Maheshwari (1990) and Cadogan, et. al. (1992) add the uncertainty of (4) installed capital costs; and another uncertainty is that of (5) generation unit outages (this can also be called supply uncertainty). All of these uncertainties can be placed within the context of the overall uncertainty of how the future utility industry will be structured.

The uncertainties listed in the previous paragraph interact with the attributes listed in Table 3-1 in a number of ways. The following subsections identify the important uncertainties and which attributes interact with these uncertainties (see Table 3-2 for a summary). Chapter 4 is devoted to the market structure uncertainty and Chapter 5 is dedicated to determining the value of the interaction.

Table 3-2. Interaction between uncertainties and attributes.

\begin{tabular}{|c|c|}
\hline Uncertainty & Relevant Attributes \\
\hline Fuel Price & Operation Costs \\
\hline Demand & Capability, Availability, Modularity, Location \\
\hline Environmental Regulations & Externality Costs \\
\hline Capital Cost & Capital Costs, Modularity, Location \\
\hline Outages (Supply) & Capability, Availability, Modularity, Location \\
\hline Market Structure & Costs \\
\hline
\end{tabular}




\subsection{FUEL PRICE UNCERTAINTY}

Most utilities currently have fuel adjustment clauses. These clauses offer utilities' stockholders security because they do not take the risk associated with uncertain fuel prices. Rather, the utilities' customers bear the risk associated with fluctuating fuel prices. These clauses, however, have been eliminated at some utilities and may be eliminated at others as the market becomes more competitive.

Fuel price uncertainty is directly correlated with the attribute of operating costs. Volatile fuel prices, however, have no effect on renewable energy technologies such as wind and PV because their fuel source is the wind or the sun. Renewable resources that are firmed up by spot purchases or backup fossil generation are affected by fuel price uncertainty but to a lesser degree than resources that are 100 percent fossil generation.

There have been some efforts to quantify the value of fuel diversity. In preparation for the 1992 Electricity Report in California, the Electricity Report Committee directed parties to estimate the value of fuel diversity based on portfolio theory or other available and appropriate methods. Brathwaite and Gopal (1992) from the California Energy Commission applied financial option valuation to determine the value of fuel diversity; Jacobs and Huntley (1992) at Pacific Gas and Electric Company used decision analysis and portfolio theory to determine the value. ${ }^{10}$ Awerbuch (1995) has evaluated how to select the correct discount rate for future fuel costs.

\subsection{DEMAND UNCERTAINTY}

Another uncertainty associated with the business of electric utilities is demand uncertainty. Demand uncertainty can be viewed from two broad perspectives: short-term and long-term. In the short-term (i.e., few hours to several days), the utility must consider what arrangements it must make, such as generation plant scheduling and spot purchases, in order to satisfy what it expects demand to be. In the long-term (i.e., several years), the utility must consider what arrangements it must make, such as long-term power purchase contracts and resource additions, in order to satisfy the peak system capacity and energy requirements.

Several attributes are related to demand uncertainty. They include modularity, location, capability, and availability. Renewable energy technologies such as wind and PV are highly modular. The attribute of modularity has two beneficial aspects to the utility. First, modular technologies can be installed in small increments so that capacity closely matches system demand. This can reduce the amount of money invested in capital resources. Second, modular technologies tend to have short lead-times. Thus, in addition to more closely matching supply with demand, the utility can wait longer until it must make a decision of whether or not to install additional generation. Utilities have recognized the value of short lead-times by giving benefit to resources with start-date flexibility (Staschus, et. al.). Cadogan, et. al. (1992) use decision

10 Both sets of authors determined that the value of fuel diversity was low. Jacobs and Huntley (1992) state that if greater variances in gas prices are identified, then the value of fuel diversity could increase. A forecasting method that allows for random risks such as price shocks (such as the 1973 and 1979 oil price shocks) rather than being based on long-term trends might be one source of increased variance. 
analysis and Lowell (1995) uses option valuation to show that resources with short lead-times allow the utility to delay construction of an investment until there is greater certainty that the investment will actually be needed.

Location is a second attribute that is affected by demand uncertainty. The same conclusions presented in the previous paragraph apply to the transmission and distribution (T\&D) system where very large investments are made and the capacity is not fully used for long periods of time. The fact that modular resources can be installed in small increments in locations where they are needed to defer capacity investments in the T\&D system is the basis for the distributed utility concept. The short lead-times further allow the utility to capitalize on these attributes when demand growth is uncertain.

One approach to determining the value of distributed generation under certainty is to use a detailed planning model such as the one developed for the Delta Case Study (Orans, et. al. 1992). A simpler approach has been developed Hoff (1996) and Wenger and Hoff (1996) and validated by Wenger and Hoff (1995b). This approach could be modified to account for the benefits of short lead-times when there is demand uncertainty.

\subsection{ENVIRONMENTAL REQUIREMENTS UNCERTAINTY}

There is uncertainty about what environmental restrictions will be placed upon generators in the future. There is the potential that generators will have to satisfy stringent emissions standards. If stringent emissions standards are imposed, the utility might have to improve the emissions profile of the generation unit or purchase emissions credits. In any case, there is a positive probability that there will be a future cost associated with meeting these standards. Since this is the case, even if there are no environmental restrictions at the present time, resources that might be affected by future standards must include an emissions cost in the cost of the plant because there is a positive probability that they will have to meet the standards in the future. Renewable technologies, by contrast, have low or no emissions. Thus, the attribute of external costs for renewable energy technologies is likely to be negligible.

\subsection{CAPITAL COSTS AND TECHNOLOGICAL UNCERTAINTY}

Utilities are concerned about the capital cost of resource additions. There are several aspects of this uncertainty. They include uncertainty of the final capital cost due to cost overruns and project delays. They also include uncertainty associated with purchasing a resource that has a very long lifetime ( 30 years or more) but could become economically obsolete due to technological progress before costs are recovered.

This uncertainty interacts with a number of attributes. The modularity attribute tends to reduce the uncertainty associated with cost overruns and project delays because projects can be constructed in small increments with short lead-times. The project can be stopped if there is an overrun without a total loss. When combined with location flexibility, the modularity attribute also allows the utility to capitalize on technological innovation as it is reflected through resource cost reductions. For example, Hoff, Wenger, and Farmer (1996) use dynamic discounted cash flow to demonstrate that distributed generation technologies can have substantially greater value 
when there is technology cost uncertainty. This is due to the fact that the utility has the flexibility to purchase the traditional transmission system upgrade if distributed generation technology costs do not decline as rapidly as predicted while the converse is not true if the transmission system is upgraded.

\subsection{EQUIPMENT OUTAGES OR SUPPLY UNCERTAINTY}

Closely related to the issue of demand uncertainty is the issue of equipment outages or supply uncertainty. This uncertainty is an issue at the generation system level as well as the T\&D system level. From a generation perspective, the utility needs to know if it will be able to satisfy demand if a generating unit has a forced outage. From a transmission system perspective, utilities evaluate their systems to make sure that if they lose a major transmission line into an area that they will still be able to satisfy demand with the remaining transmission system capacity.

The attributes of capability, availability, modularity, and location are associated with this uncertainty. Availability includes planned and unplanned outages, and availability of the fuel or energy source.

The attributes of modularity and equipment availability interact in a positive way. Logan, Neil, and Taylor (1994, p. 4-8) point out that a large number of small units subject to independent equipment-related outages can be modeled as a single unit with a forced outage rate of zero. If fuel source availability were not an issue (i.e., the sun is always shinning and the wind is always blowing), combining this with the location attribute suggests that a large number of distributed generation resources within a transmission planning area might provide greater reliability to the area than a few transmission conductors coming into the area. That is, from an equipment reliability perspective, distributed technologies might provide a higher level of reliability than conductors.

This suggests that the focus on availability should be on the availability of the fuel source. There are several ways to address this uncertainty. One is to examine the historical correlation between demand and weather conditions. Hoff and Iannucci $(1988,1990)$, for example, found PV plant output to be highly correlated with peak system demand at Pacific Gas and Electric Company over several years.

In the case of solar technologies, there exists the obvious concern regarding sunlight availability. One possible solution is to firm up the solar power with spot market purchases. If markets are unavailable, which might be the case at the transmission system level, an alternative would be to create a market by offering an "interruptible" service: i.e., an offer to pay to be curtailed (i.e., pay them only if they are actually curtailed). If firming up the power turns out to be excessively costly (due to poor availability of the fuel source), the resource owner has the option of installing backup generation. That is, the resource owner can wait to resolve some of the uncertainty associated with the correlation between fuel source availability and demand. This option has a positive value to the resource owner because, even though fuel source intermittency is an issue, one does not have to deal with this issue immediately but can wait to decide how best to respond once some of the uncertainty is resolved by operating the facility. 


\subsection{MARKET STRUCTURE UNCERTAINTY}

A final uncertainty that is of great concern is future market structure uncertainty. This is an important source of uncertainty because it can affect all other uncertainties. One way to address regulatory uncertainty is to develop several different scenarios of future market structure and then to evaluate how the various attributes of renewable technologies can be beneficial in the different scenarios. That is the approach that will be taken in the next chapter. 


\section{MARKET STRUCTURE}

\subsection{INTRODUCTION}

The previous chapters discussed project evaluation methods, described the attributes associated with resource additions, and discussed how these attributes interact with uncertainties that are of concern to utilities. This chapter explores issues associated with market structure. Section 4.2 defines various plant ownership scenarios. Section 4.3 describes market transactions that are relevant under various ownership scenarios. Section 4.4 describes those renewable energy technology attributes that are attractive to the various ownership scenarios.

\subsection{PLANT OWNERSHIP SCENARIOS}

The approach taken in this report is to define and evaluate alternative ownership scenarios for renewable power plants for both electricity consumers and generators. Consumers use power in the course of operating their businesses or residences and generators produce power for profit. While other factors may influence the ownership decision, these are the only definable ownership groups.

Power consumers include current residential, commercial, agricultural, and industrial electrical customers while generators include investor-owned utilities (IOUs), municipal utilities, independent power producers (IPPs), and other market segments such as distribution utilities and rural cooperatives that can use generation to satisfy multiple requirements such as within a distributed generation configuration.

An emerging trend is the movement toward a group of integrated utilities surrounded and served by many IPPs. For example, more than a third of both Southern California Edison Company's (1994, p. 1) and Niagara Mohawk Power Corporation's (1994, p. 23) energy production came from IPPs in 1994. Some IPPs are partially owned by integrated utilities so that while investment in generation by regulated IOUs may be decreasing some IOUs have moved into the power production business through their unregulated subsidiaries. For example, Figure 4-1 presents the change in Pacific Gas and Electric Company's (PG\&E's) undepreciated regulated electric assets (non-nuclear and nuclear) and other assets from 1989 to 1994 (PG\&E, 1989 through 1994 Annual Reports). A large part of the increase in other investments in 1994 is associated with PG\&E's investment in U.S. Generating Company, an unregulated IPP joint venture with Bechtel Enterprises, ${ }^{11}$ which PG\&E (1994, p. 10) claims to be "the nation's third largest independent power producer." Other utilities, such as Southern California Edison (1994) and its unregulated subsidiary, Mission Energy, have entered the power producing business as well.

11 The 1994 Annual Report actually adds a new category called Investment in Nonregulated Projects, a category with $\$ 761$ Million in assets. 


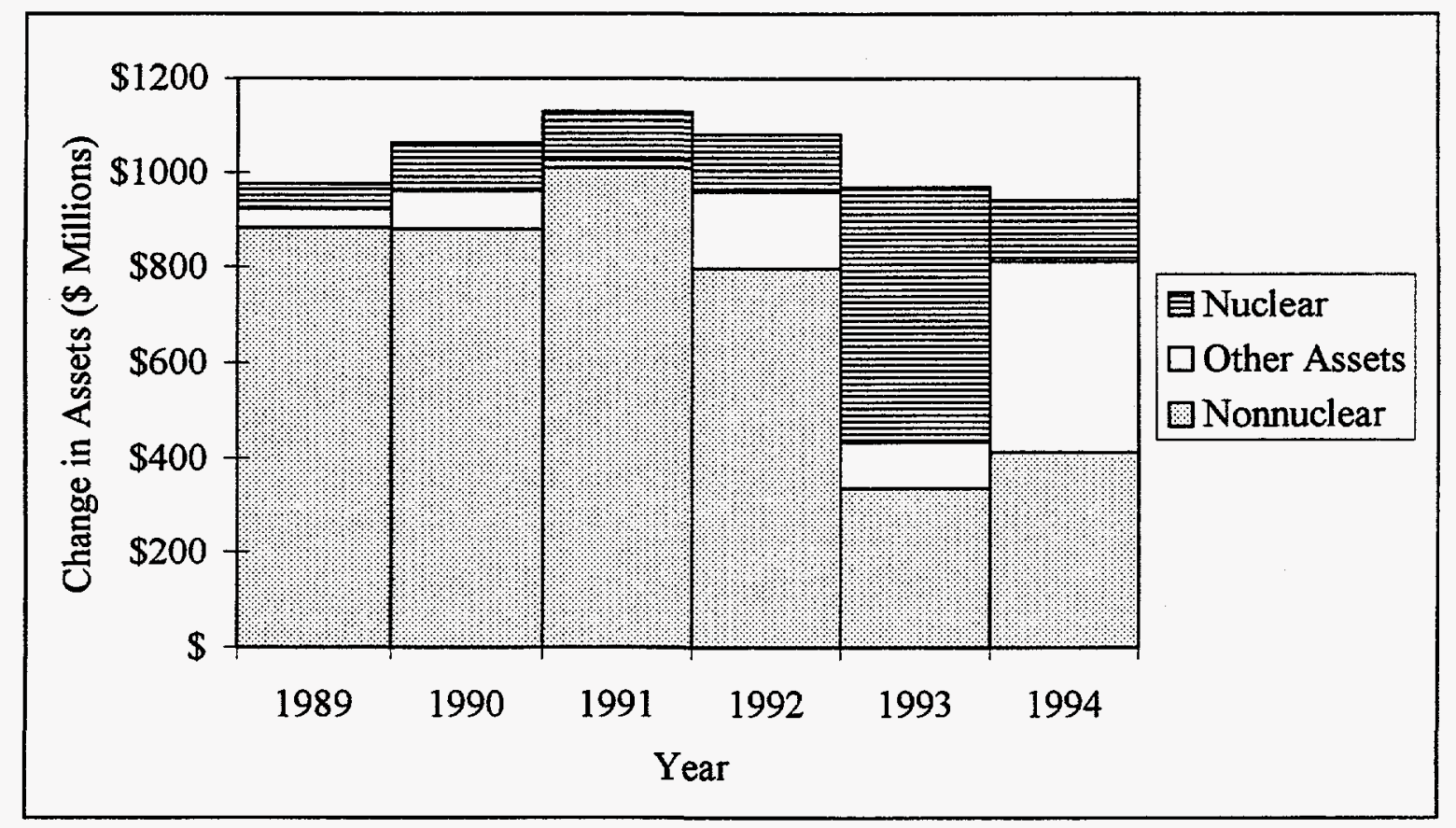

Figure 4-1. Additions to PG\&E's undepreciated assets.

This trend suggests that IPPs (whether owned by third-party investors or IOUs) may become more important in the power generation business while the role of regulated IOUs may decrease. This trend will be even more pronounced as the generation market becomes more competitive, which suggests that the central station ownership scenarios considered in this report should include municipal utilities and IPPs. ${ }^{12}$

Ownership scenarios considered in the analysis are:

i. distributed generation owned by IOUs;

ii. distributed or central station generation owned by municipal utilities and IPPs; and

iii. generation owned by consumers.

\subsection{MARKET TRANSACTIONS}

The decision to own a renewable power plant will be influenced by a number of economic issues, some of which depend on the technology and others of which depend on the market structure. Two issues significantly influenced by market structure are to whom the plant owners are allowed to sell their output and the contractual relationships between plant owners and output purchasers.

12 IOUs may invest in distributed generation, however, because distributed generation simultaneously supports the generation and T\&D systems. 


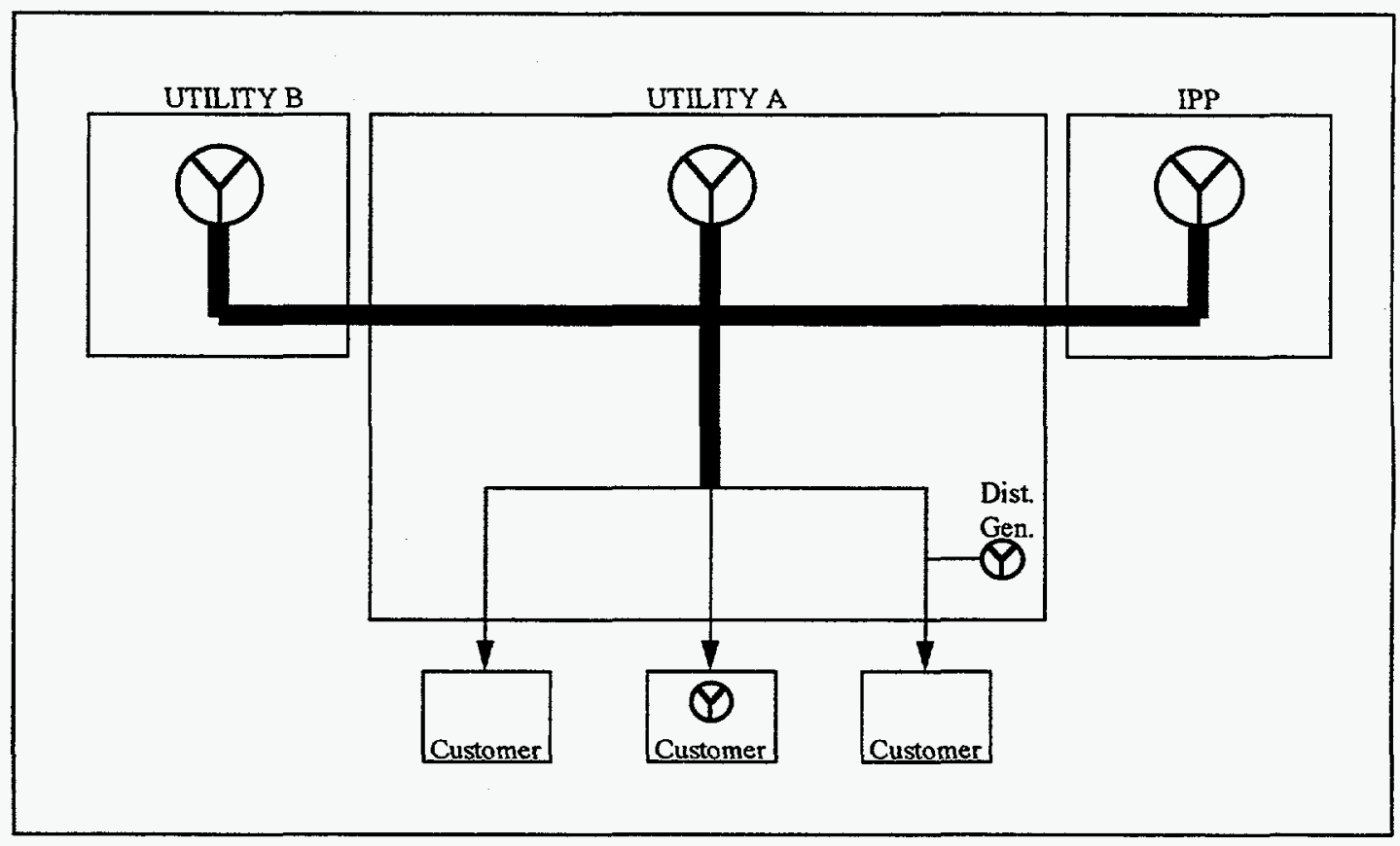

Figure 4-2. Current electric supply system.

\subsubsection{Output Sales}

One issue of concern to plant owners is their allowable choice of customers, which is affected by the structure of the electric utility market. Current market structure is composed of a group of integrated utilities and IPPs as shown in Figure 4-2. ${ }^{13}$ The thick lines correspond to the transmission system and the thin lines to the distribution system.

Under this structure, renewable power plants can be owned by IPPs, by IOUs and municipal utilities (either as central station or distributed generation), and by power consumers. IPPs are limited under this structure to selling their output to the utilities that supply power to power consumers. Power consumers are limited in their ability to own plants depending upon whether or not the plant can be physically located on their premises.

The electric utility industry is becoming more competitive. There is likely to be a transition period as this occurs. Figure 4-3 suggests that this transition period will represent greater contractual freedom between generators and consumers. While the physical characteristics of the electric supply system may not change, the dashed lines in the figure indicate that renewable IPPs can sell their output directly to power consumers ${ }^{14}$ in addition to utilities. The power flows through the same electrical wires but the payment flows directly from the consumer to the generator with some charge going to the utility that manages the transmission and distribution system. This opens up an additional market for renewable technologies that may not necessarily be physically located on customer premises.

13 The following three figures are based on Hyman (1994).

14 There is debate as to whether this will occur on the wholesale level or the retail level or both. 


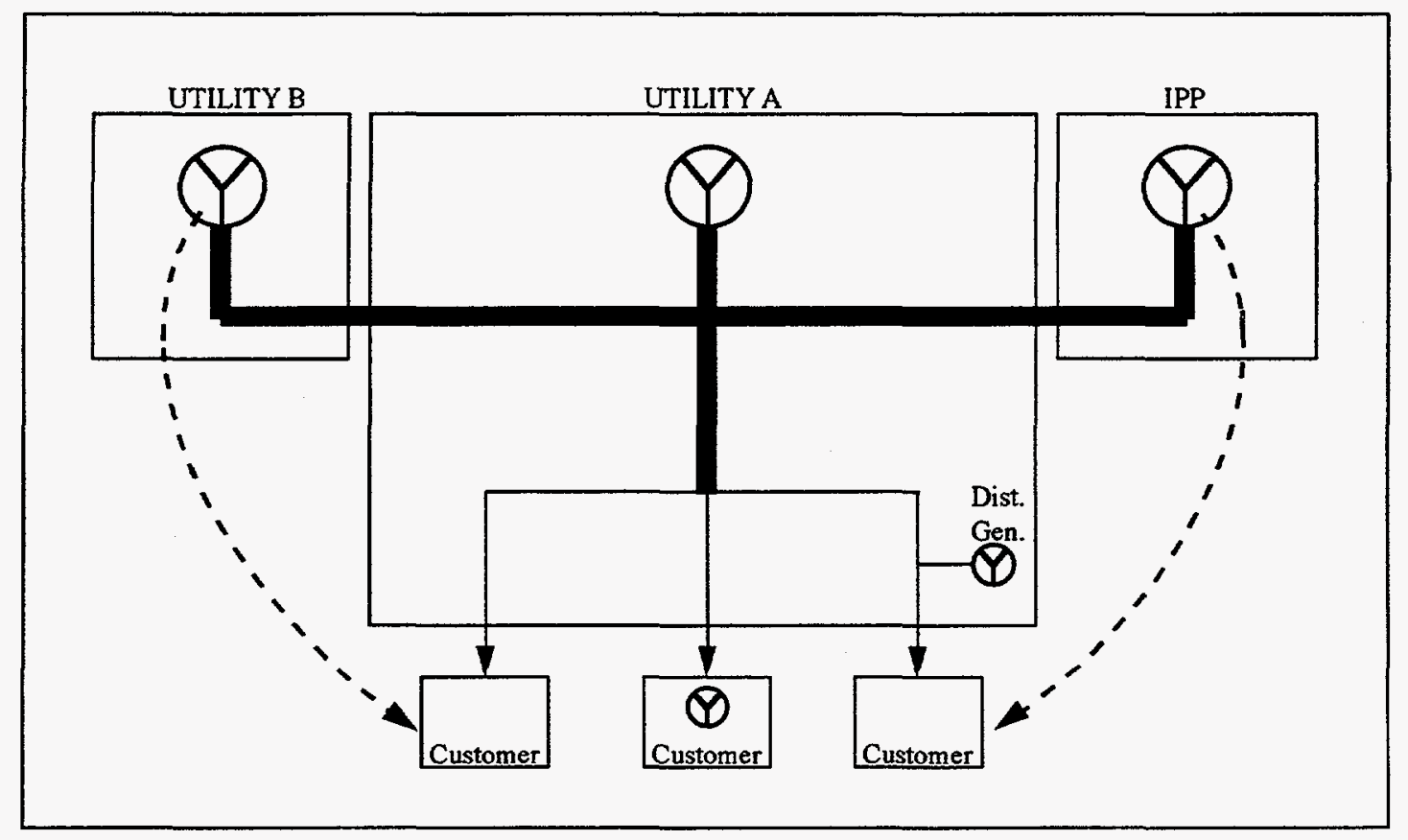

Figure 4-3. Transitional electric supply system.

Full-scale competition, however, is likely to result in structural change. In particular, the generation market will probably become fully competitive and transmission and distribution companies will distribute the power (see Figure 4-4). Now, generation is not owned by the same companies that operate the transmission and distribution systems in order to avoid conflicts of interest. Power generators might sell their output to a transmission utility or power pool, to local distribution utilities, or directly to consumers.

In addition to this increased access, greater competition is likely to encourage the market for distributed generation IPPs for several reasons. First, IPPs could serve a group of consumers but use only a portion of the distribution system. This reduces the IPPs' costs associated with using the T\&D system (if the IPP is central generation) and the transaction costs associated with siting many small plants on customers' premises. Second, the IPPs could sell their output to the consumers at retail rates at the times when they are consuming power and then have access to the T\&D system to sell their excess output when the consumers do not need the output, thus increasing their revenues. 


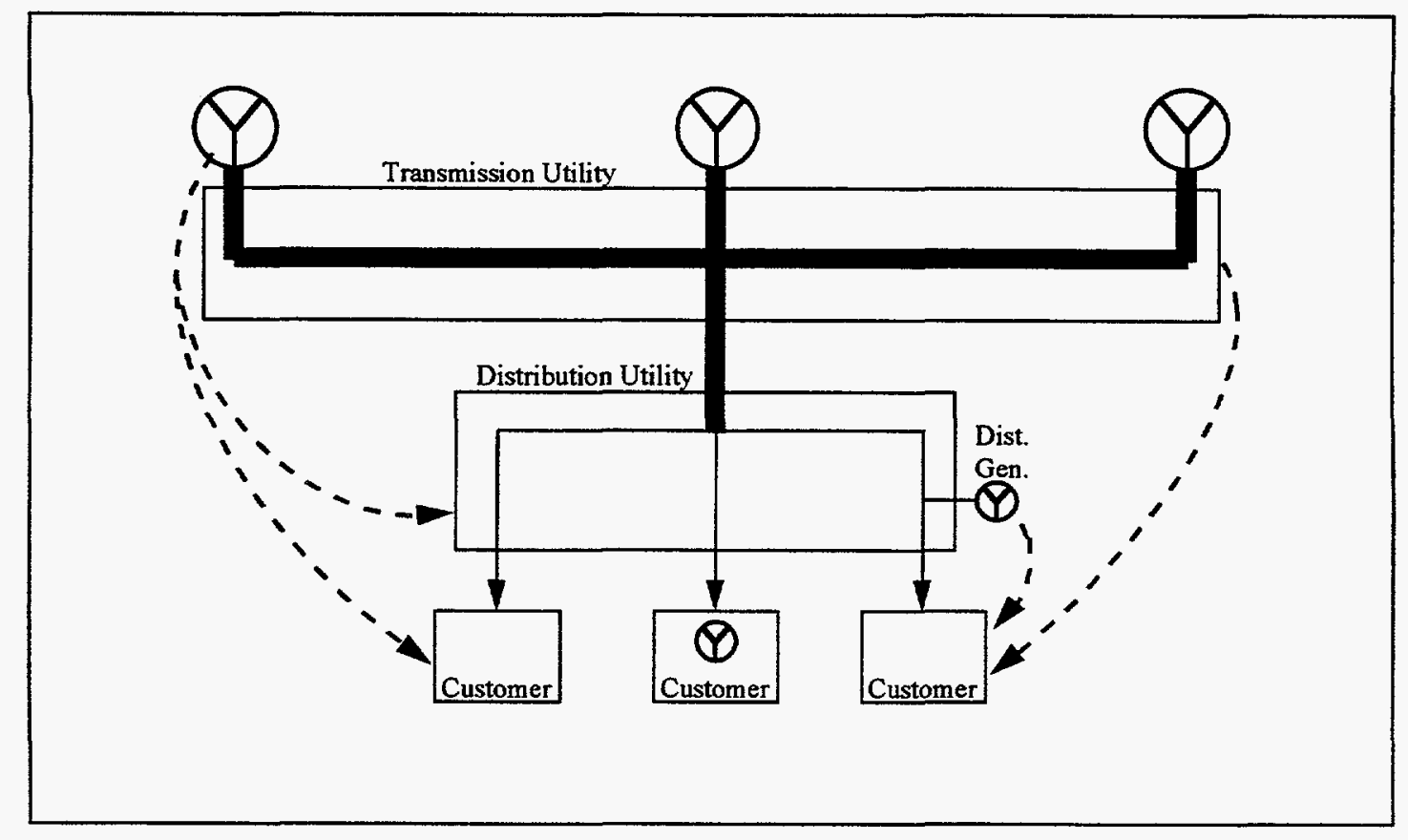

Figure 4-4. Competitive electric supply system.

Finally, power marketers play a potentially important role, acting as intermediaries between the plant owners and customers in each of the three scenarios described above. Hamrin and Rader (1994) suggest a specific type of power marketer is a renewable power marketing authority or "renewable aggregator". Such a power marketer aggregates, firms, and transmits renewable resources and then sells the power. Hamrin and Rader suggest that this is necessary to enable renewables to participate in a wholesale commodities market because it allows intermittent renewable resources to be packaged as a commodity and marketed in sizes that reduce transactional costs.

Renewable aggregators might also play a role in obtaining more attractive financing for renewable power plants since they may be able to attract capital from investors interested in promoting the use of renewable energy. The renewable aggregator in this role would aggregate capital for project developers rather than demand for electricity.

\subsubsection{Sales Contracts}

The contractual relationship between the renewable plant owner and electricity customer is another important issue. No contract is needed if the plant owner is the electricity consumer. Contract terms and conditions become very important, however, when the owner is not the consumer.

Utilities have historically operated as if they had long-term sales contracts with their customers even though no contracts existed. Utilities set their rates with the oversight of public utility commissions and the customers' only options were to pay the rates or to leave the system. This structure has not offered much choice to customers with regard to contractual relationships for future power needs. 
This structure has, however, been the basis for the long-term power purchase agreements that the utility has offered to IPPs. These long-term contracts have been essential to the development of the IPP market, particularly for capital-intensive renewable energy technologies. ${ }^{15}$

The changing electricity supply environment is affecting long-term contracts in several ways. First, public utility commissions are moving away from traditional rate making to performance based rate making; this encourages utilities to be more cost conscious and to exercise great care about the contracts that they sign. ${ }^{16}$ Second, many utilities are currently financially exposed due to long-term contracts. ${ }^{17}$ Third, utilities recognize that there are no guarantees that customers will remain in the system; this makes them more hesitant to enter into long-term contracts.

While these changes make it unclear what types of contracts that will exist between generators and consumers, it may represent an opportunity for renewable energy. A more competitive market structure will offer customers choice about the contracts they enter into. It is likely that some customers will be willing to enter into long-term contracts simply because the technology is renewable energy. ${ }^{18}$

This desire may be further increased if a competitive market results in highly volatile electricity prices. Other commodity markets abound with risk-management tools such as forward and futures contracts and swaps. In addition, other competitive industries contain examples of the decision to commit to long-term capital improvements over accomplishing the same goal through short-term variable costs. Consider, for example, the manufacturing sector and automated machines versus labor intensive machines. Substantial investments have been made in automated machines to replaced labor-intensive machines in competitive manufacturing industries. This is a source of strategic competitive advantage for some firms. Renewable energy technologies with their high capital costs are comparable to automated machines and fossil-based technologies with their high variable costs are comparable to labor intensive machines.

15 For example, Kenetech Corporation, a wind turbine manufacturer, had sales in the general categories of power purchase agreements (PPA), direct sale to a utility, and equipment sales (1994b). Under the PPA category, Kenetech arranges for third-party financing based on the value of the power contract entered into with the utility. Three-quarters of Kenetech's installed base is owned by third-party investors and fall into the PPA category; three-fifths of Kenetech's 1,114 MW of wind plants that are under construction or are in the contracting process fall into the PPA category; and all of the $945 \mathrm{MW}$ of wind plants that were proposed in the California Biennial Resource Planning Update (BRPU) were going to be PPAs. Direct sale to a utility accounts for the remainder of the domestic sales while equipment sales have been confined to the foreign market.

16 Traditional rate making is where revenue equals cost plus profit (as determined by the public utility commission). Performance based rate making is where profit equals revenue (as determined by the public utility commission) minus cost.

17 For example, Southern California Edison Company (1994 pp. 1, 9) and Pacific Gas and Electric Company (1994 p. 40), for example, paid an average of $\$ 0.080 / \mathrm{kWh}$ and Niagara Mohawk Power Corporation (1994, p. 23) paid an average of $\$ 0.065 / \mathrm{kWh}$ for purchased power in 1994 . The two west coast utilities estimate that the market price of electricity at this generation level in a competitive environment would be closer to half of what they are currently paying.

18 A renewable aggregator might be able to play the role of finding consumers who want long-term contracts and setting up long-term contracts between them and the renewable power producers. 


\subsection{SUMMARY}

This chapter discussed market transaction issues relevant under the various ownership scenarios. Table 4-1 summarizes the ownership scenarios that benefit from the different attributes; $X$ denotes some benefit and XX denotes much benefit. Chapter 5 will develop quantitative methods to calculate the value of the individual attributes and provide examples of how to apply the methods.

Table 4-1. Important attributes to various decision-makers.

\begin{tabular}{|l|c|c|c|c|}
\hline & Consumers & IOUs & Municipals & IPPs \\
\hline Fuel Costs & $\mathrm{XX}$ & $\mathrm{XX}$ & $\mathrm{XX}$ & $\mathrm{XX}$ \\
\hline Environmental Costs & $\mathrm{X}$ & $\mathrm{XX}$ & $\mathrm{XX}$ & $\mathrm{XX}$ \\
\hline $\begin{array}{l}\text { Modularity } \\
\text { (Satisfy System Demand) }\end{array}$ & & $\mathrm{X}$ & $\mathrm{XX}$ & \\
\hline $\begin{array}{l}\text { Modularity \& Location } \\
\text { (Satisfy T\&D Demand) }\end{array}$ & & $\mathrm{XX}$ & $\mathrm{X}$ & \\
\hline Availability & $\mathrm{X}$ & $\mathrm{X}$ & $\mathrm{X}$ & $\mathrm{X}$ \\
\hline Capital Cost & & & & $\mathrm{XX}$ \\
\hline Reversibility & $\mathrm{X}$ & $\mathrm{X}$ & $\mathrm{X}$ & $\mathrm{XX}$ \\
\hline
\end{tabular}




\section{THE VALUE OF RISK-MITIGATING ATTRIBUTES}

\subsection{INTRODUCTION}

This chapter develops methods to quantify the value of the risk-mitigating attributes of renewables. There is a section for fuel costs, environmental costs, modularity, lead-time, modularity and lead-time, availability, initial capital cost, and investment reversibility. Each of the sections includes an example of how to apply the methods; sections 5.4.2, 5.6.3, 5.6.5, and 5.8.3 include detailed examples.

\subsection{FUEL COSTS}

\subsubsection{Introduction}

A frequently cited attribute of renewables is that they require no fuel and thus, there is no uncertainty about the future fuel costs to operate the plant. ${ }^{19}$ This absence of fuel cost uncertainty needs to be accounted for when comparing renewable and fossil-based plants.

A typical utility approach to determining the present value cost of the fuel required to operate a fossil-based plant is to project future fuel costs and then to discount the results at the utility's cost of capital. The weakness of this approach is that it converts the uncertain future fuel costs into a stream of certain costs without accounting for the cost of eliminating this uncertainty.

One solution to this problem is to estimate expected future fuel costs and then to discount these expected costs at the risk-adjusted discount rate. There is controversy, however, about what is the correct risk-adjusted discount rate (Awerbuch 1995).

Another solution is to remove the uncertainty in future fuel costs by entering into a long-term, fixed price fuel contract, such as a natural gas contract. This contract should be considered a form of debt financing since it is a fixed financial commitment like a loan. Thus, the contract's present value cost is the fixed price fuel costs discounted at the debt rate. This is the direct cost of entering into the contract.

An indirect cost is incurred when the firm enters into such a contract. Assuming that the firm is initially at its optimal capital structure, signing the contract shifts it away from its optimal capital structure. An indirect cost is incurred in order to move the firm back to its optimal capital structure. This indirect cost is similar to the adjusted present value rule of Brealy and Myers (1991, p. 458-460).

19

All ownership scenarios benefit from this attribute. Different ownership scenarios, however, will benefit to a different degree with those realizing the greatest benefit being the ones that experience the most uncertainty. The ones that currently experience the most uncertainty are IPPs and power consumers. Fluctuations in fuel costs directly affect the profit of IPPs, the profit of power consumers that use the electricity to produce their product, and the well being of residential consumers that use the power for living purposes. IOUs and municipal utilities that generate power realize less of a benefit from fuel price certainty because they currently pass this uncertainty on to their customers through fuel cost adjustment clauses. In a more competitive environment, however, IOUs and municipal utilities will not be able to pass these costs through to customers. 
Section 5.2.2 describes how to calculate the direct cost. Section 5.2.3 discusses the indirect cost. Section 5.2.4 presents an example.

\subsubsection{Direct Cost}

Suppose that the firm signs a contract to pay a constant $F$ dollars per year for the next $T$ years to supply an amount of energy equivalent to what would have been supplied by the renewable energy technology. In addition, suppose that the average yield to maturity on the firm's debt is $r_{D}$ and the annual after-tax fuel costs equal $F\left(1-T_{F \& S}\right)$, where $T_{F \& S}$ is the effective combined state and federal tax rate. The costs are discounted at the after-tax cost of debt of $r_{D}\left(1-T_{F \& S}\right)$ since fuel costs are expensed.

Direct Fuel Cost $=\sum_{i=1}^{T} \frac{F\left(1-T_{F \& S}\right)}{\left[1+r_{D}\left(1-T_{F \& S}\right)\right]^{i}}$.

Equation (5.1) simplifies to ${ }^{20}$

Direct Fuel Cost $=\left[\frac{F}{r_{D}}\right]\left[1-\left(1+r_{D}\left(1-T_{F \& S}\right)\right)^{-r}\right]$

where $F$ is the annual fixed-price fuel contract, $r_{D}$ is the firm's debt rate, and $T_{F \& s}$ is the firm's effective combined state and federal tax rate.

\subsubsection{Indirect Cost}

Entering into a debt-like obligation can make a firm's capital structure sub-optimal by having too much debt and not enough equity. This has the potential to result in lower bond ratings and a

20 In this case, discounting after-tax costs at the after-tax cost of debt results in a smaller result than would have been obtained by discounting before-tax costs at the before-tax cost of debt. This differs from the situation for actual debt where discounting before-tax costs at the before-tax cost of debt results in an identical value as discounting after-tax costs at the after-tax cost of debt. To demonstrate, calculate the present value cost of repaying a debt issue of $\$ 1$ where the cost of debt is $r_{D}$ and the duration is $T$. The equal annual payment required to repay this debt is $P=\frac{r_{D}\left(1+r_{D}\right)^{T}}{\left(1+r_{D}\right)^{T}-1}$. The before-tax cost of repaying this debt discounted at the before-tax cost of debt is $\sum_{i=1}^{T} \frac{P}{\left[1+r_{D}\right]^{i}}$, which equals 1 . The after-tax cost of repaying this debt equals the annual payments less the interest tax savings (i.e., the balance due in the previous period, $B_{i-1}$, times the cost of debt times 1 minus the tax rate, $T_{F \& S}$ ) discounted at the after-tax cost of debt. That is, $\sum_{i=1}^{T} \frac{P-r_{D}\left(1-T_{F \& S}\right) B_{i-1}}{\left[1+r_{D}\left(1-T_{F \& S}\right)\right]^{i}}$, which also equals 1 . 
consequent rise in interest costs. As a result, one must account for the financial impacts of entering into a long-term contract as it increases the firm's debt load. If this moves the firm away from its optimal capital structure, the cost of this needs to be determined. The specific computation necessary to determine this cost will depend upon the type of firm and its financial characteristics. For example, there is no indirect cost for a municipal utility since its cost of capital is based only on its debt cost.

\subsubsection{Example: Municipal Utility - Part 1}

Suppose that a municipal utility is considering building a $25 \mathrm{MW}$ wind plant that will produce 88 GWh/year (i.e., a 40 percent capacity factor) for 20 years. The utility would have to enter into a 20 -year fixed price natural gas contract at a price of $\$ 2.50 / \mathrm{MBtu}$ to eliminate fuel price uncertainty. Since its gas plant has a heat rate of $6,000 \mathrm{Btu} / \mathrm{kWh}$, the fuel cost is $\$ 0.015 / \mathrm{kWh}^{21}$ and the annual fixed-price fuel contract cost, $F$, is $\$ 1.3$ Million/year.

The present value cost of this contract is calculated using Equation (5.2). The utility's debt rate is 5 percent $\left(r_{D}\right)$. The tax rate is 0 percent since this is a municipal utility and it does not pay taxes. The life of the contract is 20 years $(T)$. Thus, the present value cost of the contract is $\$ 16.2$ Million. There are no indirect costs in this case since this is a municipal utility. (This result is used in Section 5.6.3 as an input to the more detailed municipal utility example.)

\subsection{ENVIRONMENTAL COSTS}

\subsubsection{Introduction}

Another frequently cited attribute of renewables is that they produce low or no environmental emissions. There is debate, however, over how to quantify the value of this lack of emissions. The debate stems from the issue of whose perspective is taken in the analysis.

This report takes the perspective of the plant owner and focuses on the costs incurred by the plant owner. There are two types of costs. First, there is the cost of building the plant to satisfy current environmental standards. This cost is usually included in evaluating the cost of all types of plants, both fossil-based and renewable. This cost is minimal when environmental standards are low.

Second, there is the cost associated with future environmental standards that have not yet been established. $^{22}$ As Swezey and Wan (1995) point out, "prospective environmental cleanup costs of

21 $\$ 2.50 / \mathrm{MBtu} \times 6,000 \mathrm{Btu} / \mathrm{kWh}=\$ 0.015 / \mathrm{kWh}$.

22 A third category of environmental costs are the costs associated with potential plant failures in the future. These costs are based on the technical uncertainty about how well the plant will perform as well as natural disasters that can cause a plant to fail. They include cleanup costs, damage costs, and legal costs. These costs can be calculated by performing an engineering risk assessment. They are not calculated in this report. 
fossil-fuel-based plants are never considered up-front when generation investment decisions are made." Future costs have the potential to be quite high. ${ }^{23}$

Potential future costs are analogous to stock options given by companies to employees as part of their compensation. While costs are not incurred when the stock options are given, companies recognize that the options may be exercised in the future. This will dilute the stock's value and thus, the options represent a cost to the stockholders.

In a similar manner, a plant owner will incur costs if the government exercises its option to make emissions standards more stringent in the future. While costs are not incurred when the plant is built, the plant owner should recognize that costs might be incurred in the future. These costs should be accounted for since it is an unsound economic practice to give something of value away for free. The result is that plant owners should require compensation for the option that is given to the government. ${ }^{24}$

Section 5.3.2 describes how to evaluate potential future costs. Section 5.3.3 continues with the municipal utility example from the previous section. Section 5.3.4 discusses some of the method's limitations.

\subsubsection{Future Costs}

The first step is to identify where future costs might be incurred in the energy supply chain due to potential environmental regulations. If a market exists for the potential costs that are identified, the second step is to hedge the risks by entering into market transactions. This approach is similar to that taken in the fuel cost section so that the cost of eliminating the risks equals the cost of the market transactions. If, on the other hand, the identified cost risks are not market-traded, the second step is to quantify the potential costs identified in the first step and to assign a probability to their occurrence. The third step in the case without a market is to compute the expected cost (for a risk neutral decision-maker) or to compute how much the decision-maker would be willing to pay today to mitigate the future costs using expected utility theory (for a risk-averse decisionmaker).

Consider these three steps in more detail. The first step, whether or not a market exists, is to identify where costs might be incurred in the energy supply chain. For example, a utility may be considering two alternatives: a distributed PV plant or a central station fossil-based plant. Future

23 PG\&E (1994, p. 20), for example, estimates that compliance with NOx emissions rules for its existing power plants could require capital expenditures of up to $\$ 355$ million over the next ten years. It is likely that these costs were not anticipated by PG\&E when the plants were initially constructed. Power plants that are considered to be very clean by today's standards (e.g., natural gas based generation) may fare very poorly in five years.

24 The value of a lack of future environmental costs depends upon who owns the plant. Some plant owners are more likely to incur environmental costs than other plant owners. For example, utilities and IPPs are likely to experience more stringent regulation than power consumers that own plants. This is not to say that power consumers do not place a high value on the lack of emissions - green pricing proves that this is not the case. Rather, it is that the power consumers are less likely to be required by the government to clean up a generation source than an entity whose primary business is power generation. 
environmental costs could occur in a number of areas for the central station fossil-based plant. Costs could be incurred in: 1) the fuel supply process due to stricter environmental standards designed to prevent fuel spills thus increasing the cost of delivering the fuel to the plant; 2) the energy conversion process due to stringent air emissions standards (e.g., NOx, SOx, Carbon); and 3) delivering the electricity to the consumer due to regulation of electromagnetic fields associated with transmission lines. None of these future environmental costs, by contrast, exist for the distributed PV plant.

The second step is to quantify potential costs and to assign probabilities to their occurrence if a market for the identified cost risks does not exist. This step is particularly difficult because the decision-maker typically does not even know the form of future environmental regulations much less how stringent the regulations will be. For example, regulations could take the form of zero emission standards with all emissions being taxed, or a total level of allowable emissions with a system of tradable permits, or a command and control approach with all plants required to satisfy minimum standards. Each of these forms could have a different set of compliance costs.

One way to deal with this difficulty is to develop a set of environmental regulation scenarios, to calculate the cost of complying with these scenarios, and to assign probabilities of their occurrence. Consider, for example, the case of potential future environmental regulations of Carbon emissions due to the threat of severe consequences associated with global warming. One scenario might be that the generation owner is allowed to plant enough trees so as to offset an equivalent amount of Carbon produced by the generation resource such that it has no net Carbon emissions. Another scenario might be that all Carbon emissions are taxed. A third scenario might be that a new innovation is developed that removes Carbon and that all generation resources are required to install this device.

Once the costs of compliance and probabilities are specified, the third step is to compute the expected cost or to compute how much the decision-maker would be willing to pay today to mitigate the future costs using expected utility theory. The most realistic approach due to the great amount of uncertainty introduced in the second step may be to assume that decision-makers are risk neutral, thus avoiding the difficulty of the expected utility approach.

\subsubsection{Example: Municipal Utility - Part 2}

Continuing with the municipal utility example from the previous section, suppose that the utility wants to determine the environmental benefits associated with the wind plant by comparing what the costs would be with the natural gas plant. First, it calculates the expected per unit costs; second, it determines the annual costs for the natural gas plant; and third, it discounts the results.

\subsubsection{Step 1: Expected Environmental Costs}

While no costs are currently associated with Carbon emissions, there may be costs in the future. Bernow, et. al. (1994) have developed a set of scenarios of the potential future costs associated with Carbon emissions. They have cases of no taxes (\$0/ton), medium taxes $(\$ 37 /$ ton), and high 
taxes (\$110/ton). Assigning equal probability to these three scenarios results in an expected cost of $\$ 49 /$ ton. $^{25}$

\subsubsection{Step 2: Annual Environmental Costs}

Natural gas has a carbon content of 0.0145 tons of Carbon/MBtu (Masters 1991, p. 398). Thus, the expected emissions cost for a natural gas plant with a heat rate of $6,000 \mathrm{Btu} / \mathrm{kWh}$ is $\$ 0.004 / \mathrm{kWh}$ and the total cost for the plant is $\$ 0.375$ Million/year. ${ }^{26}$

\subsubsection{Step 3: Present Value Costs}

Suppose that the utility believes that nothing will happen for the first 10 years of the plant's life but that one of the three scenarios will occur from years 10 to 20 . In this case, the present value cost is $\$ 1.76$ Million. $^{27}$ (This result is used in Section 5.6.3 as an input to the more detailed municipal utility example.)

\subsubsection{Discussion}

The fact that fossil-based plant owners face potential future costs due to environmental standards that have not yet been established is fairly obvious. Quantifying the current cost of these potential future costs, however, is difficult, particularly when there is no market for the cost risks. The approach suggested in this section is a first approximation of what the actual current cost might be. Future refinements in the methodology will certainly be desirable. A few possible refinements are mentioned below.

First, a given form of a regulation can have varying levels of stringency and these levels can change over time. Second, not only can the stringency change over time, but the form of the regulation itself can change over time. Third, taking an expected value of the future costs does not account for the decision-maker's risk aversion. Fourth, there are various ways to satisfy a given regulation. For example, under current Sulfur emissions standards, one can satisfy the requirements by purchasing permits or by making capital investments. These, as well as other factors, need to be considered.

$25 \overbrace{\left[\left(\frac{1}{3}\right)(\$ 0 / \text { ton })+\left(\frac{1}{3}\right)(\$ 37 / \text { ton })+\left(\frac{1}{3}\right)(\$ 110 / \text { ton })\right]}^{\text {Expected Emissions Cost }}=\$ 49 /$ ton .

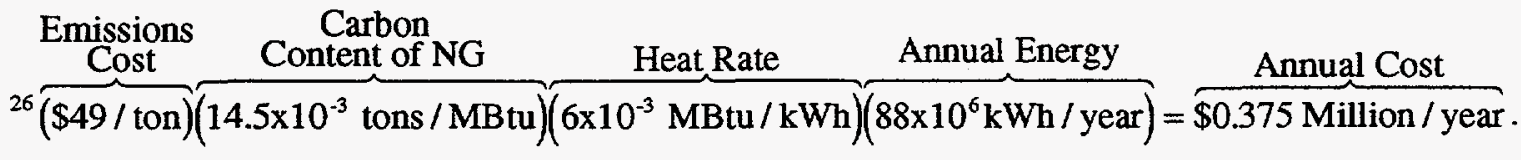

${ }_{27} \sum_{i=11}^{20} \frac{\overbrace{(\$ 0.375 \text { Million } / \text { year })}^{\text {Annual Cost }}}{1.05^{i}}=\$ 1.76$ Million. 


\subsection{MODULARITY}

\subsubsection{Introduction}

Renewable technologies such as PV and wind are modular. As will be seen in the following sections, their modularity interacts positively with a number of different attributes. This section provides one example of how modularity can be beneficial. Several more examples will be given later in this chapter.

\subsubsection{Example: Extending the Utility Grid using PV Generation}

A key uncertainty associated with a T\&D system infrastructure investment is the degree to which the infrastructure will be utilized. This example illustrates how PV systems can reduce the effect of this uncertainty by allowing a utility to build demand for electricity in a specific area prior to a large commitment of capital.

A developer wants the utility to extend the grid to a non-grid-connected area so that he can build the first 5 homes of a 50-home development. The utility, however, is uncertain whether or not the full development will be completed and thus justify a grid extension.

The situation is addressed by the utility partnering with the developer to build a solar housing development. Space heating needs are met using a passive solar design, hot water heating needs are met using solar heaters, and half of each houses' $4,000 \mathrm{kWh}$ of electricity needs are provided by a $1 \mathrm{~kW}$ customer-owned, building-integrated PV system. ${ }^{28}$ The utility provides backup generation and storage either by extending the existing grid or by installing a small generator and battery storage system. ${ }^{29}$

28 Water needs could be met with a well, sewage needs met with a septic tank system, and communication needs met with cellular communications. Thus, other types of utilities may be interested in promoting such a solar housing development.

29 There are several ways that this concept can be implemented. One is for the utility to own all of the generation and storage equipment, including the PV system. Another is for the customers to own the PV and for the utility to own the backup generation and storage system. This example is formulated with the customer owning the PV system. This approach is taken for several reasons. First, homeowners may be able to obtain better financing for the PV than the utility by incorporating its cost into their home loan. Second, homeowners receive tax write-offs for the interest payment on the PV system. Third, homeowners may qualify for tax credits and other financial incentives. Fourth, a low land cost will enable homeowners to pay a higher price for the house itself (because the PV is included) than a comparable house in a grid-connected area. Fifth, solar houses may attract "green" customers. Sixth, the utility reduces its risk because it does not have a large capital investment in the PV systems.

This approach to building demand with the goal of extending the T\&D system is attractive in both a regulated as well as a deregulated environment because utilities are likely to continue to receive revenues associated with the T\&D system in both environments. Even if the utility exits the generation business, someone will sell power to the customers that get connected to the grid and they will have to pay the utility wire charges in order to get the power to these customers. 
Five of the 50 homes are built immediately, 5 more are built if the first 5 sell sufficiently well, and the remaining 40 are built if the second 5 sell well. ${ }^{30}$ There is a 50 percent probability that the second 5 houses will be built and a 50 percent probability that the remaining 40 houses will be built if the first 10 houses are built.

The utility expects revenues of $\$ 1,000 /$ year from each house (i.e., this is based on a $\$ 600$ fixed fee plus $2,000 \mathrm{kWh}$ not met by the PV at $\$ 0.20 / \mathrm{kWh}$ ). The grid extension costs $\$ 200,000$ to install plus $\$ 0.03$ per $\mathrm{kWh}$. A $10 \mathrm{~kW}$ generator and a battery system provides service for 5 customers and costs $\$ 25,000$ to install plus $\$ 0.05$ per $\mathrm{kWh}$; the generation and storage system can be removed within two years of installation and salvaged for a value of $\$ 20,000 .{ }^{31}$

Figure 5-1 presents the full decision diagram with the non-discounted annual cash flows. The squares represent decisions and the circles represent uncertainties. The first number in each equation equals the annual revenues minus the annual operation and maintenance costs. The second number (if there is any) is the capital investment cost. For example, providing service using the generation and storage system in the first year results in $\$ 5,000$ in revenues (based on $\$ 1,000$ revenue/customer for 5 customers) and $\$ 500$ in operation costs (based on 2,000 $\mathrm{kWh} /$ customer, 5 customers, and operation costs of $\$ 0.05 / \mathrm{kWh}$ ) for a net benefit of $\$ 4,500$. In addition, the utility incurs a $\$ 25,000$ capital cost for the generation and storage system.

The decision tree is folded back with the decisions made at the decision nodes that maximize the net present value. Figure 5-2 presents the optimal path (dashed line) and cumulative discounted cash flows based on a 10 percent discount rate. For example, the top branch in year 3 has a net present value of $\$ 196,000$ (there is an annual revenue minus cost of $\$ 45,000$ from year 3 to year 30 and a capital cost of $\$ 200,000$ for more generation and storage in year 3 ).

The figure indicates that the utility will lose an expected $\$ 45,000$ (Upgrade System branch in Year 1 ) if it extends the T\&D system immediately but will gain an expected $\$ 72,000$ (Install G\&S in Year 1) if it installs generation and storage for the first 5 houses, installs a second generation and storage system if 5 more houses are built, and then extends the T\&D system and removes the two generation and storage systems if 40 more houses are built. This is a difference of more than $\$ 100,000$, or more than half of the cost of the initial $\$ 200,000$ upgrade.

30 This example could be formulated with the developer building only 5 houses at a time until all 50 houses are built. The formulation as presented, however, illustrates the concept with less complexity.

31 The PV system could be salvaged or moved to another location as well if this example had the utility owning the PV system. 


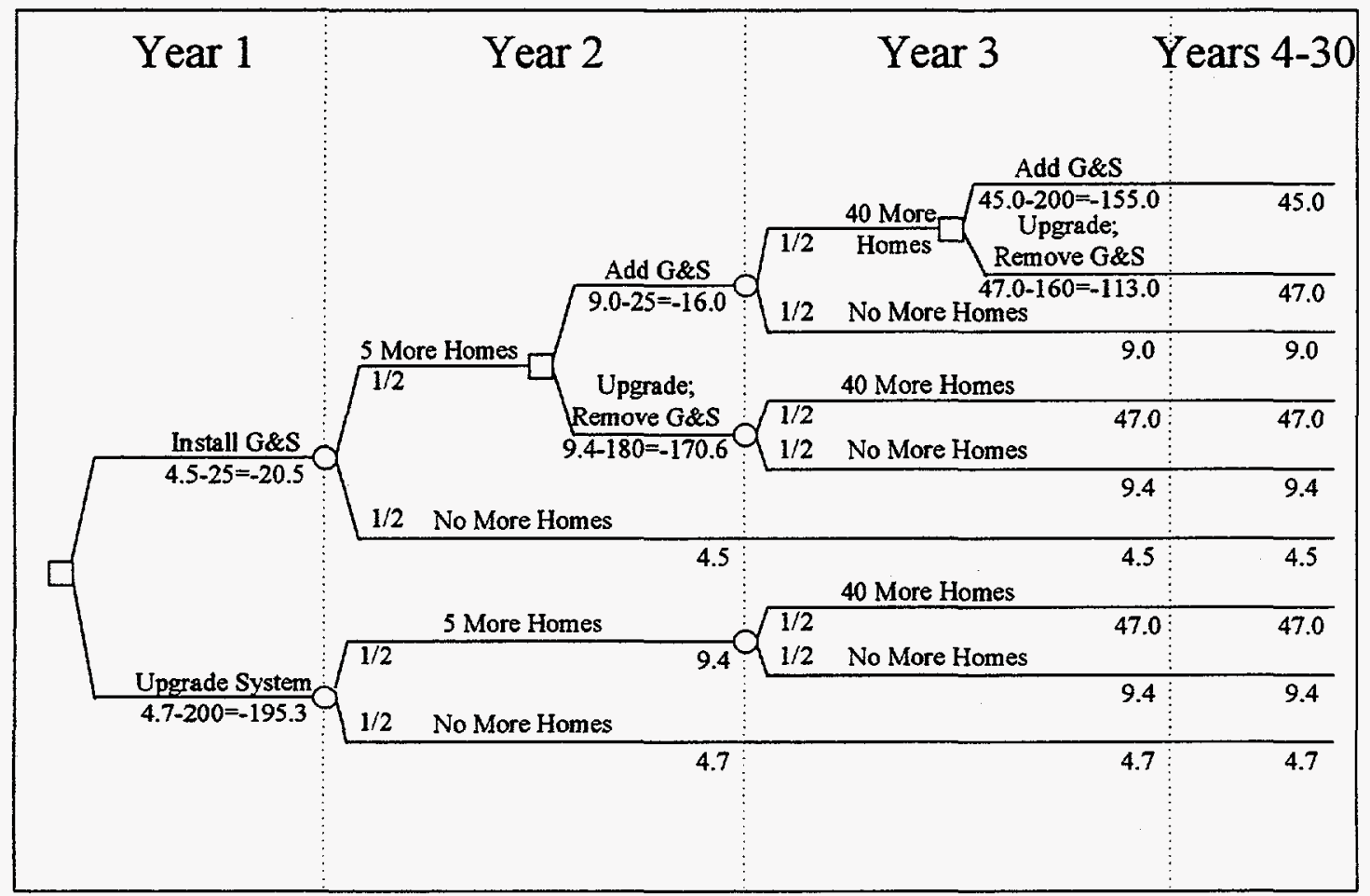

Figure 5-1. PV and grid extension costs

(Non-discounted annual cash flows in \$ Thousands).

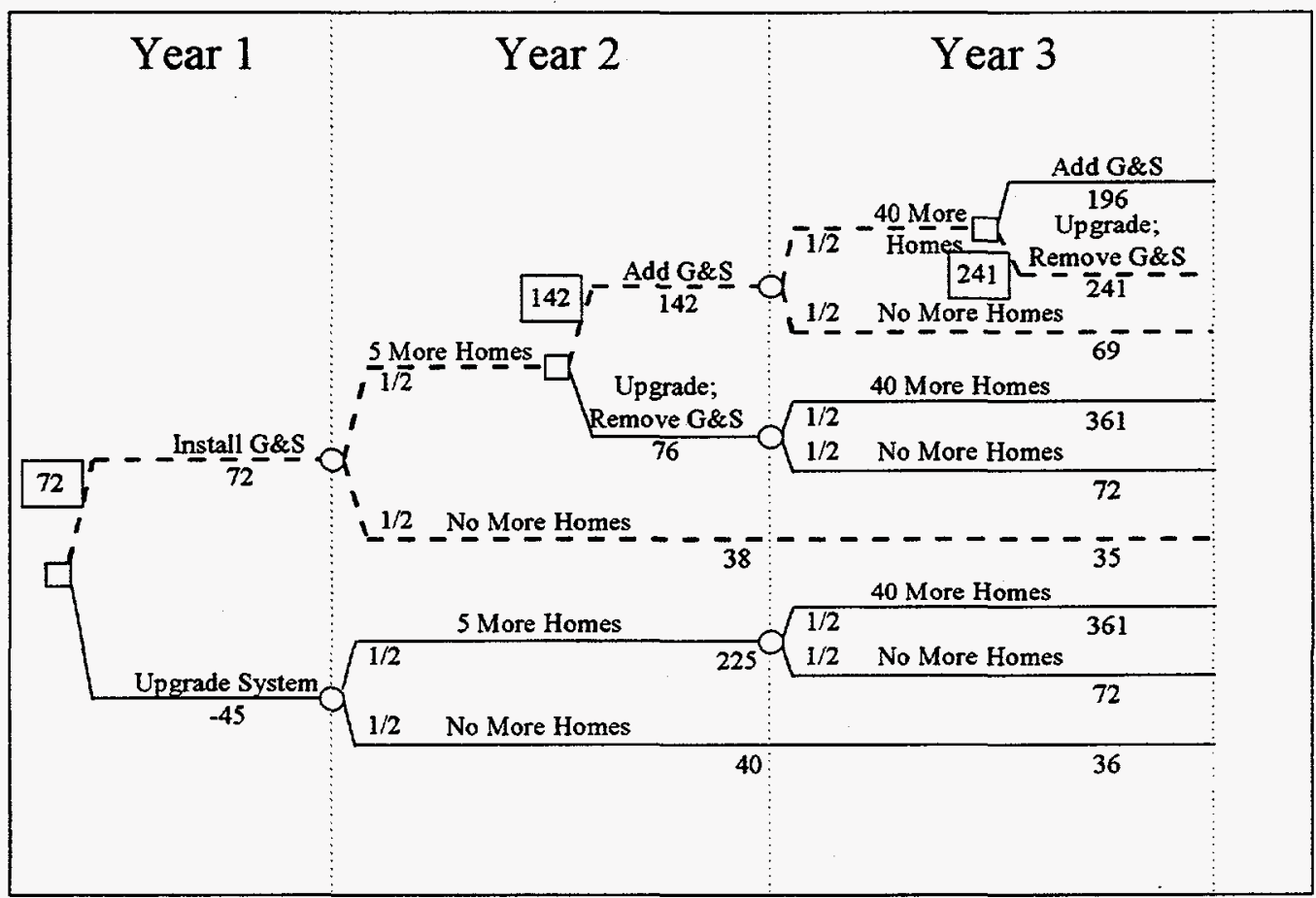

Figure 5-2. PV and grid extension decision (cumulative remaining discounted cash flows in $\$$ Thousands). 


\subsection{LEAD-TIME}

\subsubsection{Introduction}

Renewable technologies such as PV and wind have short construction lead-times. This provides plant owners with flexibility as to when they make investments. This section calculates the expected present value cost of satisfying demand using a plant when there is demand uncertainty. Utilities that are required to have sufficient capacity to satisfy all demand will be interested in these results. Section 5.5.2 describes how to account for the dynamic nature of demand uncertainty. Section 5.5.3 develops a method to calculate the expected present value costs of short lead-time plants. Section 5.5.4 illustrates how to apply the method.

\subsubsection{Dynamic Nature of Demand Uncertainty}

Evaluating the benefit of short lead-times requires capturing the dynamic nature of demand growth. This is accomplished by recognizing that demand can grow at different rates as the future unfolds. The following example illustrates this point. Figure 5-3 and Figure 5-4 present capacity and demand for a hypothetical utility generation system. The heavy lines correspond to historical data (same in both figures) and the light lines to projected data (different in the figures). The current year is 1995. Actual peak demand (heavy solid line) increased in 1992, remained constant in 1993 and 1994, and increased in 1995. System capacity (heavy dashed line) remained constant during this period.

A typical characterization of demand uncertainty is to project high, average, and low demand scenarios at a specific point in time (e.g., Price, Clauhs, and Bustard 1995) as shown in Figure 5-3. The weakness of this characterization is that it only gives a static picture of the demand uncertainty.

A dynamic characterization of demand uncertainty is to recognize that demand growth can change over time as illustrated in Figure 5-4. That is, demand can grow or not grow at each point in the future as represented by the small solid circles. For example, one possible path that demand might follow is that peak demand might increase in 1996 (point B) and then not increase in 1997 (point D) and 1998 (point F); there are many possible paths.

It is assumed that demand will either increase (with probability $p$ ) or remain constant (with probability $1-p$ ) in any given year. ${ }^{32}$ This characterization of demand uncertainty results in a binomial distribution of how demand can grow.

32 The units used in this section are in years; one can, however, use other units of measurement (e.g., months, weeks, etc.). 


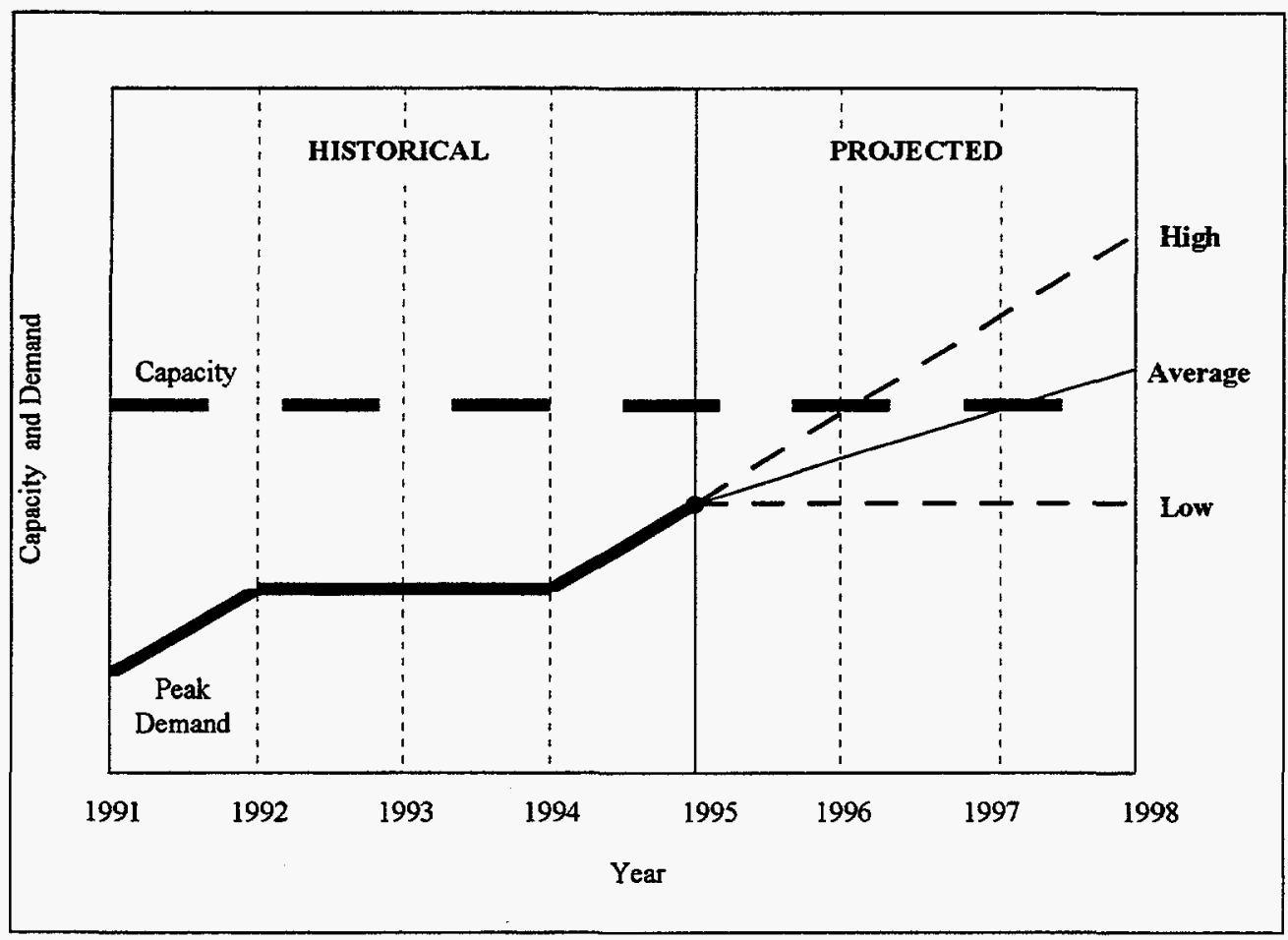

Figure 5-3. Demand growth using a static evaluation approach.

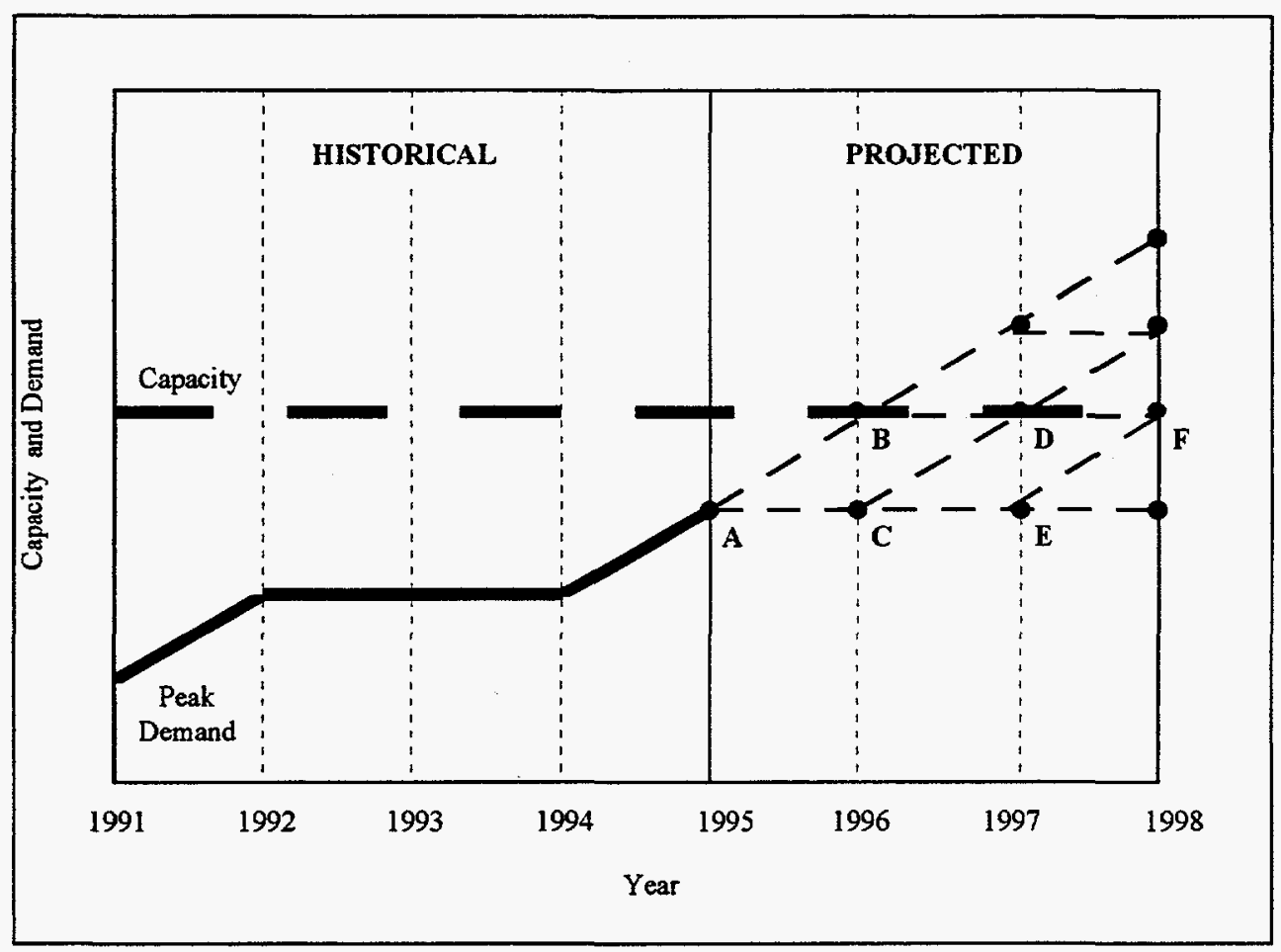

Figure 5-4. Demand growth using a dynamic evaluation approach. 


\subsubsection{Interaction Between Lead-Time and Demand Uncertainty}

The expected present value cost of a plant as a function of its lead-time can be calculated given this dynamic characterization of demand uncertainty. This section assumes that plants differ only in their cost $(I \$)$ and their lead-time ( $L$ years) but do not differ in the capacity that they provide to the system. Existing system capacity will vanish in $T$ years if demand grows at the high rate.

The expected present value cost of a plant equals the probability of needing the plant in year $k+T$ $L$ times the discounted cost. The results are then summed over all years. The lower part of Equation (5.3) is valid only when $T>L$.

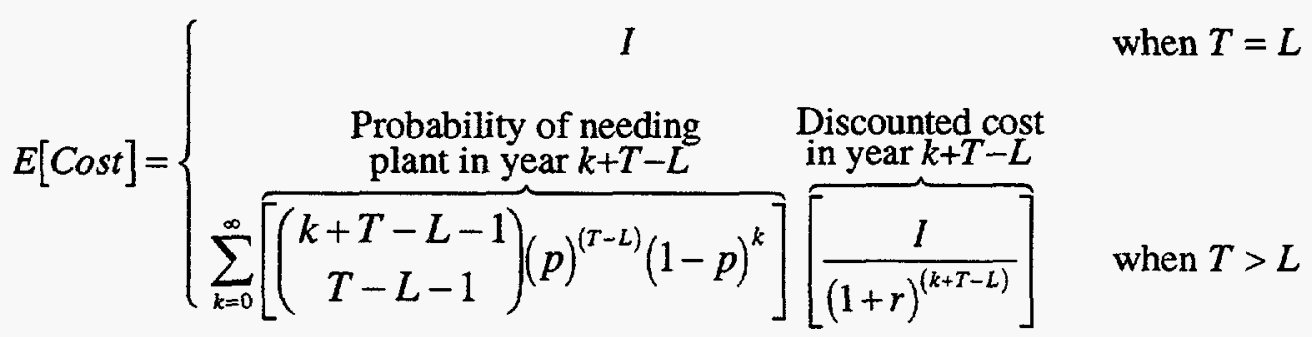

where $T$ and $L$ are both positive integers, $\left(\begin{array}{c}k+T-L-1 \\ T-L-1\end{array}\right)$ is the number of possible combinations of $(k+T-L-1)$ objects taken $(T-L-1)$ at a time, $p$ is the probability that demand will increase, $r$ is the real discount rate, and $I$ is the real cost of the plant and is assumed to be constant over time.

Equation (5.3) simplifies to

$$
E[\text { Cost }]=I\left(\frac{1}{1+r / p}\right)^{T-L}
$$

\subsubsection{Example: The Value of Short Lead-Time}

To illustrate the use of Equation (5.4), take the example from Section 5.5.2 where system capacity will vanish in one year if demand grows at the high rate (i.e., $T=1$ ). One plant has a one-year lead-time $(L=1)$ and costs $\$ 1,000 \quad(I=\$ 1,000)$ and the other plant has no lead-time and costs $\$ 1,150(I=\$ 1,150)$. There is a 50 percent probability of demand increasing in any given year $(p=0.5)$, and the real discount rate is 10 percent $(r=0.1)$. The utility wants to invest in the plant with the lowest cost. 


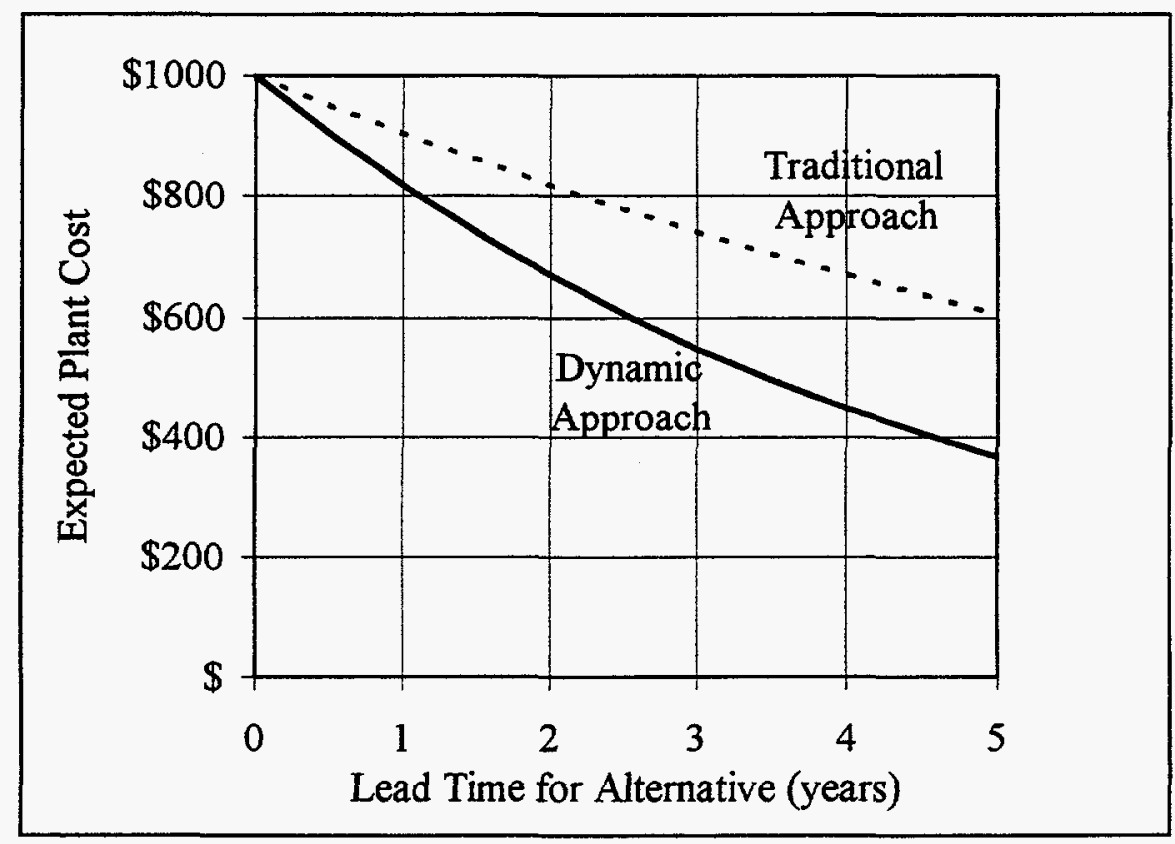

Figure 5-5. Value of short lead-time using static and dynamic evaluation approaches.

First, consider the result when a static demand growth approach is taken. In order for the utility to satisfy high projected demand (the light dashed line in Figure 5-3), construction on the plant with a one-year lead-time must begin immediately in 1995 at a present value cost of $\$ 1,000$. The plant with no lead-time will be built in 1996 at a present value cost of $\$ 1,045(\$ 1,150 / 1.1)$. In this case, the plant with a one-year lead-time has a lower cost than the plant with no lead-time.

Next, consider the result when the dynamic nature of demand uncertainty is included in the analysis. According to Equation (5.4), the one-year lead-time plant has an expected cost of $\$ 1,000$ while the no lead-time plant has an expected cost of $\$ 958$. The lower cost is a result of the fact that the need for the plant with no lead-time plant depends upon what happens with demand growth. Figure 5-4 shows that the plant will be built in 1996 if demand increases in 1996 (point B); it will be built in 1997 if demand is constant in 1996 (point C) and then increases in 1997 (point D), etc. ${ }^{33}$

The difference in results between a static and dynamic analysis becomes more dramatic as the probability of high demand growth gets smaller or as the lead-time gets bigger. ${ }^{34}$ Figure 5-5 illustrates the magnitude of this difference as a function of lead-time. The figure is based on a 50 percent probability of demand increasing, a 10 percent real discount rate, and a $\$ 1,000$ plant cost. Lead-time is varied from 0 to 5 years.

33 The results of this equation can be repeated by manually calculating the probability of a cost being incurred times the present value cost for each year. There is a 50 percent chance that the plant will be built in 1996 at a present value cost of $\$ 1,045(1,150 / 1.1)$, a 25 percent chance that the plant will be built in 1997 at a present value cost of $\$ 950\left(\$ 1,150 / 1.1^{2}\right)$, a 12.5 percent chance that the plant will be built in 1998 at a present value cost of $\$ 864\left(\$ 1,150 / 1.1^{3}\right)$, etc. Summing these together yields the same result as Equation (5.4).

34 Increases in the discount rate also magnify the difference in results, but to a lesser extent. 


\subsection{MODULARITY AND LEAD-TIME}

\subsubsection{Introduction}

In addition to having short lead-times, renewables such as wind and PV are modular. This provides plant owners with flexibility to more closely match capacity additions to system demand.

IOUs and municipal utilities have historically satisfied customer demand by generating electricity centrally and distributing it through an extensive T\&D network. As demand increases, the utility generates more electricity. Once demand increases beyond a certain level, the capacity of the generation, transmission, and distribution systems can become constrained. The traditional utility response to these constraints is to make large increases in system capacity.

Modular technologies offer utilities alternative approaches to dealing with system capacity constraints (Weinberg, Iannucci, and Reading 1991). One approach within the T\&D system is to incrementally satisfy increased demand using distributed generation technologies such as PV. Another approach is to reduce demand using targeted demand side management programs (Orans, et. al. 1992). These investments can reduce a utility's variable costs and defer capacity investments as illustrated in Figure 5-6.

Section 5.6.2 develops a method to calculate the cost of providing system capacity with either a modular or with a non-modular investment. Section 5.6 .3 presents an example of how to apply the method to the generation system using wind plants. Section 5.6 .4 develops a method to calculate the cost of providing system capacity using a combination of the modular and nonmodular investments. Section 5.6 .5 presents an example of how to apply the method to the T\&D) system using PV plants.

35 The value of modularity when combined with location in a distributed generation setting is probably of greater value to IOUs than to municipal utilities. The reason for this is that municipal utilities tend to have systems that are highly concentrated in urban areas (and thus are highly interconnected) while IOUs have a system that is more spread out. 


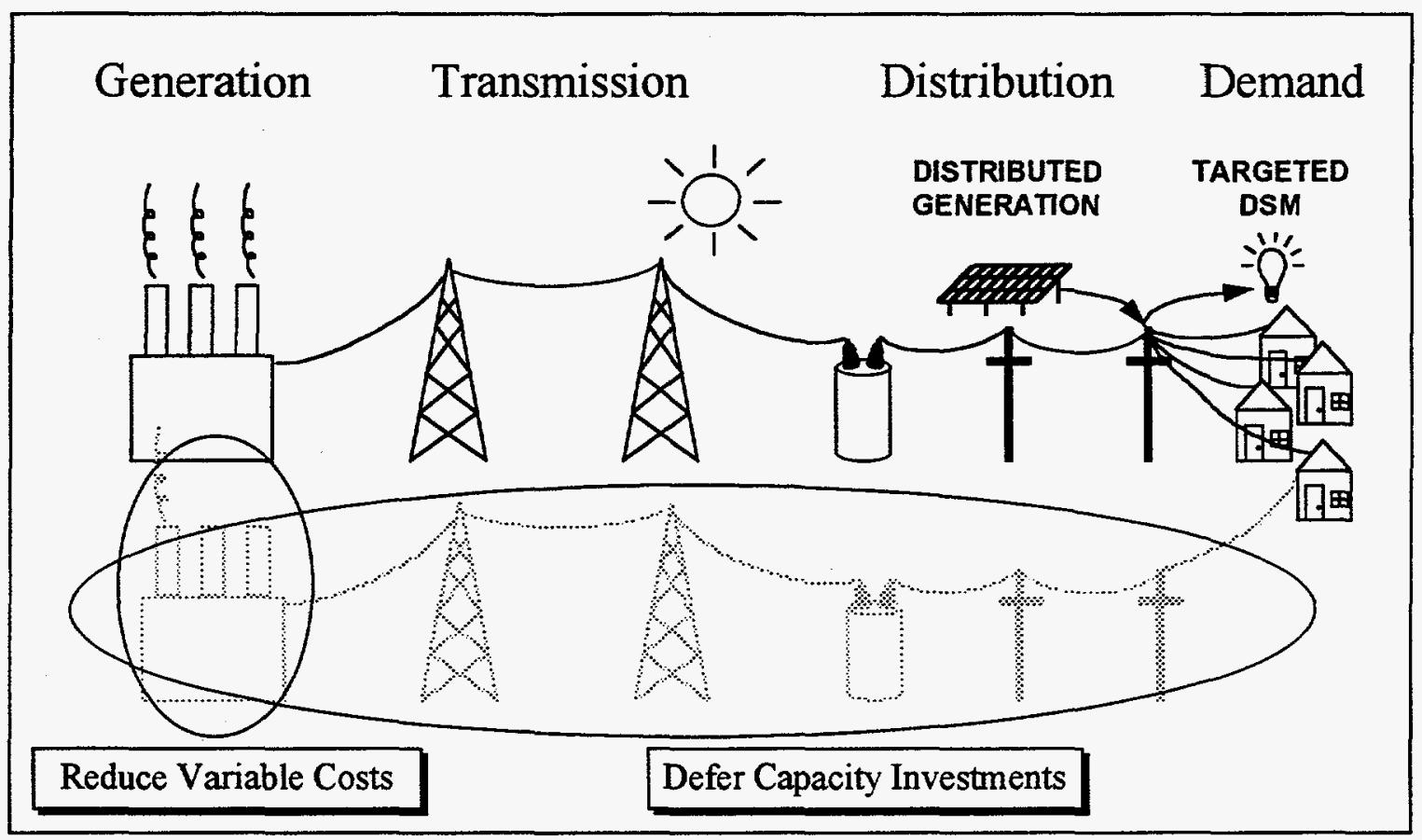

Figure 5-6. Benefits of distributed generation.

\subsubsection{Mutually Exclusive Investments}

Suppose that a utility's excess capacity will vanish in $T$ years if demand grows at the high rate every year. It wants to upgrade its system's capacity by $C \mathrm{MW}$, where $C$ is divisible by the high demand growth rate. It will use either a non-modular investment or a modular investment.

The expected cost equals its cost of each increment ( $I$, adjusted for when it occurs using Equation (5.4), summed over the number of increments needed to provide $C \mathrm{MW}$ of capacity (the number of increments, $N$, equals the desired capacity upgrade divided by the high growth rate). This cost is represented by adjusting the number of years until excess capacity vanishes for each increment and summing the results as shown below.

$$
\begin{aligned}
& \text { Expected cost } \\
& \text { Sum of all per increment } \\
& E[\text { Cost }]=\sum_{\sum_{t=0}^{\text {increments }}}^{\text {Sul }} \overbrace{\left(\frac{1}{1+r / p}\right)^{(T+t)-L}}^{\text {. }}
\end{aligned}
$$

Equation (5.5) simplifies to the following equation. The first term is the benefit of modularity and the second term is the benefit of short lead-time. 


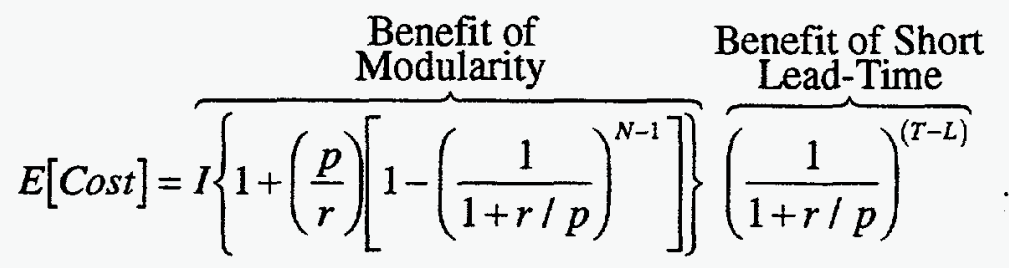

\subsubsection{Example: Municipal Utility - Part 3}

Continue with the municipal utility's decision to invest in either wind generation or natural gasbased generation from Sections 5.2.4 and 5.3.3. ${ }^{36}$ The risk-mitigating benefits of wind generation include the elimination of fuel price uncertainty (the result from Section 5.2.4), the elimination of potential future environmental costs associated with carbon emissions (the result from Section 5.3.3), and the value of modularity and short lead-time.

The municipal utility's historical and projected peak demand and its existing generation system capacity are presented in Figure 5-7. The current year is 1995 and the peak demand for this year is $480 \mathrm{MW}$. The lower solid line describes historical peak demand from 1991 to 1995 . The dashed lines describe projected peak demand with the light lines corresponding to the possible peak demands and the heavy line corresponding to the average peak demand. The utility has been experiencing an annual load growth of either $10 \mathrm{MW} /$ year or $0 \mathrm{MW} / \mathrm{year}$, each with an equal probability of 0.5 . It believes that this same trend will continue in the future. The figure suggests that excess system capacity will vanish in 1997 if peak demand increases for two consecutive years (i.e., $T=2$ ).

The utility will purchase either a $50 \mathrm{MW}$ natural gas-based plant or a $100 \mathrm{MW}$ wind plant to satisfy this capacity shortfall. As shown in Table 5-1, the plants provide the same amount of capacity and energy ${ }^{37}$ but differ in that the gas plant is not modular and has a two-year lead-time $(L=2)$ while the wind plant is modular and has a one-year lead-time $(L=1)$.

Construction on the natural gas plant must begin immediately in 1995 for the plant to be available if demand increases by $10 \mathrm{MW} /$ year for two consecutive years. The top dashed line in Figure 5-8 represents system capacity with the natural gas-based generation. Construction on the first 25 MW segment of the wind plant, however, can be postponed at least until 1996. The lower dashed capacity line in Figure 5-8 represents the expected increase in system capacity with the wind plant.

36 Municipal utilities represent an important market for wind technologies for several reasons. First, they appear to be able to represent the preferences of their customers for renewable energy technologies in their purchase decisions. Second, they have a lower cost of capital, thus reducing some of the bias against generation technologies that have high initial capital costs and low operation and maintenance costs. Third, their taxexempt status eliminates the tax benefit of expenses (e.g., fuel costs) over long-term capital costs.

37 The gas plant has a 20 percent forced outage rate. Results of a detailed wind resource assessment indicate that the capacity and energy provided by the wind plant equal 40 percent of its rating. 
Summing the individual costs from Table 5-1 results in a gas plant cost of slightly more than $\$ 100$ Million. The cost for one of the four segments of the wind plant is $\$ 30.9$ Million. Instead of the total wind plant costing four times this amount, however, Equation (5.6) suggests the expected wind plant cost is $\$ 98$ Million with the reduction in cost almost equally due to the plant's modularity and short lead-time. ${ }^{38}$ Thus, the cost for the two plants is comparable.

Table 5-1. Municipal utility example.

\begin{tabular}{|c|c|c|}
\hline & Non-Modular Gas Plant & Modular Wind Plant \\
\hline \multicolumn{3}{|l|}{ TECHINICAL DATA } \\
\hline Lead Time (years) & 2 years & 1 year \\
\hline Segment Size (MW) & $50 \mathrm{MW}$ & $25 \mathrm{MW}$ \\
\hline Number of Segments & 1 & 4 \\
\hline Capacity & $40 \mathrm{MW} /$ plant & $10 \mathrm{MW} /$ segment \\
\hline Energy & $350 \mathrm{GWh} / \mathrm{yr}$-plant & $88 \mathrm{GWh} / \mathrm{yr}$-segment \\
\hline \multicolumn{3}{|l|}{ COST DATA } \\
\hline Capital Cost & $\$ 25.0$ Million/plant ${ }^{39}$ & $\$ 20.0$ Million $/$ segment $^{40}$ \\
\hline Fuel Cost & $\$ 51.4$ Million/plant ${ }^{41}$ & none \\
\hline O\&M Cost & $\$ 17.1$ Million/plant ${ }^{42}$ & $\$ 10.9$ Million/segment ${ }^{43}$ \\
\hline Environment Cost & $\$ 7.0$ Million/plant $^{44}$ & none \\
\hline
\end{tabular}

$38 I=\$ 30.9$ Million $/ \mathrm{seg}, N=4$ seg., $r=0.05 \%, p=0.5, T=2$ years, and $L=1$ year. Equation (5.6) suggests that Benefit of

Benefit of Short

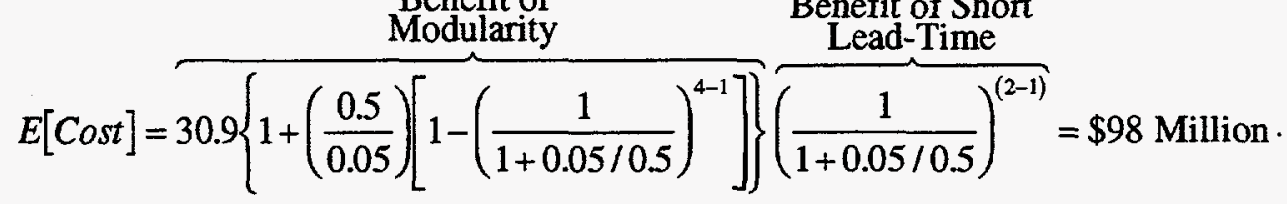

39 Based on a capital cost of $\$ 500 / \mathrm{kW}$, the cost of a $50 \mathrm{MW}$ plant is $(\$ 500 / \mathrm{kW})(50,000 \mathrm{~kW})=\$ 25$ Million .

40 Based on a capital cost of $\$ 800 / \mathrm{kW}$, the cost of a $25 \mathrm{MW}$ segment is $(\$ 800 / \mathrm{kW})(25,000 \mathrm{~kW})=\$ 20$ Million .

41 Section 5.2.4 showed that the fuel cost for a gas plant equivalent to a $25 \mathrm{MW}$ wind plant is $\$ 16.2$ Million. Since the fuel costs for the natural gas plant are not incurred until the time when the wind plant would have been built, this cost is treated in the same way as a segment of a wind plant. (See Footnote 38 for an example). The result is a present value fuel cost of $\$ 51.4$ Million.

42 Based on an O\&M cost of $\$ 0.005 / \mathrm{kWh}$ and a similar analysis as in footnote 41 , the O\&M cost for the plant is $\$ 17.1$ Million.

43 Based on an O\&M cost of $\$ 0.01 / \mathrm{kWh}$, the present value O\&M cost for one $25 \mathrm{MW}$ segment is $\sum_{\mathrm{i}=1}^{20} \frac{(\$ 0.01 / \mathrm{kWh})(8760 \mathrm{~h} / \mathrm{yr})(0.4)(25,000 \mathrm{~kW})}{1.05^{i}}=\$ 10.9$ Million

44 Section 5.3.3 showed that the environmental cost for a gas plant equivalent to a $25 \mathrm{MW}$ wind plant is $\$ 1.76$ Million. The plant is in full operation by year 2005 so that the cost is four times this amount, or $\$ 7.0$ Million. 


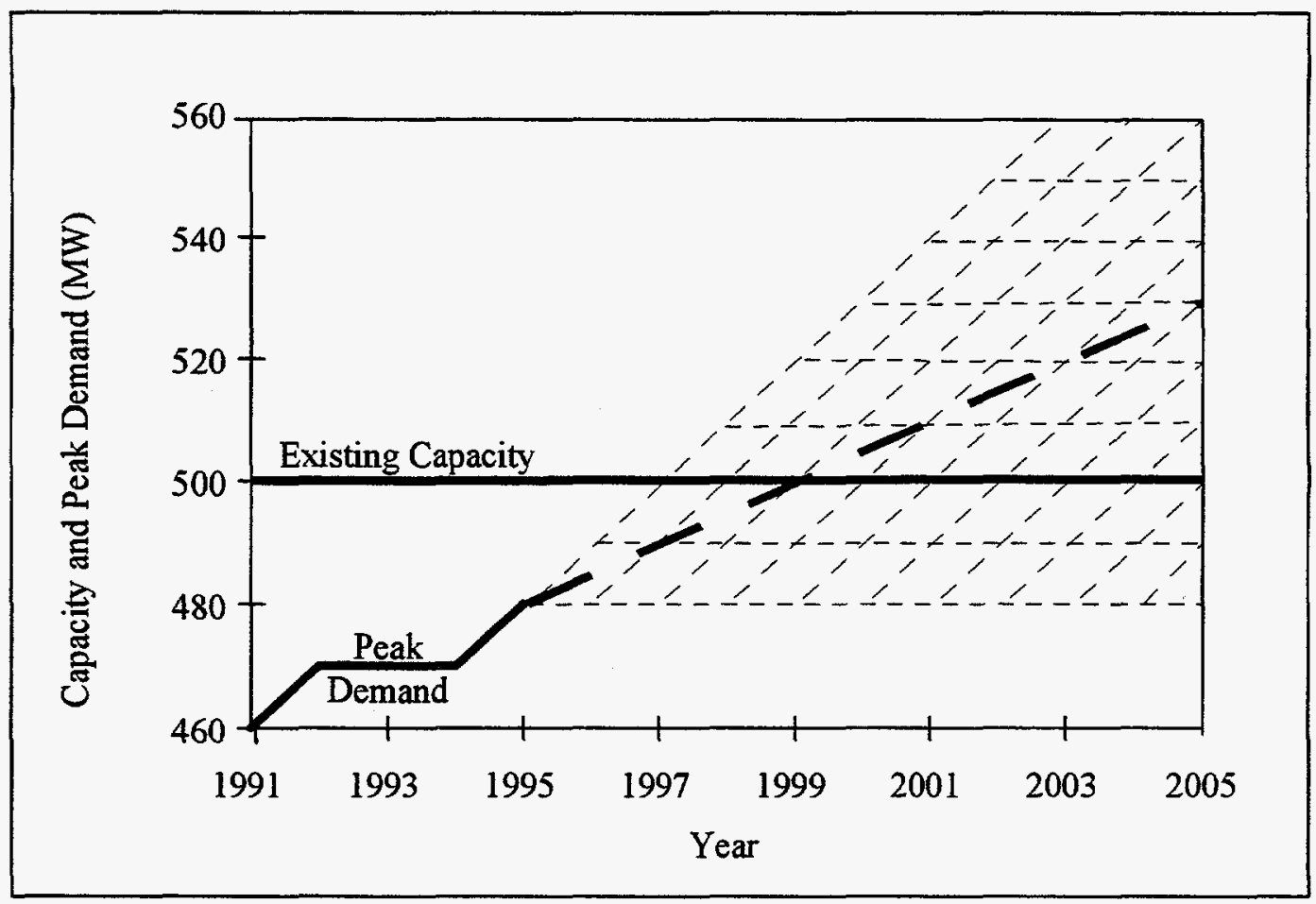

Figure 5-7. Municipal utility capacity and peak demand.

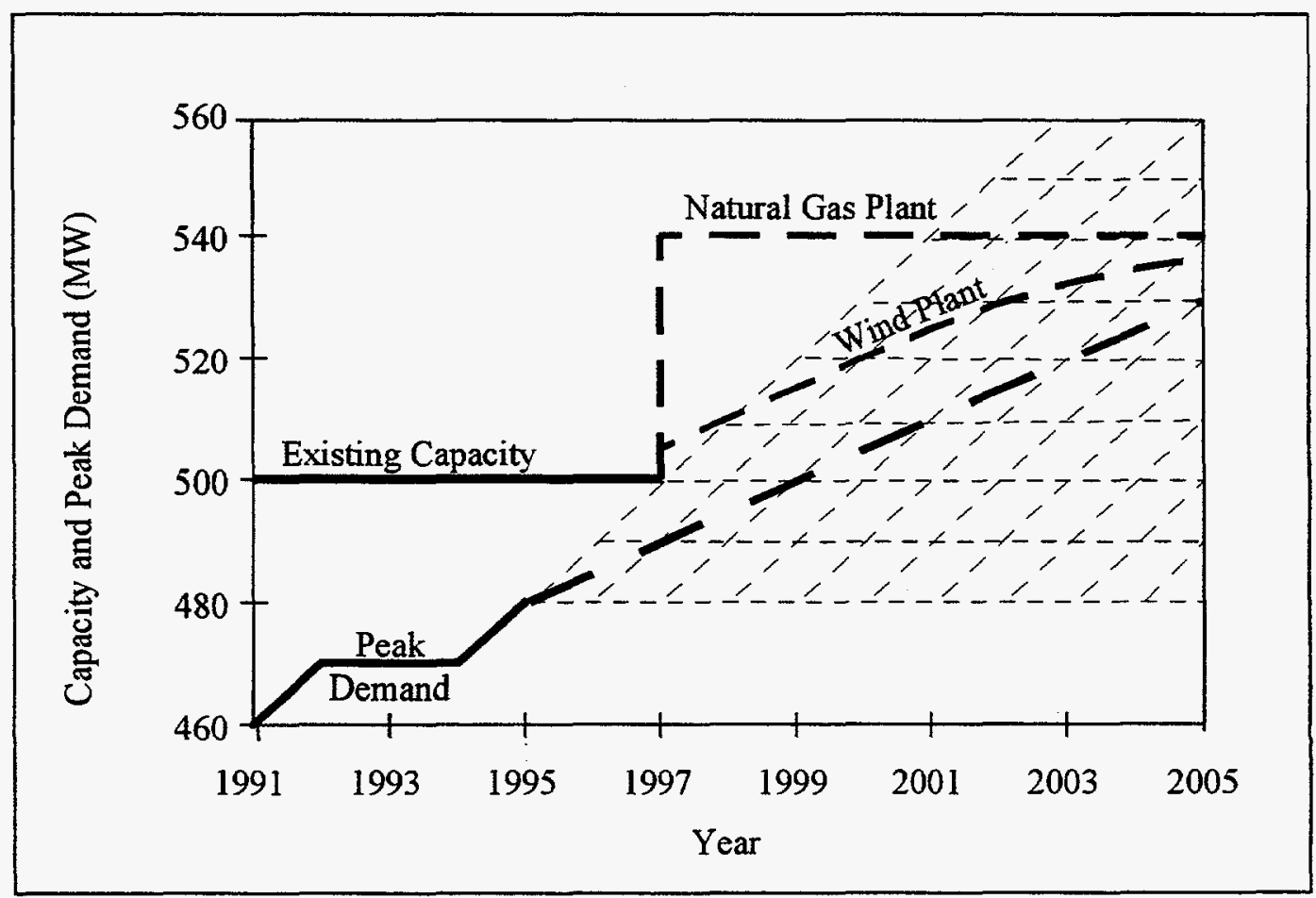

Figure 5-8. Municipal utility capacity with gas and wind plants. 


\subsubsection{Combined Investments}

Another approach to satisfying capacity needs is to use a combination of both the modular and non-modular investments. Rather than incurring the cost of the non-modular investment immediately, the utility waits to begin the investment until the number of years until the excess system capacity vanishes if demand grows at the high rate is reduced to $T_{R}$, where $T_{R} \leq T$. The longer the utility waits, however, the more likely it is that peak demand will occur before the nonmodular investment is completed and it will be required to incrementally invest in enough modular generation to satisfy the demand that exceeds capacity.

The expected cost of this combined approach equals the expected discounted cost of the nonmodular investment plus the expected discounted cost of satisfying peak demand using modular investments after the non-modular investment is started but before it is completed (i.e., the nonmodular investment is triggered when the remaining years until excess capacity vanishes is $T_{R}$ but it is unavailable for its lead-time of $L$ years) times the probability that demand reaches the trigger level of $T_{R}$ at any given time.

$$
\begin{aligned}
& \text { Prob. demand reaches Modular investment cost present valued to } \\
& \text { investment trigger level initiation of non-modular investment } \\
& E[\text { Cost }]=\sum_{h=0}^{\infty} \overbrace{\left(\begin{array}{c}
h+A-1 \\
A-1
\end{array}\right)(p)^{A}(1-p)^{h}}^{\left[I^{N}+\right.}[\overbrace{\sum_{j=B}^{L-2}\left[\sum_{k=B}^{j}\left(\begin{array}{l}
j \\
k
\end{array}\right)(p)^{k+1}(1-p)^{j-k}\left(I^{M}\right) e^{-r(j+1)}\right]}] e^{-r(h+A)}
\end{aligned}
$$

where $A=T-T_{R}, B=T_{R}-1, T$ is the number of years that excess capacity will vanish if demand grows at the high rate, $T_{R}$ is the number of years that excess capacity will vanish if demand grows at the high rate if the utility waits to make any investment, $L$ is the number of years required to construct the non-modular investment, $p$ is the probability that load growth will be high in any given year, $1-p$ is the probability that there will be no load growth, $I^{N}$ is the real non-modular investment cost (\$), $I^{M}$ is the real modular investment cost (\$) to satisfy one year's worth of demand growth at the high rate, and $r$ is the real discount rate. It is assumed that there is no leadtime for the modular investment.

The first summation in Equation (5.7) corresponds to the probability that demand reaches the trigger level, $T_{R}$, for the first time; the second summation corresponds to the time after the nonmodular investment is initiated but before it is completed; and the third summation corresponds to the various possible states at a given time after the non-modular investment is initiated but before it is completed when modular investments may be required. If a capacity shortfall occurs, the modular investment is made to satisfy one year's worth of load growth at the high level. It is assumed that $A, B$, and $L$ are all integers and that $A \geq 1, B \geq 0$, and $L \geq 2$ so that the binomial formulas will remain valid. It is also assumed that all economic variables are constant over time, that the uncertainty associated with future load growth is not resolved over time (i.e., no 
additional information about future load growth is gained by waiting), and that the modular investments have infinite lives. ${ }^{45}$

Equation (5.7) can be simplified since a binomial distribution is approximately normal.

$$
E[\text { Cost }]=\sum_{h=0}^{\infty}\left(\begin{array}{c}
h+A-1 \\
A-1
\end{array}\right)(p)^{A}(1-p)^{h}\left[I^{N}+I^{M} p \sum_{j=B}^{L-2}\left[1-\Phi\left(\frac{B-\frac{1}{2}-p j}{\sqrt{p(1-p) j}}\right)\right] e^{-r(j+1)}\right] e^{-r(h+A)}
$$

where $\Phi$ is the cumulative unit normal distribution.

The first summation is reduced to a single number as was done for Equation (5.3).

$$
E[\operatorname{Cos} t]=\left[I^{N}+I^{M} p \sum_{j=B}^{L-2}\left[1-\Phi\left(\frac{B-\frac{1}{2}-p j}{\sqrt{p(1-p) j}}\right)\right] e^{-r(j+1)}\right] e^{-r A / p}
$$

The expected cost in Equation (5.9) is minimized by varying the number of years remaining when the non-modular investment construction is started ( $T_{R}$ in the $B$ term).

\subsubsection{Example: Lead-Time and Modularity for T\&D System with PV}

As an example, consider the value of a distributed PV generation facility when there is demand uncertainty at the T\&D system level. The system currently has $12 \mathrm{MW}$ of unused capacity. There is a 50 percent probability $(p)$ that the load will grow at the high rate of $2 \mathrm{MW} /$ year and a 50 percent probability that the load will not grow at all in any given year. Thus, excess capacity will vanish in 6 years $(T=6)$ if demand grows at the high rate each year. The utility has a 10 percent real discount rate $(r)$.

\subsubsection{Satisfiv Demand Using T\&D Upgrade}

The first alternative is to satisfy demand by upgrading the T\&D system. Suppose that the upgrade costs $\$ 2$ Million $\left(I^{N}\right)$, has a 6 years lead-time $(L)$, and will increase system capacity by 24 MW (C). Construction must begin immediately in order to prepare for the situation that the load grows at the high rate $(2 \mathrm{MW}$ /year) for the 6 years it will take to complete the upgrade. The present value cost of this alternative is $\$ 2$ Million.

45 The formulation in Equation 4.11 may understate the value of this combined approach for three reasons. First, this formulation will provide at least $C_{N}$ units of capacity and probably more because the distributed generation investments will continue to provide capacity to the system even after the non-modular investment is completed. Second, the modular capacity investments are made later in time than the non-modular investment so that, if their lives were finite, their value could be greater. Third, the price of the modular investments may be declining and uncertain, thus increasing the value (Hoff, Wenger, and Farmer, 1996). Future work should adjust for these factors. 


\subsubsection{Satisfy Demand bv Incrementally Installing Distributed Generation}

The second alternative is to install 12 increments of distributed PV in $2 \mathrm{MW}$ sizes to provide 24 MW of capacity. Suppose that the cost of PV is $\$ 3$ Million $M W$ and that its value to the utility when used in a central station application is $\$ 2$ Million $/ \mathrm{MW}$. This implies that the per unit price of PV in terms of the capacity it provides to the T\&D system is $\$ 1$ Million/MW and the cost per 2 MW increment is $\$ 2$ Million ( $I=\$ 2$ Million). ${ }^{46}$

Equation (5.6) implies that the expected cost of using the distributed PV is $\$ 3.6$ Million, with slightly more of the benefit coming from the short lead-time than from the modularity. ${ }^{47}$ Thus, the distributed PV generation alternative costs more than the upgrade.

\subsubsection{Satisfv Demand Using Upgrade and Distributed Generation}

A third alternative is to wait to begin the upgrade until the load grows and there is less unused capacity. Figure 5-9 presents the expected cost of this option and shows that the most cost effective option is to wait until demand grows by $4 \mathrm{MW}$ so that number of years until system excess system capacity vanishes is 4 years $\left(T_{R}=4\right)$. The figure illustrates that, while this may involve installing some $P V$, it reduces the cost of the T\&D upgrade by about 25 percent. That is, even though the cost of the PV alternative by itself exceeds the cost of the T\&D upgrade, it can effectively be used to delay the upgrade until the load grows with the possibility of some cost being incurred before the upgrade is completed.

46 It is assumed that the each MW of PV provides $1 \mathrm{MW}$ of capacity.

$$
{ }_{47} E[\text { Cost }]=2 \overbrace{\left\{1+\left(\frac{0.5}{0.10}\right)\left[1-\left(\frac{1}{1+0.10 / 0.5}\right)^{12-1}\right]\right\}}^{\begin{array}{c}
\text { Benefit of } \\
\text { Modularity }
\end{array}} \overbrace{\left(\frac{1}{1+0.10 / 0.5}\right)^{(6-0)}}^{\begin{array}{c}
\text { Benefit of Short } \\
\text { Lead-Time }
\end{array}}=\$ 3.6 \text { Million . }
$$




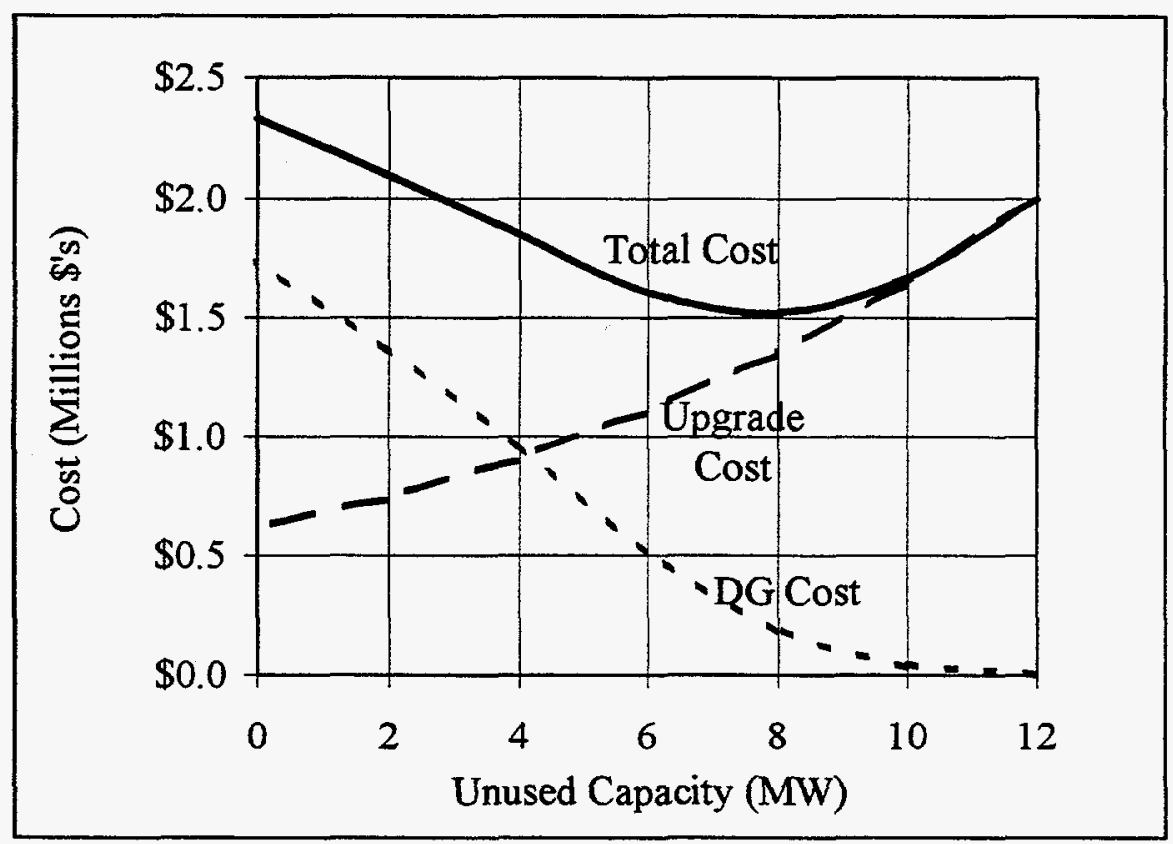

Figure 5-9. Cost of using PV and upgrade to satisfy T\&D capacity.

\subsection{AVAILABILITY}

\subsubsection{Introduction}

The modularity of a plant also affects some aspects of the plant's availability that are of interest under all ownership scenarios. Modular plants are likely to begin producing power (and thus revenue for utilities and IPPs or cost-savings for power consumers) earlier than non-modular plants. This is because a modular plant can begin operation as each segment of the plant is completed. The value of this is that the plant will begin to produce revenue earlier than a plant that is not modular.

Suppose, for example, that a utility wants to build a $500 \mathrm{MW}$ facility. The modular plant can be constructed in $50 \mathrm{MW}$ increments with each increment having a six-month lead-time (it takes 5 years to complete the plant). A $500 \mathrm{MW}$ non-modular plant is built in one segment and has a five-year lead-time. Capital equipment has a twenty-year life beginning at the point when the equipment starts operating. As shown in Figure 5-10, the modular plant begins earning revenue six months after the start of construction while the non-modular plant produces no revenues until the fifth year. It can be shown that this increases the present value of the revenues from the modular plant over the non-modular plant by 25 percent when the discount rate is 10 percent. 


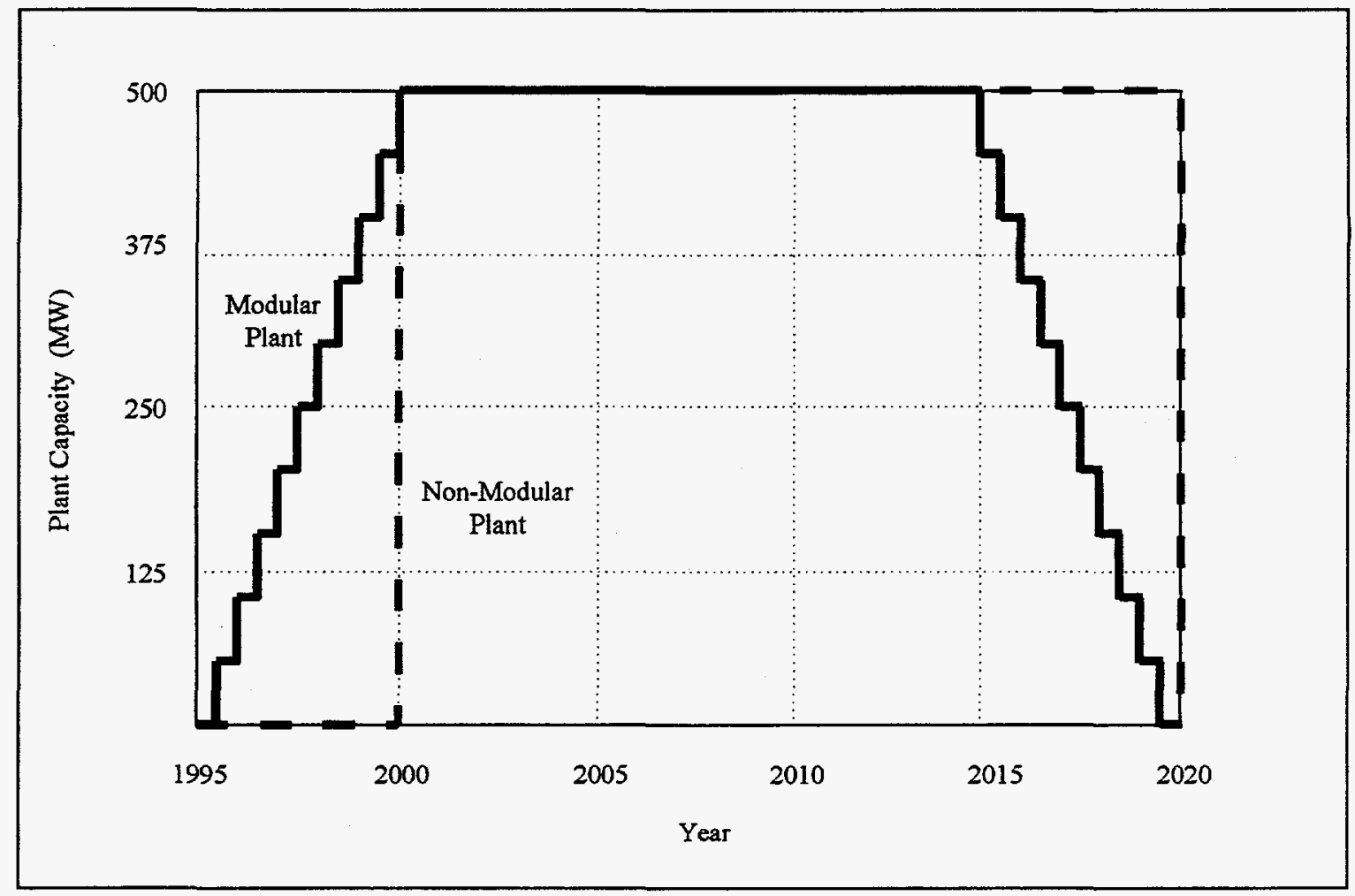

Figure 5-10. Modular plant produces revenue earlier than non-modular plant.

In addition, when all else is equal, modular plants are likely to have a less of a range of uncertainty of their availability than non-modular plants. This is due to the fact that the timing of equipment related outages in one particular piece of capital (e.g., a wind turbine) is not likely to be correlated with the timing of equipment related outages in another particular piece of capital. That is, a large number of small units will usually have less of a range of uncertainty than a small number of large units that are of similar characteristics. While the plant may lose one wind turbine or PV panel, the whole plant will not be shut down until the problem is corrected. The same is not necessarily true of non-modular plants.

Section 5.7.2 presents a method to calculate the added value associated with early plant operation. Section 5.7.3 presents a method to calculate the reduction in variance associated with modular plants.

\subsubsection{Early Operation}

Consider, first, the value associated with the fact that modular plants can begin operation as each segment is completed. ${ }^{48}$ Assume that both the non-modular and modular plants take $L$ years to finish completely and have an equipment life of $T$ years. Assume also that the modular plant is infinitely divisible, that $r$ is the continuous time real discount rate, and that the annual revenues for the full plant equal $R$.

48 Notice that only plant value is discussed in this section; plant cost is not considered. 
The present value of the revenues from the modular plant equals the sum of plant revenues as it is under construction plus revenues from the fully completed plant plus revenues as parts of the plant begin to die due to the fact that they began operating earlier than other parts of the plant. ${ }^{49}$ The shape of plant capacity is a trapezoid that is similar to Figure 5-10 above.

$$
\text { Modular }=\overbrace{\int_{0}^{L}\left(\frac{x}{L}\right)(R) \exp (-r x) d x}^{\begin{array}{c}
\text { Revenues as plant } \\
\text { is under construction }
\end{array}} \overbrace{\int_{L}^{T}(R) \exp (-r x) d x}^{\begin{array}{c}
\text { Revenues from } \\
\text { completed plant }
\end{array}} \frac{\begin{array}{c}
\text { Revenues from plant } \\
\text { as segments go off-line }
\end{array}}{\int_{T}^{T+L}\left(\frac{T+L-x}{L}\right)(R) \exp (-r x) d x}
$$

Equation (5.10) simplifies to

$$
\text { Modular }=[R]\left[\frac{1-\exp (-T r)}{r}\right]\left[\frac{1-\exp (-L r)}{L r}\right] .
$$

The present value of the revenues from the non-modular plant equal

$$
\text { Non-Modular }=\int_{L}^{T+L}(R) \exp (-r x) d x
$$

Equation (5.12) simplifies to

$$
\text { Non-Modular }=[R]\left[\frac{1-\exp (-T r)}{r}\right][\exp (-L r)] \text {. }
$$

The added revenues of the modular plant over the non-modular plant equals the ratio of the revenues from the modular plant to the non-modular plant. Dividing Equation (5.11) divided by Equation (5.13) results in

$$
\text { Ratio }=\left[\frac{\exp (L r)-1}{L r}\right]
$$

Notice that the only variables in Equation (5.14) are the continuous time real discount rate ( $r$ ) and the number of years it takes to complete the plants $(L)$; that is, the life of the plants is irrelevant. Figure 5-11 plots the shape of this equation for several discount rates versus the amount of time it: takes to fully complete the plants $(L)$. As can be seen in the figure, the higher the discount rate and the longer the plant construction time, the greater the increase in value.

\footnotetext{
49 The following equation is true for $T>L$, and for $T, L$, and $r>0$.
} 


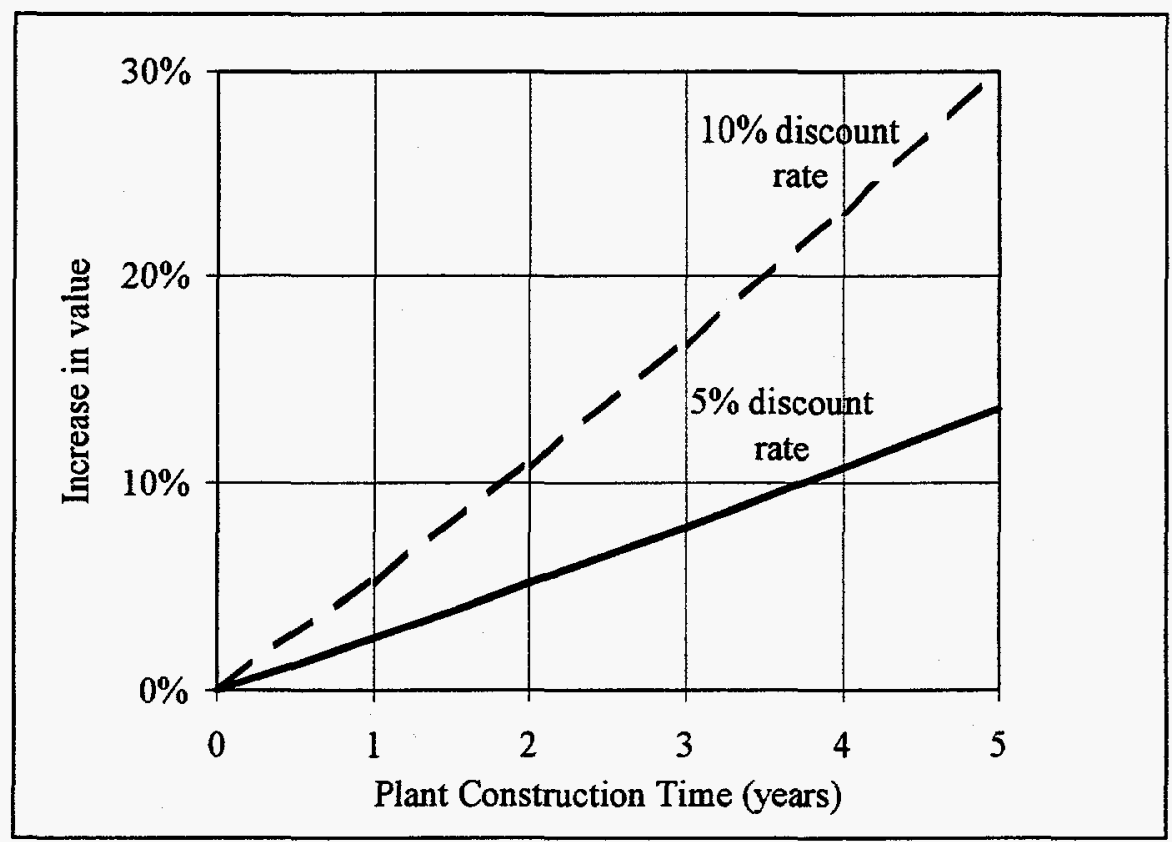

Figure 5-11. Value of early availability increases with construction time.

\subsubsection{Reduced variance}

A second aspect of plant availability, this time from an operational perspective, is that modular plants have less variance in their equipment availability than non-modular plants when equipment failures in the modular plant are independently distributed. A non-modular plant can be considered to be either operating or not operating. If its forced outage rate is $(1-p)$, it has full availability with probability $p$ and is unavailable with a probability of (1-p). Modular plants, by contrast, can have partial availability. For example, a modular plant with two identical segments has three possible levels of availability as depicted by the probability tree in Figure 5-12: the plant is 100 percent available if both segments are functional; it is 50 percent available if either the first or the second segment is functional (thus the 2 in the probability distribution in Figure 5-12); and it is unavailable if both segments are non-functional. 


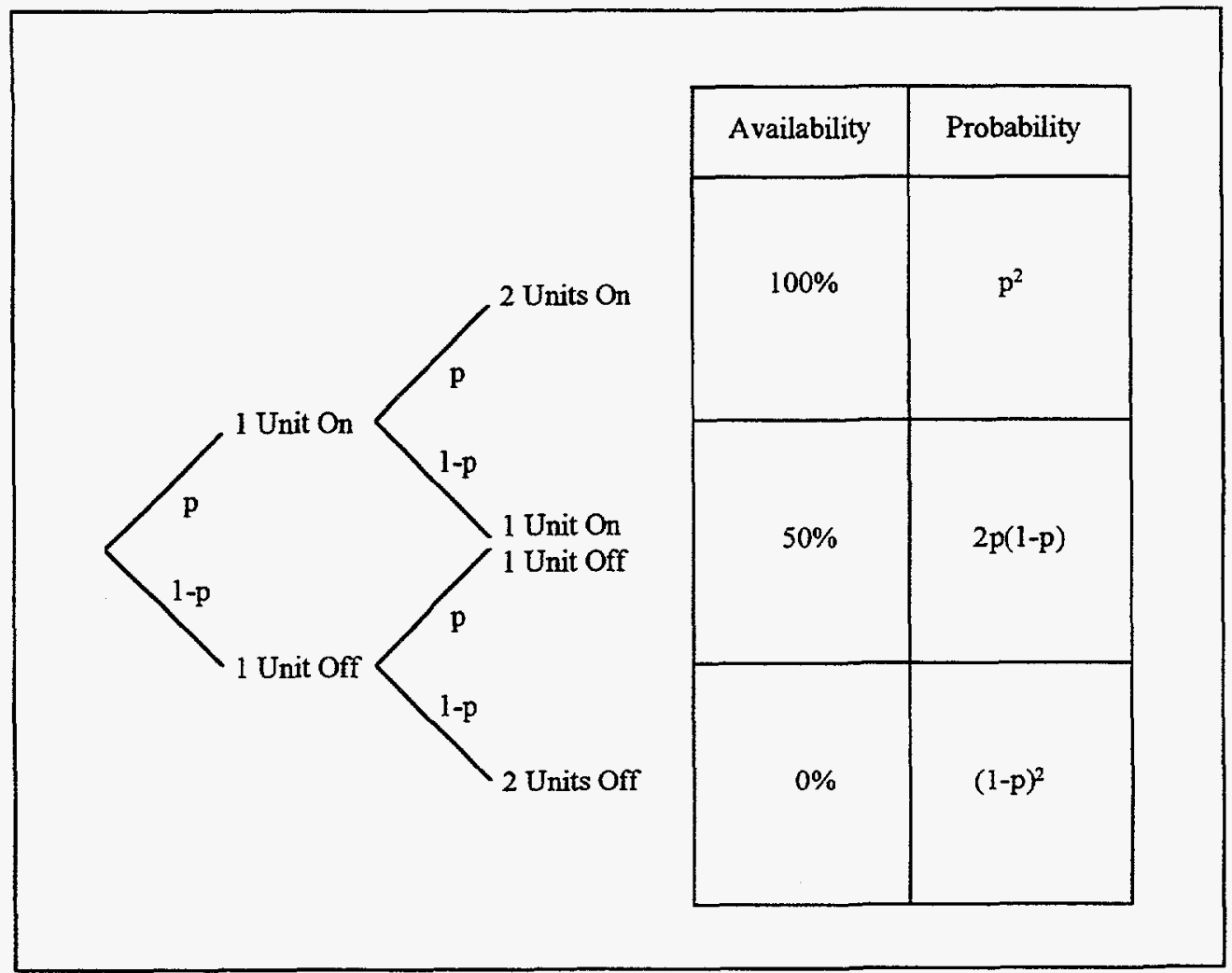

Figure 5-12. Distribution of plant outages for a two-unit modular plant.

The mean or expected availability of a plant regardless of the number of segments is one minus its forced outage rate. Since the forced outage rate is $(I-p)$, the mean availability is $p$. Variance for a non-modular plant is $\left[p(1-p)^{2}+(1-p)(0-p)^{2}\right]$, which simplifies to $p(1-p)$. ${ }^{50}$ Variance for a modular plant with two segments equals $\left[p^{2}(1-p)^{2}+2 p(1-p)\left(\frac{1}{2}-p\right)^{2}+(1-p)^{2}(0-p)^{2}\right]$, which simplifies to $p(1-p) / 2$.

In general, it can be shown by using either an iterative repetition of the variance calculation above (i.e., the binomial tree in Figure 5-12) or by an application of the Central Limit Theorem (Ross 1988) that the variance for a plant with $n$ independent identical segments equals

$$
\text { Variance }=p(1-p) / n
$$

Thus, variance decreases as the number of segments increases: the more modular the plant, the more reliable is its availability. Figure 5-13 illustrates this point using Equation (5.15) and a 15 percent forced outage rate; the shape of the figure is similar for other forced outage rates. The value of this variance reduction depends upon the consequences if the plant is unavailable.

50 The variance of a random variable $X$ is $\operatorname{Var}(X)=E\left[(X-\mu)^{2}\right]$, where $E$ is the expectation and $\mu$ is the mean. 


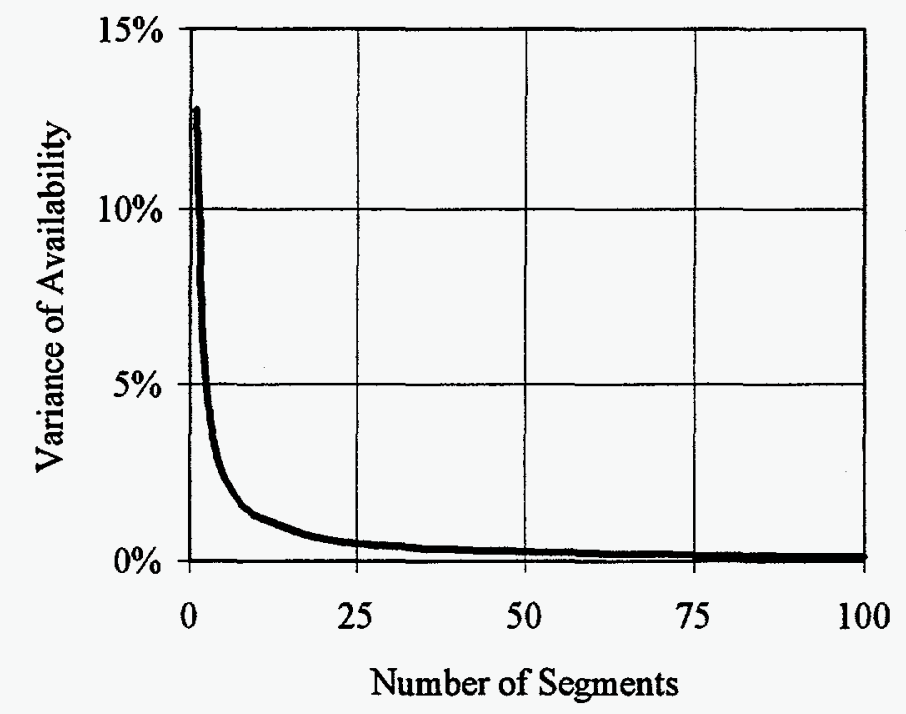

Figure 5-13. Variance of availability versus number of segments.

\subsection{INITIAL CAPITAL COST}

\subsubsection{Introduction}

Modular plants provide plant owners with several benefits in terms of initial capital costs. First, projects with short lead-times tend to have greater certainty associated with the installed capital cost due to fewer cost overruns and less lost revenue due to plant delays. This is of interest to any party that is responsible for the plant's construction. This primarily includes IPPs because many utilities and power consumers install generation facilities through a contracting procedure, thus shifting the construction risk away from themselves to the contractor. Standard and Poor's (1996) estimates that many fixed-price, turnkey contracts charge upward of a 30 percent premium.

Second, modular plants tie up fewer capital resources during construction. The developer only needs enough working capital to finance one increment at a time (i.e., one-tenth of the overall project in the previous example). Once the first segment is completed, the unit can be fully financed, and the proceeds used to finance the next segment.

Figure 5-14 presents the unrecovered capital costs for both plants based on the example in Section 5.7.2 assuming a linear investment rate. The company building the modular plant requires at most one-tenth of the total project cost at any one time. This benefit is likely to be of particular interest to companies with limited financial resources, such as IPPs. The lower capital requirements are likely to reduce the possibility that the company will get close to or enter bankruptcy. The result is that debt and equity investors will require a lower rate of return because there will be less of a risk of loss due to bankruptcy. 


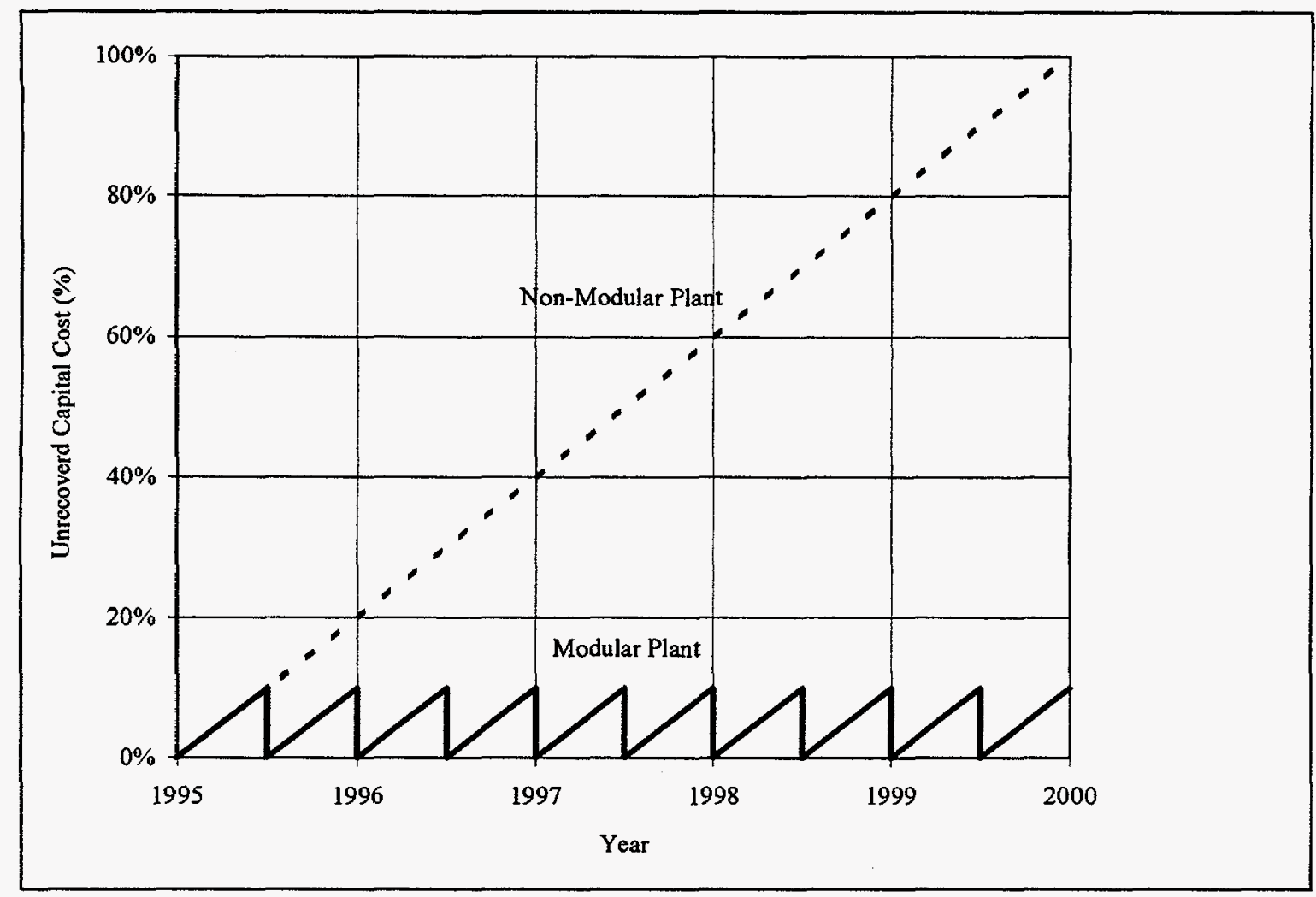

Figure 5-14. Modular plants have lower unrecovered costs than non-modular plants.

This benefit is similar to a developer that chooses to build single-family dwellings rather than an apartment building. The full financial resources are tied up in the apartment building before it is sold while the single-family dwellings can be sold as they are completed, thus requiring less working capital.

Third, construction of the modular plant can also be contingent on the results of the previous phase. After each segment is built, there is the opportunity to stop building the overall project without experiencing a total loss. That is, the completed increments of the project can be used to produce revenue whether or not the full project is completed. The same is not true for projects that are not modular. While there is always the opportunity to halt construction on any project, doing this on a project that is not modular will result in a loss of sunk costs installed to date less the partially-completed project's salvage value. While this has typically been identified as a value to utilities who want to be able to respond to demand uncertainty, it is also of value to third-party investors who are funding an IPP and who may not be satisfied with the project's progress. In addition, there are valuable learning effects that occur in the construction of a modular plant.

\subsubsection{Project Off-Ramps}

Consider the benefit of project off-ramps in more detail. Figure 5-15 presents a simple example for a plant that is composed of two identical segments. It is assumed that there is no market for the uncertainty associated with capital costs. The squares and circles in the figure correspond to decisions and uncertainties, respectively. The only uncertainty is what the cost of construction 
will be for each segment. This uncertainty is resolved after the first segment is completed and before the decision to build the second segment is made. If construction cost is high for the first segment it will be high for the second segment as well. Likewise, if construction cost is low for the first segment it will be low for the second segment as well. Cost will be high with a probability $p$ and low with a probability $(1-p)$.

The figure presents the net benefits associated with the completed plant for a modular and a nonmodular plant after all decisions are made and cost uncertainty is resolved. It is assumed that the costs are proportional to the completed project for both plants. The difference between the modular and non-modular plants is that the modular plant has value after the first segment is completed while the non-modular plant has value only after both segments are built. That is, half of the value minus cost is obtained for the modular plant if only one segment is completed while there is only a cost for the non-modular plant if only one segment is completed. The plants have no salvage value.

Suppose, for example, that the value of a complete plant $(V)$ is $\$ 1,000,000$, high cost $\left(C_{H}\right)$ is $\$ 1,500,000$, low cost $\left(C_{L}\right)$ is $\$ 500,000$, and the probability of high cost, $p$, is 0.5 . Figure 5-16 shows the result of putting these numbers into Figure 5-15. The ovals represent the net benefit for the modular and non-modular plants depending upon whether the cost is high or low. Both segments of the modular plant are completed only if the cost is low while both segments of the non-modular plant are completed no matter what the cost is. The expected net benefits of the modular plant is $\$ 125,000$ while the expected net benefits of the non-modular plant is $\$ 0$.

\subsubsection{Example: Project Off-Ramps Associated with Wind Project}

This example illustrates the off-ramps associated with a wind project undertaken by a renewable aggregator. $^{51}$ The renewable aggregator is a project developer who has a long-term firm power delivery contract with a customer that is scheduled to begin in 1 year (i.e., the beginning of the second year) and that lasts for 10 years. The contract specifies that the plant deliver $20 \mathrm{MW}$ of firm power during peak times and deliver a total of $175 \mathrm{GWh} /$ year. All investments have 20-year lives and the aggregator will renegotiate a new 10-year contract when the original contract expires.

The aggregator can satisfy the contract by: 1) using wind generation firmed with spot-market purchases; 2) using wind generation firmed with natural gas-based generation; 3) using natural gas-based generation; or 4) using wind, natural gas-based generation, and spot-market purchases. This example considers the fourth approach and the project off-ramps associated with it. It focuses on the uncertainties of: 1) wind plant cost due to the uncertain wind resource and uncertain site-specific environmental requirements ; and 2) spot-market costs.

s1 Various forms of this concept have been proposed, including: output aggregated from a number of renewable resources sold directly to a group of customers under a long-term contract; output from at least one renewable resource combined with output from other non-renewable technologies sold to aggregated consumer demand with or without a long-term contract; output from a renewable resource aggregated with another resource sold to a poolco, with the aggregation performed to take advantage of the highest pool prices; etc. 


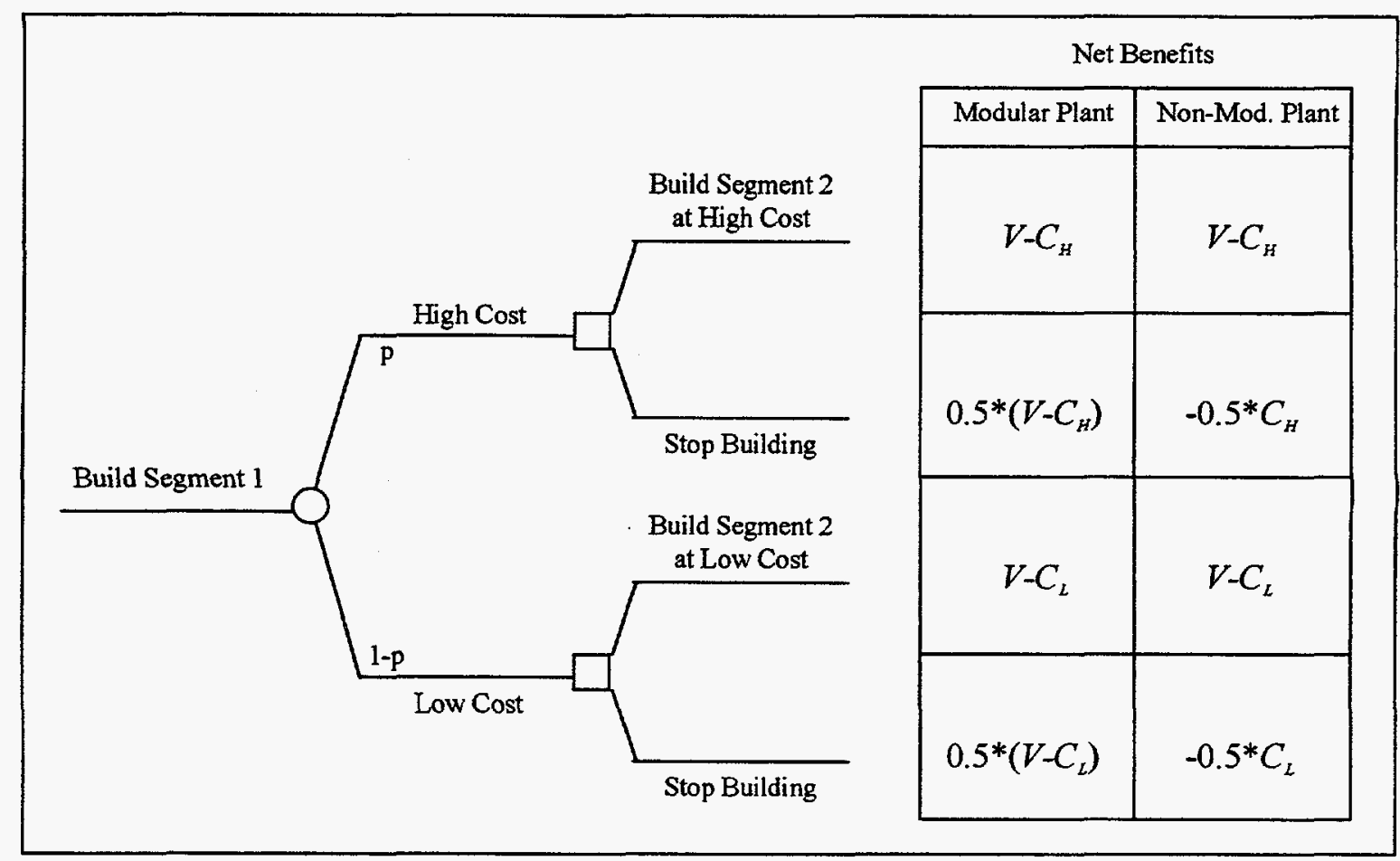

Figure 5-15. Project off-ramps associated with modular plants.

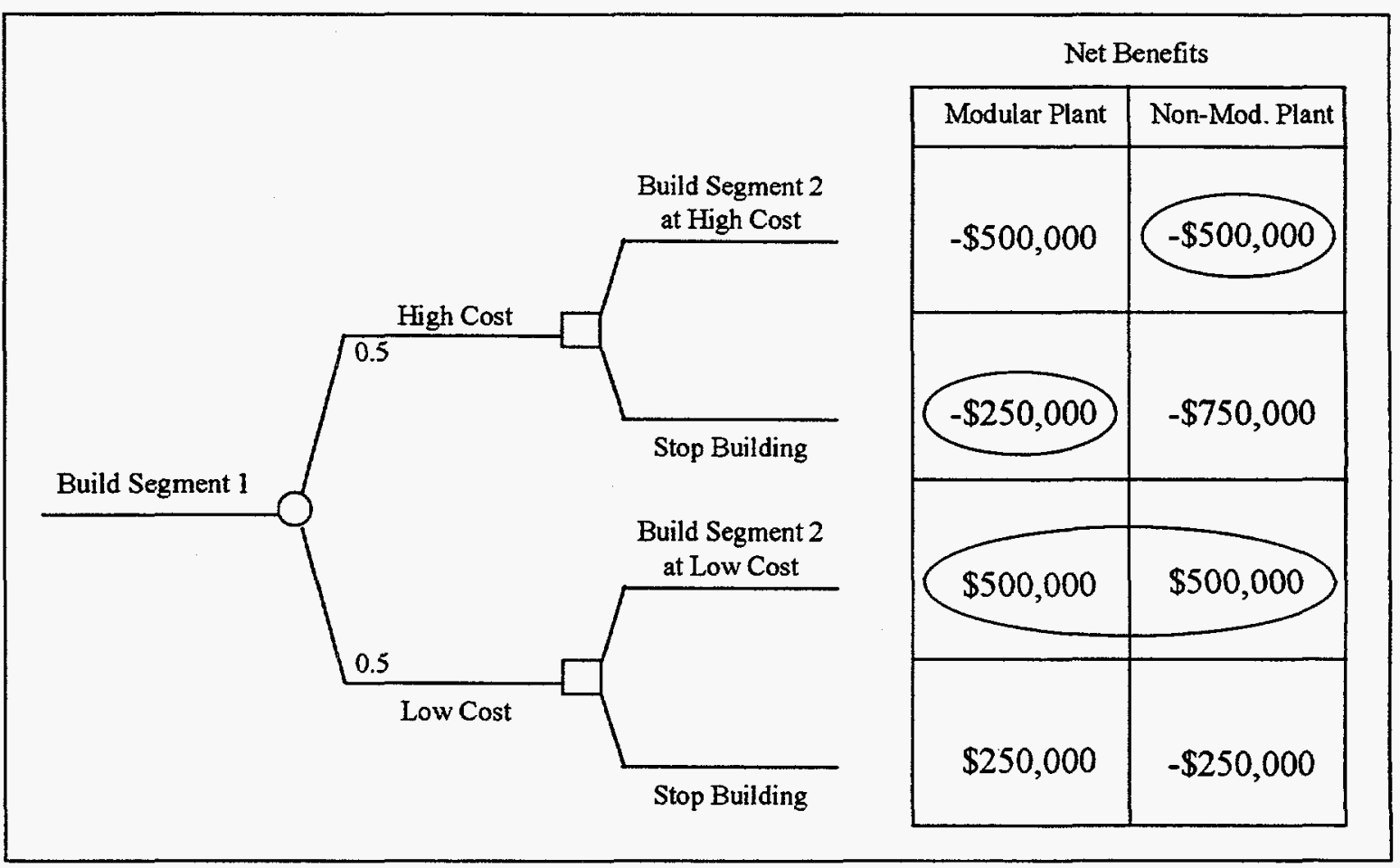

Figure 5-16. Project off-ramps associated with modular plants - example. 


\subsubsection{Decision Diagram}

Figure 5-17 presents the three stages of the aggregator's problem along with the nominal costs and probabilities of each stage. ${ }^{52}$ Stage 1 is to assess the wind resource and environmental costs or to build the natural gas plant. Stage 2 is to build the wind plant or the natural gas plant (given that the natural gas plant is not built in stage 1). Stage 3 is to firm the wind power with spot purchases or to build natural gas backup generation. Consider each of these stages in more detail.

\subsubsection{Stage 1}

Stage one, which is performed in the first six months, is to obtain environmental permits $(\$ 1.75$ Million cost) and to install met towers ( $\$ 0.25$ Million cost) for a total cost of $\$ 2$ Million. A preliminary wind resource assessment composed of a single met tower that recorded wind measurements for two years has already been performed. Preliminary results indicate that there is minimal inter-annual wind variability and that the wind resource is either a class 4 (25 percent probability) or class 5 resource ( 75 percent probability). A class 5 resource means that a $50 \mathrm{MW}$ wind plant will be needed and a class 4 resource means that a $75 \mathrm{MW}$ wind plant will be needed to satisfy the contract. ${ }^{53}$ It is assumed that there are no environmental costs if the resource is class 5 but there will be $\$ 10$ Million in costs if the resource is class $4 .^{54}$

\subsubsection{Stage 2}

Stage two, which is performed during the second six months of the first year, is to either build the wind plant or the natural gas plant. The total wind plant cost is $\$ 40$ Million in a class 5 resource $^{55}$ and $\$ 70$ Million in a class 4 resource. ${ }^{56}$ The total cost of the natural gas-based generation alternative is $\$ 56$ Million. ${ }^{57}$ These costs are all incurred at the end of year 1 .

\subsubsection{Stage 3}

Stage three is the aggregator's option of installing back-up generation if the wind plant is constructed and spot-market purchases to firm the wind power turn out to be excessive. The

52 The squares represent decisions and the circles represent uncertainties. The uncertainties are limited to only two possibilities for the sake of clarity; more possibilities could be included if desired.

53 A class 5 resource translates to a translates to a 40 percent wind plant capacity factor, which means that the wind plant must have a $50 \mathrm{MW}$ of nameplate capacity to satisfy the contracts terms of $175 \mathrm{GWh}$ of energy and $20 \mathrm{MW}$ of firm capacity. A class 4 wind resource translates to a 27 percent wind plant capacity factor, which means that the wind plant must have a $75 \mathrm{MW}$ nameplate capacity to satisfy the contract.

54 This assumption is made to simplify the analysis. The decision tree can easily be modified to account for this uncertainty. Capital cost of $\$ 800 / \mathrm{kW} \times 50 \mathrm{MW}=\$ 40$ Million.

56 Capital cost of $\$ 800 / \mathrm{kW} \times 75 \mathrm{MW}+\$ 10$ Million environmental cost $=\$ 70$ Million.

57 The natural gas-based generation costs $\$ 500 / \mathrm{kW}$ and fuel and O\&M costs $\$ 0.025 / \mathrm{kWh}$ when a fixed price natural gas contract is entered into to eliminate fuel price uncertainty. It has an 80 percent capacity factor and a 20 percent forced outage rate when used as the primary generation source (i.e., not as backup generation). Thus, $25 \mathrm{MW}$ of capacity are required to satisfy the contract's terms. The capital cost for a $25 \mathrm{MW}$ unit is $\$ 12.5$ Million, the annual O\&M cost is $\$ 4.4$ Million, and the present value O\&M cost for 20 years is $\$ 43.2$ Million based on an 8 percent discount rate. 
spot-market cost uncertainty is resolved after the first full year of wind plant operation. ${ }^{58}$ There is a 25 percent chance that it will cost $\$ 2$ Million/year to firm the power and a 75 percent chance that it will cost $\$ 0.5$ Million/year to firm the power. The aggregator will incur this cost in the first full year of operation, whether the cost is low or high, and then will make the decision of whether or not to install back up generation. The annual cost of backup generation is $\$ 1$ Million/year.

\subsubsection{Results}

The decision tree is "folded back" by starting at the final nodes of the tree to determine the current value of the investment and what decisions should be made. The result is presented in Figure 5-18 with the numerical values representing the cumulative remaining discounted cash flows. For example, the top branch of the tree indicates that the discounted cost of making spot purchases from year 3 to year 21 if the cost is high equals \$16 Million. The squares with a numerical value in them correspond to the optimal decision (if it is a decision node) or to the expected value (if it is a probability node). The optimal path is denoted by the dashed lines.

The analysis suggests that the aggregator should begin the permitting process and the detailed wind resource assessment. The aggregator should build the wind plant if cost is low but should build the natural gas-based plant if cost is high. If the wind plant is built and the cost of spot market purchases is high, the aggregator should install backup generation after the first year of operation; the aggregator should continue to firm with spot market purchases if the cost is low.

The cost of satisfying the terms of the contract with this combined approach is about $\$ 47$ Million. This is less than the $\$ 52$ Million cost of the natural gas-based generation option alone. It can be shown using a decision tree with no decision nodes that the expected cost of the wind approach without the off-ramp after permitting and firmed only back natural gas generation equals $\$ 55$ Million, which exceeds the natural gas-based option alone. That is, there are positive synergies between the various options presented.

58 In reality, this does not have to be a single decision point because the aggregator can install backup generation in the second year of operation if it is not installed at the end of the first year; the aggregator can install backup generation in the third year if it is not installed in the first two years; etc. 


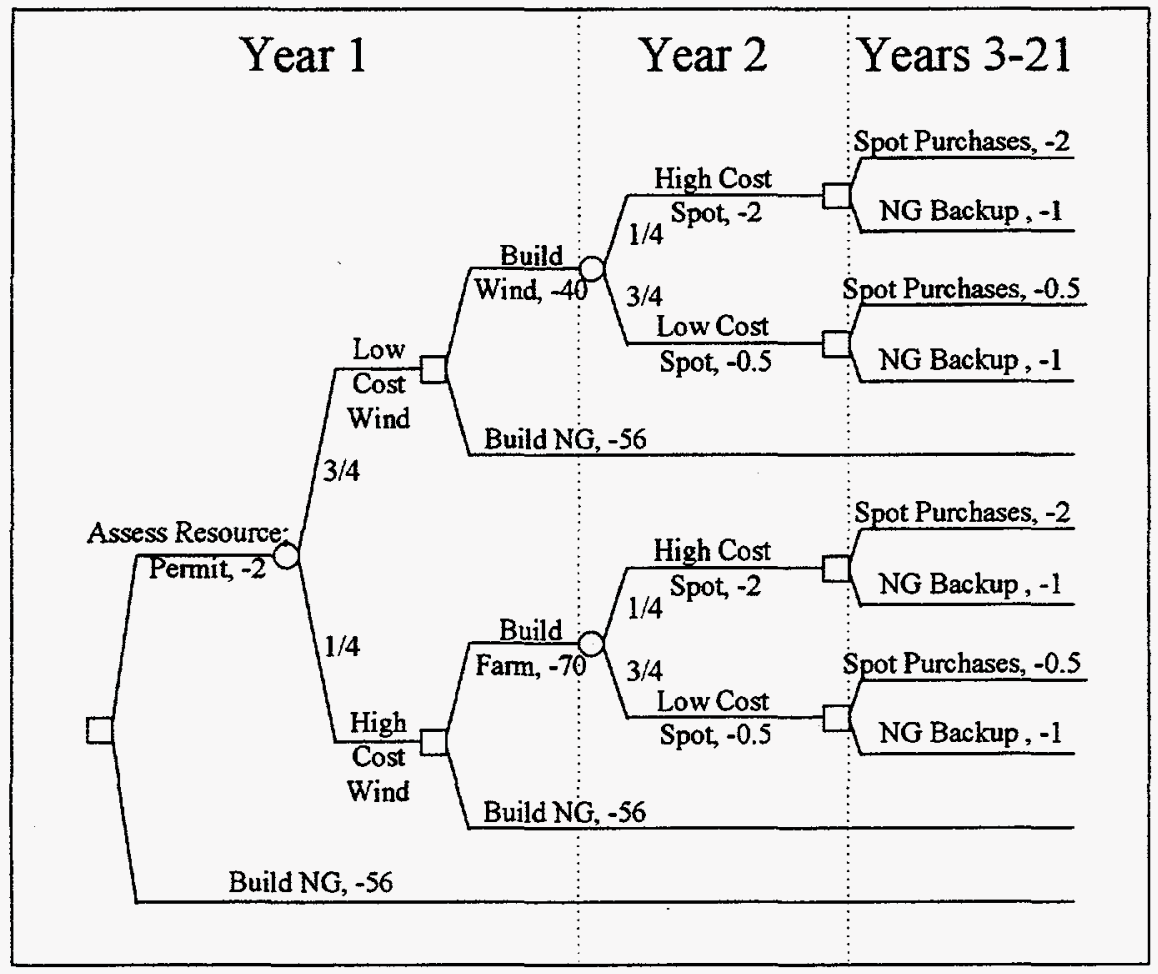

Figure 5-17. Staged wind plant investment (non-discounted annual cash flows in \$ Millions).

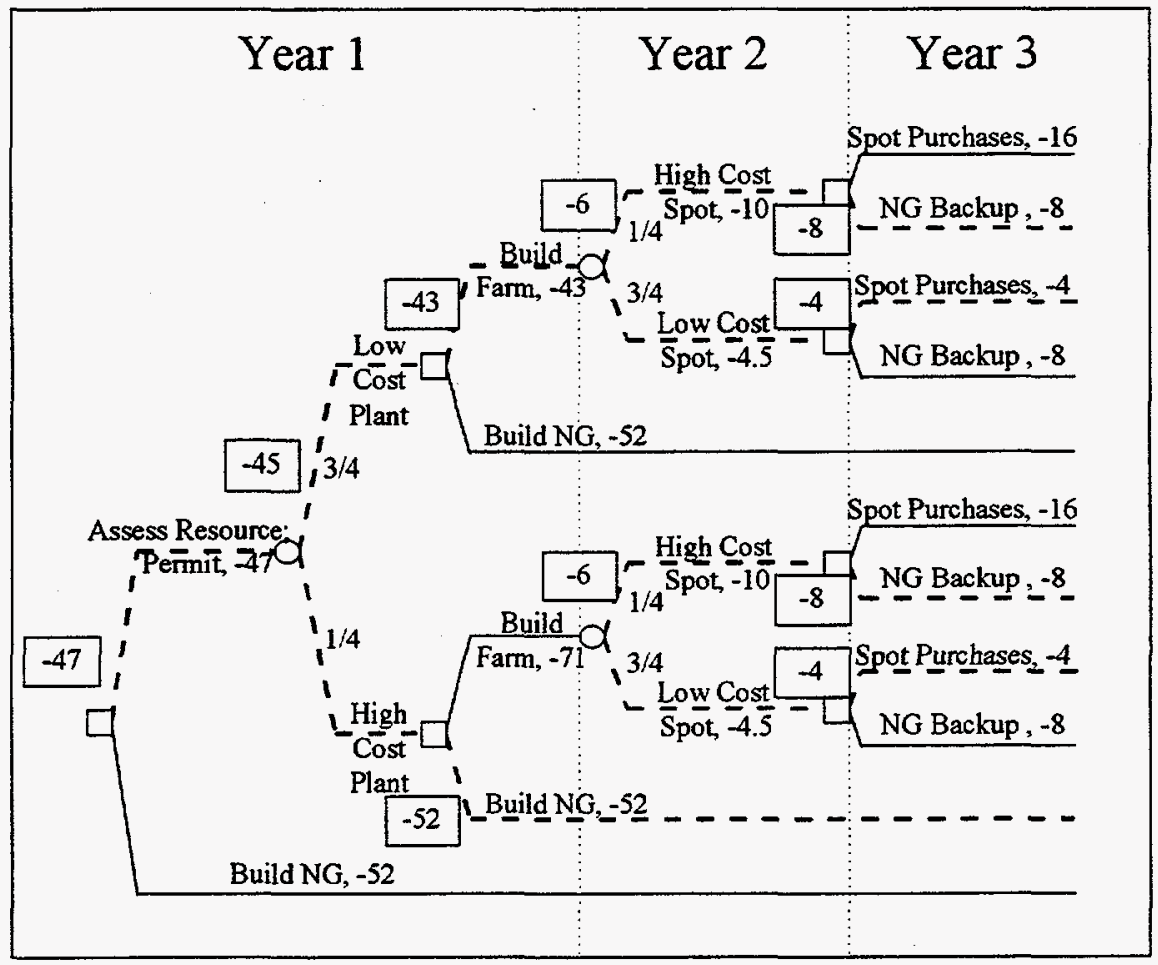

Figure 5-18. Staged wind plant investment decision (cumulative remaining discounted cash flows in \$ Millions). 


\subsection{INVESTMENT REVERSIBILITY}

\subsubsection{Introduction}

Investment reversibility is the degree to which an investment is reversible once it is completed. This is of interest to plant owners because they need to know if it is possible to salvage the plant and what its value is should the plant's value in the particular application become very low. Modular plants are likely to have a higher salvage value to investors than non-modular plants because it is more feasible to move the plants to areas of higher value or even for use in other applications. There are two aspects to consider with this attribute. First, how difficult is it to move the technology to another location but in a similar application. Second, is it possible to use the technology in a different application.

To illustrate this concept, suppose that a utility is accepting bids for a $50 \mathrm{MW}$ battery facility. Two IPPs submit bids with identical prices. The two technologies have identical efficiencies, lifetimes, and maintenance requirements. The only difference is that one plant is a single, $50 \mathrm{MW}$ battery while the other plant is 50,000 automobile batteries (rated at 12 volts and $83.3 \mathrm{amp}$ hours). Look down the road a few years and assume that there is a technological breakthrough in Superconducting Magnetic Energy Storage so that the battery plant becomes obsolete. The plant composed of automobile batteries could be salvaged for use in cars, while the $50 \mathrm{MW}$ battery would have no other use and would be sold as scrap. This makes the modular plant superior to the non-modular plant because the plant has a higher salvage value should it turn out that the facility is not needed.

This value is not merely a hypothetical one. Consider, for example, the case of the $6 \mathrm{MW}$ Carrisa Plains PV plant facility (California). Its original owner (Arco Solar) sold the plant for strategic reasons to another company. This company dismantled the plant and resold the modules at a retail price of $\$ 4,000$ to $\$ 5,000$ per kilowatt at a time when new modules were selling for $\$ 6,500$ to $\$ 7,000$ per kilowatt (Real Goods, 1993).

Determining the option's value is accomplished in several steps. First, the plant's current market value is determined. Second, the stochastic process that plant value follows is identified. Third, the option value is calculated. Section 5.9.2 presents the evaluation in discrete time. Section 5.9 .3 presents the evaluation in continuous time. Section 5.9 .4 concludes the section with an example. 


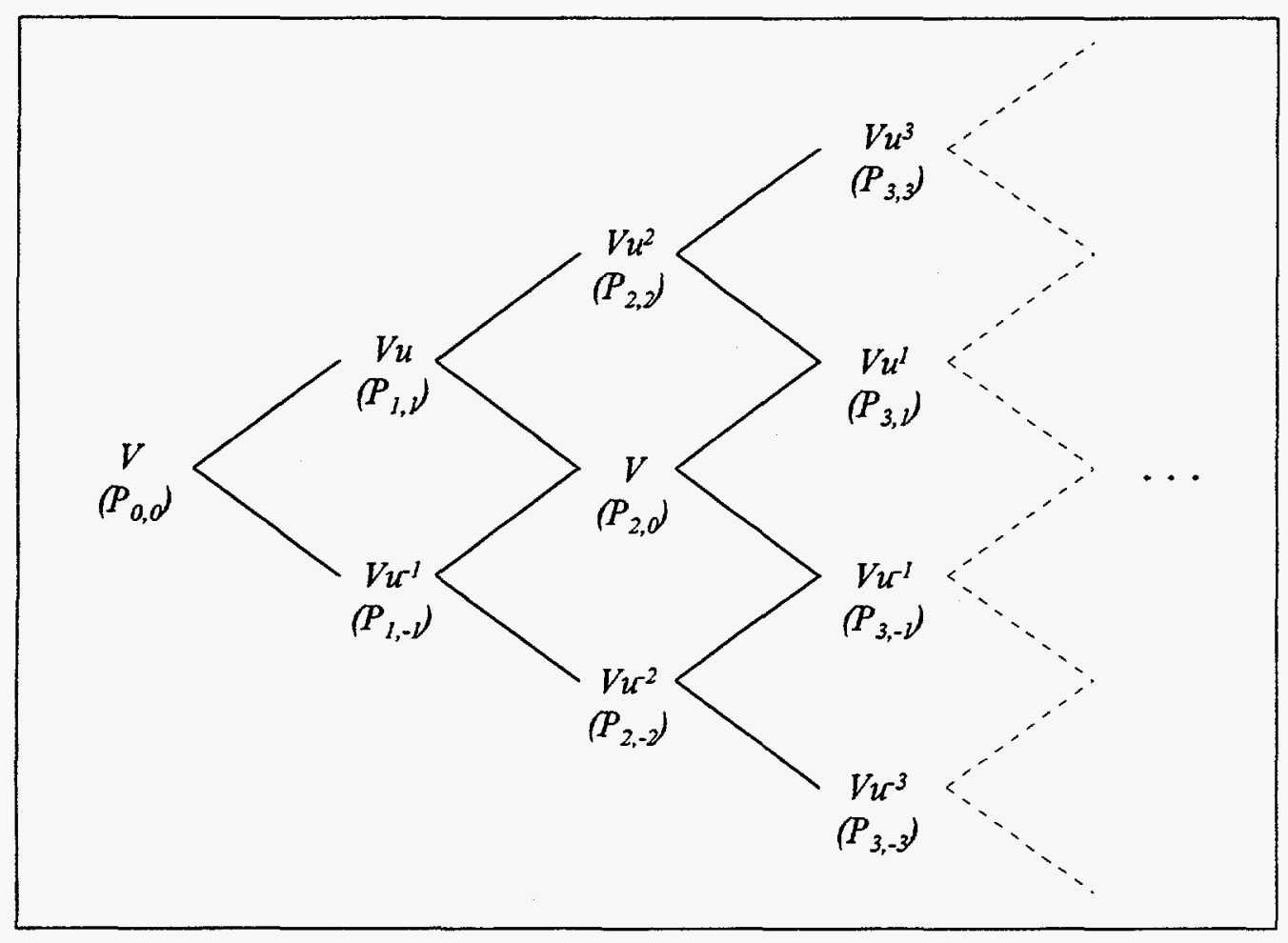

Figure 5-19. Project value and abandonment option value.

\subsubsection{Discrete Time Solution}

Suppose that a project's current market value is $V$. A typical assumption in financial markets is that stock prices follow geometric Brownian motion so that future price has a log-normal distribution; this assumption is often made in the real options literature as well. ${ }^{59}$ This distribution can be approximated by allowing project value to increase by a factor of $u$ or decrease by a factor of $1 / u$ at any particular time, where $u=\exp (\sigma \sqrt{\Delta t}), \sigma$ is the standard deviation of the project's value, and $\Delta t$ is the time increment selected (see, Hull 1993 for further details). The resulting binomial tree is shown in Figure 5-19

The $P_{i, j}$ in parenthesis below the $V$ s correspond to the value of the put option at each point in time and in each state. For example, $P_{l, l}$ is the put option value at time 1 in state 1 . The goal is to calculate $P_{0,0}$.

One approach to calculating $P_{0,0}$ is to construct a portfolio of the project and a risk-less asset (i.e., a risk-free bond) at each point in time and in each state so that the payoff from the portfolio is the same as the payoff of the option regardless of which state actually occurs; this approach is used in the continuous time subsection. Another approach is to calculate the state prices that one would

59 This assumption may be accurate in determining the downside potential of the value of the project (because the lowest that the value can go with geometric Brownian motion is 0 ) but may be questionable when working with call options because the upside potential of the project becomes unlimited. Since this analysis is working with the put option, the geometric Brownian motion assumption is retained. 
pay to receive a dollar in the given states and multiply the put option payoff by these prices to determine its current value; that is the approach taken in this subsection.

The state prices for a process that follows geometric Brownian motion do not change over time if the risk-free interest rate and cash flow (as a percentage of project value) are constant over time. That is, only one set of state prices needs to be calculated for all nodes of the binomial tree. The prices are calculated as follows. The current value of the project, less any dividends received from owning the project, equals the state price weighted sum of the project's value at the next time period.

Suppose that that project pays dividends at a continuous rate of $\delta$ times the project's value, or $\delta V$. The dividend received in discrete time from time 0 to time $\Delta t$ equals $V[1-\exp (-\delta \Delta t)]$. Plant value less the dividend equals $V \exp (-\delta \Delta t)$. This, in turn, equals the state-price weighted sum of the value in the next time period. ${ }^{60}$

$$
V \exp (-\delta \Delta t)=V u \pi_{u}+V u^{-1} \pi_{u^{-1}}
$$

where $\pi_{u}$ is the current price of receiving one dollar if project value increases to $V u$ and $\pi_{u^{-1}}$ is the current price of receiving one dollar if project value decreases to $V u^{-1}$.

The other part of the portfolio is to buy a risk-less asset. The current value of the risk-less asset must equal the state price weighted sum of the value at the next time period. The current price of the risk-less asset is 1 and has an identical payoff in either state.

$$
1=\exp (r \Delta t) \pi_{u}+\exp (r \Delta t) \pi_{u^{-1}}
$$

The solution to this system of linear equations, which can be determined using linear algebra, ${ }^{61}$ is that $\pi_{u}=\frac{\exp (\sigma \sqrt{\Delta t}-\delta \Delta t)-\exp (-r \Delta t)}{[\exp (2 \sigma \Delta t)-1]}$ and $\pi_{u^{-1}}=\frac{\exp (\sigma \sqrt{\Delta t}-r \Delta t)-\exp (-\delta \Delta t)}{\exp (2 \sigma \Delta t)-1}$. These state prices are used to calculate the abandonment option value.

The value of the abandonment option at time $i$ in state $j$, where $X_{i}$ is the salvage value of the project at time $i$, equals the greater of exercising the option (for a value of $X_{i}-V u^{j}$ ) or holding the option (for a state-price weighted value of $\pi_{u} P_{i+1, j+1}+\pi_{u^{-1}} P_{i+1, j-1}$ ). Thus,

60 The dividend is not included because it is the one who owns the plant at time 0 that receives the dividend, not the one who buys the plant at time 1 .

61 $\left[\begin{array}{cc}V \exp (-\delta \Delta t) \\ 1\end{array}\right]=\left[\begin{array}{cc}V u & V u^{-1} \\ \exp (r \Delta t) & \exp (r \Delta t)\end{array}\right]\left[\begin{array}{c}\pi_{u} \\ \pi_{u^{-1}}\end{array}\right]$ so $\left[\begin{array}{c}\pi_{u} \\ \pi_{u^{-1}}\end{array}\right]=\left[\begin{array}{cc}V u & V u^{-1} \\ \exp (r \Delta t) & \exp (r \Delta t)\end{array}\right]^{-1}\left[\begin{array}{c}V \exp (-\delta \Delta t) \\ 1\end{array}\right]$. 
$P_{i, j}=\max \left[X_{i}-V u^{j}, \pi_{u} P_{i+1, j+1}+\pi_{u^{-1}} P_{i+1, j-1}\right]$.

(Note that the state-price weighted value of the option when it expires equals 0 so that $P_{i, j}$ is always non-negative.) Equation (5.18) is iteratively entered into a spreadsheet program to calculate the value of the abandonment option at time 0 (i.e., $P_{0,0}$ ).

\subsubsection{Continuous Time Solution}

This subsection presents a continuous time solution to the value of the abandonment option. It assumes that the plant's salvage value is constant over time (i.e., $X_{i}=X$ for all $i$ ). The reader can skip the mathematical details of this section go right to the solution (Equations (5.23) and (5.24)). Interested readers should refer to a source such as Dixit and Pindyck (1994) for details of the mathematical approach employed in this subsection.

Construct a portfolio that consists of the abandonment option, $F(V)$, and a short position of $F^{\prime}(V)$ units of the project (the ' represents the derivative of $F$ ). The value of the portfolio equals $F(V)-F^{\prime}(V) V$. The short position requires a payment $\delta V F^{\prime}(V)$ dollars per time period in order to compensate the investor who holds the long position because the investor is not obtaining any of the plant's output (i.e., its dividends). The total return from holding this portfolio over a short time interval $d t$ equals

$d F(V)-F^{\prime}(V) d V-\delta V F^{\prime}(V) d t$.

Since $V$ follows geometric Brownian motion (i.e., $d V=\alpha V d t+\sigma V d z$, where $\alpha$ is the expected growth in value, $\sigma$ is the standard deviation, and $d z$ in an increment of a Wiener process), Ito's Lemma states that $d F(V)=F^{\prime}(V)(d V)+\frac{1}{2} F^{\prime \prime}(V)(d V)^{2}$. This is substituted into Equation (5.19) along with the recognition that $(d V)^{2}=\sigma^{2} V^{2} d t$ to determine the total return on this portfolio.

$\frac{1}{2} \sigma^{2} V^{2} F^{\prime \prime}(V) d t-\delta V F^{\prime}(V) d t$

The portfolio has been constructed so that it is risk-free over the short interval of time $d t$. Thus, it must earn the risk-free rate of return times the portfolio value.

$r\left[F(V)-F^{\prime}(V) V\right] d t$

Equating Equations (5.20) and (5.21) and divided by $d t$ yields the differential equation that $F(V)$ must satisfy.

$\frac{1}{2} \sigma^{2} V^{2} F^{\prime \prime}(V)+(r-\delta) V F^{\prime}(V)-r F(V)=0$. 
It turns out that Equation (5.22) is solved by substituting $F(V)=A V^{\beta}$ and its derivatives into the equation, where $\beta$ has two solutions. The solution that applies in the case of the abandonment option is that

$$
\beta=\frac{1}{2}-(r-\delta) / \sigma^{2}-\sqrt{\left[(r-\delta) / \sigma^{2}-\frac{1}{2}\right]+2 r / \sigma^{2}} .
$$

The solution is completed (i.e., the value of $A$ is determined) based on the boundary conditions that when the option is exercised, its value $\left(V^{*}\right)$ equals the plant's salvage value less the remaining plant value (i.e., $F\left(V^{*}\right)=X-V^{*}$ ) and that the derivatives are equal as well (i.e., $\left.F^{\prime}\left(V^{*}\right)=-1\right)$.

The result is that the value of the abandonment option equals

$$
F(V)=\left(\frac{-1}{\beta}\right)\left[\left(\frac{\beta}{\beta-1}\right) X\right]^{(1-\beta)} V^{\beta}
$$

where $\beta$ must equal the value that is calculated in Equation 4.27, $X$ is the plant's salvage value, and $V$ is the current value of the plant. Equation (5.24) is valid as long as $\left(\frac{\beta}{\beta-1}\right) X<V$; beyond this range, the option should be exercised immediately for a value of $F(V)=X-V$.

\subsubsection{Example: Abandonment Option Value}

It is useful to illustrate how these results can be used. This subsection presents the value of an abandonment option based on the salvage value's relationship to the current plant value. It uses the results from the continuous time section, thus assuming a constant salvage value over the plant's infinite life.

Figure 5-20 presents the value of the option to abandon a plant as a percent of current market value versus the plant's salvage value. It assumes a 10 percent risk-free rate, 5 percent value of plant output (i.e., the dividend), infinite plant life, constant salvage value over time, and standard deviations of the plant's value of 10 percent, 25 percent and 50 percent. The figure suggests, for example, that the value of the abandonment option is 20 percent of the plant's current market value when the standard deviation equals 50 percent and plant salvage value is 75 percent of the current market value. 


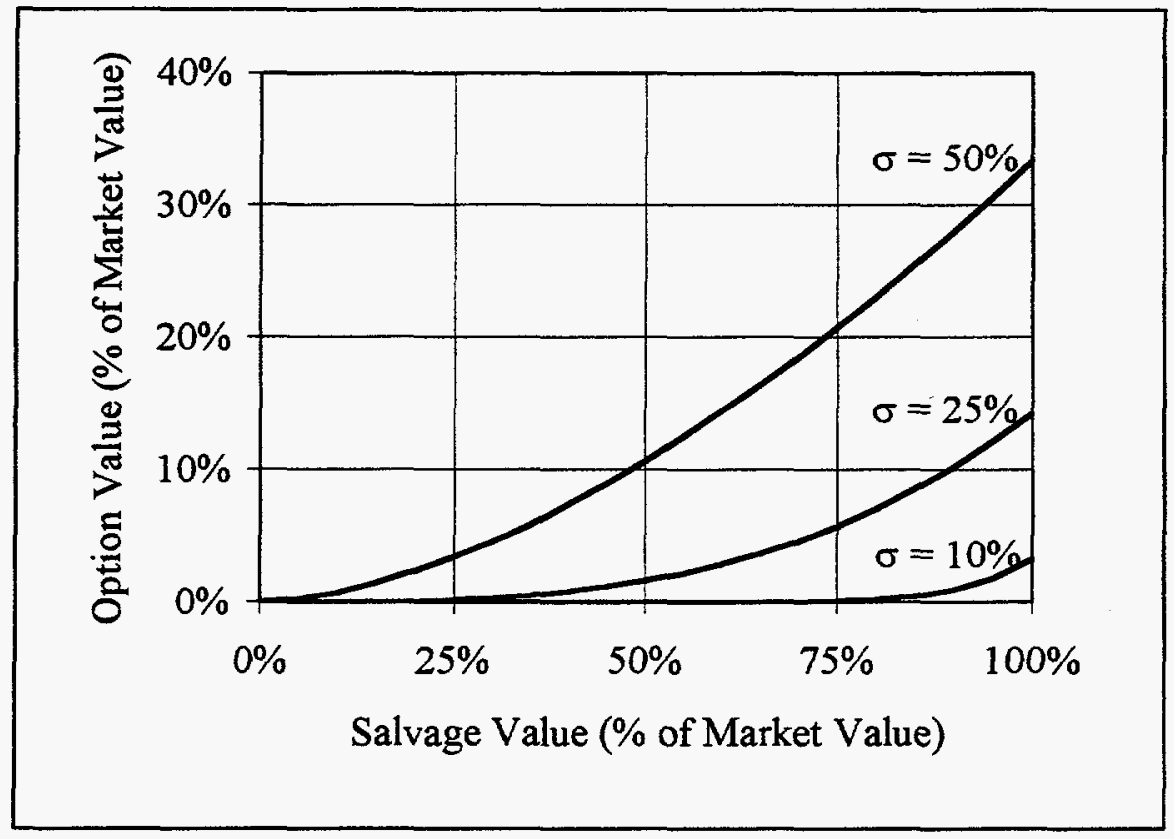

Figure 5-20. Value of abandonment option. 


\section{CONCLUSIONS AND FUTURE RESEARCH}

\subsection{CONCLUSIONS}

Regulatory and technical forces are causing electric utilities to move from a natural monopoly to a more competitive environment. Associated with this movement is an increasing concern about how to manage the risks associated with the electric supply business. One approach to managing: risks is to purchase financial instruments such as options and futures contracts. Another approach is to own physical assets that have low risk attributes or characteristics.

This research investigated the potential of controlling risk in the electric supply industry by owning renewable energy technologies. It identified uncertainties that are of concern to utilities and other power producers, including fuel prices, demand, environmental regulations, capital cost, supply, and market structure. The research qualitatively discussed how the attributes of renewable energy technologies are of value to various types of plant owners in light of these uncertainties. It developed methods to quantify the risk-mitigation value of each of the attributes. Explicit consideration was given to the attributes of fuel costs, environmental costs, lead-time, modularity, location flexibility, availability, initial capital costs, and investment reversibility. It demonstrated how to apply the methods with examples. The more detailed examples included:

- a municipal utility's investment in wind; this resulted in a reduction in fuel price uncertainty (Section 5.2.4), a reduction in environmental cost uncertainty (Section 5.3.3), and enabled the utility to respond to demand uncertainty using the wind plant's modularity and short lead-time (Section 5.6.3);

- a utility's expansion of the grid to non-grid-connected areas using customer-owned PV when there is demand uncertainty (Section 5.4.2);

- a utility's use of distributed PV generation to respond to demand uncertainty on the T\&D system (Section 5.6.5); and

- a renewable aggregator's use of wind technologies and the project off-ramps that they provide (Section 5.8.3).

In general, this research concludes that renewable energy technologies, especially modular technologies such as wind and $\mathrm{PV}$, can provide decision-makers with physical risk-management investments. In particular, it:

- provided an overview of project evaluation methods as background information;

- described how renewables can be used to manage known risks faced by various types of plant owners in the electric supply industry;

- developed methods to calculate the risk-mitigating value of the various attributes; and

- applied the methods using simple examples.

\subsection{FUTURE RESEARCH}

\subsubsection{Apply Results to Actual Case Studies}

The bulk of this work focused on identification and quantification of the risk-mitigation value of renewable technology attributes. Application of the methods was demonstrated using detailed examples. As such, it would be valuable to perform comprehensive case studies. It would be 
particularly useful to present decision-makers contemplating an actual investment decision with a renewable technology alternative that allows them to mitigate some of the risks they are facing based on the risk-mitigating attributes identified in this report. This would help to determine how effective someone making an investment decision thinks that renewable energy technologies could be in helping to mitigate real risks. A particular type of decision-maker that needs further definition and clarification is the renewable aggregator.

\subsubsection{Develop Methodology and Paradigm}

\subsubsection{Additional Attributes}

While important work has been presented in this research, it is by no means comprehensive. There are several areas that need further development. First, the attributes here are arbitrary and there are undoubtedly other important uncertainties and attributes that need to be considered. As these are identified, perhaps during the course of conducting detailed case studies, there will be the need to develop analytical approaches to determine their risk-mitigating value.

\subsubsection{More Effective Incorporation of Risk Preference}

Second, at perhaps a more fundamental level, the analytical methods developed to quantify the risk-mitigation value can be further developed. In particular, while the methods are generally effective at incorporating uncertainty into the analysis, many of them do not explicitly incorporate the decision-maker's risk preferences into the decision. This is indicated by the number of calculations that assume the decision-maker is an expected value decision-maker. A next step in the development of these methods is to more effectively incorporate risk preference into the analysis.

\subsubsection{Framework Re-examination}

Third, this research based the analysis primarily on known resource attributes and uncertainties as defined in the literature. It used these defined attributes to demonstrate how renewable energy technologies can mitigate defined risks. Re-examining this evaluation framework would be beneficial. This might take the form of re-defining the attributes. Table 6-1 illustrates one way that this might be done by defining the relevant attributes based on inputs, outputs, capital investments, and human investments associated with any resource investment. The area of human investments and how renewables affect this category, for example, has not even been considered in this research; other neglected categories may exist as well. Other definitions may be more beneficial.

A more fundamental approach may be to suggest a new paradigm by which new investments should be evaluated. Such a result may be particularly timely and appropriate given utility restructuring. 
Table 6-1. Alternative attribute descriptions.

\begin{tabular}{|c|c|c|}
\hline Attribute & Flexibilities & Uncertainties \\
\hline \multicolumn{3}{|l|}{ Inputs } \\
\hline Fuel & $\begin{array}{l}\text { Fuel types that can be used to } \\
\text { generate power }\end{array}$ & $\begin{array}{l}\text { Fuel availability (both short-term } \\
\text { and long-term) }\end{array}$ \\
\hline \multicolumn{3}{|l|}{ Outputs } \\
\hline Electricity & $\begin{array}{l}\text { Output capability and timing } \\
\text { (dispatchability; planned outages) }\end{array}$ & $\begin{array}{l}\text { Demand; Supply reliability } \\
\text { (unplanned outages) }\end{array}$ \\
\hline Emissions & $\begin{array}{l}\text { Amount and type of emissions or } \\
\text { potential emissions }\end{array}$ & Emissions costs \\
\hline \multicolumn{3}{|l|}{ Capital Investment } \\
\hline Cost & & $\begin{array}{l}\text { Project delays, cost overruns, } \\
\text { economic obsolescence }\end{array}$ \\
\hline Reversibility & $\begin{array}{l}\text { Degree to which fixed capital } \\
\text { investments can be reversed }\end{array}$ & Salvage value \\
\hline Size & Modularity & Demand \\
\hline Lead-time & $\begin{array}{l}\text { pre-construction/construction lead- } \\
\text { time flexibility }\end{array}$ & Demand \\
\hline Location & $\begin{array}{l}\text { Flexibility of where resource can } \\
\text { be connected to system }\end{array}$ & Demand \\
\hline Human Investment & & \\
\hline
\end{tabular}

\subsubsection{Develop Software}

An examination of Chapter 5 will show that a substantial amount of mathematical detail is required to perform some of the value calculations. It would be useful to develop software to assist in calculating the risk-mitigating value of the various attributes. This could be particularly effective if the software is constructed in a way so as to enable decision-makers to construct their own case studies based on their needs and to quantitatively assess the risk-mitigation potential of renewable technologies given their own assumptions. The most desirable form of the software may take more concrete shape as detailed case studies are performed. 


\section{BIBLIOGRAPHY}

Awerbuch, S., and W. Deehan, "Do Consumers Discount the Future Correctly? A Market-Based Valuation of Residential Fuel Switching" Energy Policy 23, 1 (1995), 57-69.

Awerbuch, S., "Market-based IRP: It's Easy!!!" The Electricity Journal 8, 3 (1995), 50-67.

Bailey, Bruce H., et. al., "Evaluation of a Demand Side Management Photovoltaic System." IEEE Transactions on Energy Conversion 8, 4 (1993) 621-627.

Balson, W. E., J. L. Welsh, and D. S. Wilson, "Using Decision Analysis and Risk Analysis to Manage Utility Environmental Risk," Interfaces 22, 6 (1992) 126-139.

Bashambu, R. L., and R. L. Yates, "Which is Cheaper? A Small or a Large Unit," Transactions of the American Association of Cost Engineers, AACE 29th Annual Meeting, Denver, CO, (1985).

Baugh, K., et. al., "Green Pricing: Removing the Guesswork," Public Utilities Fortnightly 133, 15 (1995), 26-28.

Bernhardt, I., "Negative Risk? A Comment on Khan and Fiorino," Engineering Economist 39, 3 (1994), 281-285.

Bernow, S., et. al., Resource and Compliance Planning: A Utility Case Study of Combined SO2/CO2 Reduction, Final Report, U.S. Environmental Protection Agency, Acid Rain Division (1994).

Bernt, R. E., M. J. Doanne, and R. J. Epstein, "Electric Utility Rates and the Evaluation of Management Performance," The Electricity Journal 8, 7 (1995), 69-77.

Birdner, J. S., et. al., "Siting, Installation, and Performance Issues for Commercial Roof Mounted PV Systems," World Conference on Photovoltaic Energy Conversion, Waikola, HI, December (1994).

Bodmer, E. C., and R. H. Waldman, "A Market-Based Approach for Analysis of Utility Decisions," The Electricity Journal 8, 3 (1995), 36-42.

Booth, L. D., "Correct Procedures for the Evaluation of Risky Cash Outflows," Journal of Financial and Quantitative Analysis 17, 2 (1982), 287-300.

Brathwaite, L., and J. Gopal, "Fuel Diversity Analysis," Analysis prepared for the 1992 Electricity Report in California, California Energy Commission (1992).

Brealey, R. A., and S. C. Myers, Principles of Corporate Finance, fourth edition, New York: McGraw-Hill Inc. (1991).

Brown, D. T., T. R. Lewis, and M. D. Ryngaert, "The Real Debate Over Purchased Power," The Electricity Journal 7, 7 (1994), 61-67.

Cadogan, J. B., et. al., "The Risks of Conventional Utility Supply Sources and the Rewards of Renewable Energy," Windpower 1992.

Cater, J. C., "Valuing Options for Electric Power Resources," The Electricity Journal 8, 3 (1995), 43-49.

Connors, S. R., "Informing Decision-Makers and Identifying Niche Opportunities for Windpower: Use of Multi-Attribute Tradeoff Analysis to Evaluation Non-Dispatchable Resources," Energy Policy 24, 2 (1996).

Constantinides, G. M., "Market Risk Adjustment in Project Valuation," J. Finance 33, 2 (1978), 603-616.

Cox, J. C. and S. A. Ross, "The Valuation of Options for Alternative Stochastic Processes," $J$. Financial Economics 3, 1/2 (1976), 145-166. 
Copeland, T. E., and J. F. Weston, Financial Theory and Corporate Policy, third edition, Massachusetts: Addison-Wesley (1988).

Copeland, T., T. Koller, and J. Murrin, Valuation: Measuring and Managing the Value of Companies, New York: John Wiley \& Sons (1990).

Dixit, A. K. and R. S. Pindyck, Investment Under Uncertainty, Princeton, New Jersey: Princeton University Press (1994).

Duffie, D., Dynamic Asset Pricing Theory, Princeton University Press, Princeton, New Jersey (1992).

Fama, E. F., "Risk-Adjusted Discount Rates and Capital Budgeting Under Uncertainty," Journal of Financial Economics 5, 1 (1977), 3-24.

Forde, J., "New Game, New Rules," Public Utilities Fortnightly 132, 19 (1994), 22-25.

Garner, W. L., "SMUD Plans a Renewable Future," Public Utilities Fortnightly 132, 22 (1994), 10-11.

Greenwell, C., "Designing Profitable Rate Options Using Area- and Time- Specific Costs," Distributed Resources 1995: EPRI's First Annual Distributed Resources Conference, Kansas City, Missouri, August (1995).

Hamrin, J., and N. Rader, Affected with the Public Interest: Electric Utility Restructuring in an Era of Competition, National Association of Regulatory Utility Commissioners, (1994).

Hassett, K. A. and G. E. Metcalf, "Energy Conservation: Do Consumers Discount the Future Correctly?" Energy Policy 21, 6 (1993), 710-716.

Hobbs, B. F., "Optimization Methods for Electric Utility Resource Planning," European Journal of Operational Research 83, 1 (1995), 1-20.

Hobbs, B. F., J. C. Honious, and J. Bluestein, "Estimating the Flexibility of Utility Resource Plans: An Application to Natural Gas Cofiring for $\mathrm{SO}_{2}$ Control," IEEE Transactions on Power Systems 9, 1 (1994), 167-173.

Hobbs, B. F., and P. Maheshwari, "A Decision Analysis of the Effect of Uncertainty Upon Electric Utility Planning," Energy 15, 9 (1990), 785-801.

Hoff, T. E., "Investment Valuation in Incomplete Markets," Stanford University Working Paper (1996).

Hoff, T. E., "Identifying Distributed Generation and Demand Side Management Investment Opportunities," The Energy Journal 17, 4 (1996), 89-105.

Hoff, T. E., and C. Herig, "Managing Risk Using Renewable Energy Technologies," Chapter 8 in The Virtual Utility, edited by Awerbuch and Preston, Kluwer Academic Publishers (1997).

Hoff, T., and J. J. Iannucci, "Maximizing the Benefits Derived from PV Plants: Selecting the Best Plant Design and Plant Location," Proceedings of the $21^{\text {St }}$ IEEE PV Specialists Conference Kissimmee, FL (1990).

Hoff, T., and J. J. Iannucci, "Siting PV Plants: A Value Based Approach,"

T. Hoff and J. J. Iannucci, Proc. of the 20th IEEE PV Specialists Conference, Las Vegas, NV (1988).

Hoff, T. E., H. J. Wenger, and B. K. Farmer, "Distributed Generation: An Alternative to Electric Utility Investments in System Capacity," Energy Policy 24, 2 (1996), 137-147.

Howard, R. A., "In Praise of the Old Time Religion," in Utility Theories: Measurements and Applications, W. Edwards (ed.), Boston, Massachusetts: Kluwer Academic Publishers (1992)

Hull, J. C., Options, Futures, and Other Derivative Securities, second edition, New Jersey: Prentice Hall (1993). 
Hull, J. C., "A Note on the Risk-Adjusted Discount Rate Method," Journal of Business Finance \& Accounting 31, 3 (1986), 445-450.

Hyman, L. S., America's Electric Utilities: Past, Present and Future fifth edition, Arlington Virginia: Public Utilities Reports, Inc. (1994).

Jacobs, F. M., and T. E. Huntley, "Valuation of Fuel Diversity," Testimony in California Energy Commission 1992 Electricity Report Proceeding, Docket No. 90-ER-92 (1992).

Jennings, E. H., "Financial Leverage and the Energy Policy Act of 1992," The Electricity Journal 6,7 (1993), 52-61.

Johnson, B. E., "Modeling Energy Technology Choices: Which Investment Analysis Tools are Appropriate," Energy Policy 22, 10 (1994), 877-883.

Jones, S. T., and F. A. Felder, "Using Derivatives in Real Decisionmaking," Public Utilities Fortnightly 132, 19 (1994), 18-21, 25.

Kahn, A. M., and D. P. Fiorino, "The Capital Asset Pricing Model in Project Selection: A Case Study," Engineering Economist 37, 2 (1992), 145-160.

Kaslow, T. W., and R. S. Pindyck, "Valuing Flexibility in Utility Planning," The Electricity Journal 7, 2 (1994), 60-65.

Kenetech, Annual Report (1993, 1994a).

Kenetech, U.S. Securities Exchange Commission Form 10-K (1994b).

Kolbe, L., and W. B. Tye, "The Cost of Capital Does Not Compensate for Stranded-Cost Risk," Public Utilities Fortnightly 133, 10 (1995), 26-28.

Kolbe, L. A., et. al., "Purchased Power - Hidden Costs or Benefits?" The Electricity Journal 7, 7 (1994), 74-83.

Lang, H. J., and D. N. Merino, The Selection Process for Capital Projects, New York: John Wiley \& Sons (1993).

LeBlanc, W., "Energy Service Marketing: ESM Supplants DSM," Public Utilities Fortnightly 133, 13 (1995), 20-24.

Lively, M., "Electric Transmission Pricing: Are Long-Term Contracts Really Futures Contracts?," Public Utilities Fortnightly 132, 19 (1994), 29-32.

Logan, D. M., et. al., "Integrated Resource Planning with Renewable Resources," The Electricity Journal 8, 3 (1995), 56-66.

Logan, D., C. Neil, and A. Taylor, Modeling Renewable Energy Resources in Integrated Resource Planning NREL/TP-462-6436 (1994).

Lowell, J., New England Electric, An Approach to Managing Risk in the Resource Portfolio, (1995) presentation at EPRI/NREL workshop.

Masters, G. M., Introduction to Environmental Engineering and Science, New Jersey: Prentice Hall (1991).

Morris, P. A, et. al., "Value of Flexibility and Modularity of Distributed Generation Technologies: Photovoltaics at PG\&E's Kerman Substation -- EPRI Investment Strategies Project," EPRI Report, September 1993.

Moskovitz, D., and P. Bradford, "Paved with Good Intentions: Reflections on FERC's Decisions Reversing State Power Procurement Processes," The Electricity Journal 8, 7 (1995), 62-68.

Myers, S. C., and S. M. Turnbull, "Capital Budgeting and the Capital Asset Pricing Model: Good News and Bad News," Journal of Finance 32, 2 (1977), 321-333.

Niagara Mohawk Power Corporation, Annual Report (1994). 
Orans, Ren, et. al., Targeting DSM for Transmission and Distribution Benefits: $A$ Case Study of PG\&E's Delta District. Research Report TR-100487, Palo Alto, California: Electric Power Research Institute (1992).

Pacific Gas and Electric Company, Annual Report (1989 through 1994).

Photovoltaic Insider's Report, August (1995).

Piepmeier, J., "The Value of Electric Utilities: Erosion of the Bond," The Electricity Journal 8, 5 (1995), 72-79.

Price, J. P., "The Growing Strategic Role of Fuels," Public Utilities Fortnightly 133, 7 (1995), 27-30.

Price, S., B. Clauhs, and J. Bustard, "Profitability and Risk Assessment of T\&D Capital Expansion Plans," Distributed Resources 1995: EPRI's First Annual Distributed Resources Conference, Kansas City, Missouri, August (1995).

Real Goods, Summer 1993 Catalog (1993).

Robichek, A. A., and S. C. Myers, "Conceptual Problems in the Use of Risk-Adjusted Discount Rates," Journal of Finance 21, 4 (1966), 727-730.

Ross, S. A., and R. W. Westerfield, Corporate Finance, third edition, Illinois: Irwin (1993).

San Diego Gas and Electric Company, Annual Report (1994)

Schwartz, P., The Art of the Long View, New York: Doubleday (1991).

Senate Bill 656 Net Metering Legislation (1995).

Smith, J. E. and R. F. Nau, "Valuing Risky Projects: Option Pricing Theory and Decision Analysis," Management Science 41, 5 (1995), 795-816.

Southern California Edison, Annual Report (1994).

Speckman, B. and S. Schleimer, "A New Index Prices the Market," Public Utilities Fortnightly 133, 5 (1995), 30-31.

Standard and Poor's Global Project Finance, September (1996), p. 9.

Staschus, K., et. al., "A Multi-Attribute Evaluation Framework for Electric Resource Acquisition in California," Electric Power \& Energy Systems 13, 2 (1991), 73-80.

Sutherland, R. J., "Natural Gas Contracts in an Emerging Competitive Market," Energy Policy 21, 12 (1993), 1191-1204.

Swezey, B. G., and Y. Wan, "The True Cost of Renewables," Solar Today 9, 6 (1995), 30-32.

Teisberg, E. O., "Capital Investment Strategies Under Uncertain Regulation," RAND Journal of Economics 24, 4 (1993), 591-604.

Teisberg, E. O., "An Option Valuation Analysis of Investment Choices by a Regulated Firm," Management Science 40, 4 (1994), 535-548.

Thuesen, G. J., and W. J. Fabrycky, Engineering Economy, eighth edition, New Jersey: Prentice Hall (1993).

Trigeorgis, L. and S. P. Mason, "Valuing Managerial Flexibility," Midland Corporate Finance J. 5, 1 (1987), 14-21.

Value Line Investment Survey, Part 1 Summary \& Index, August 18, 1995.

Van Horne, J. C., Financial Management and Policy, tenth edition, New Jersey: Prentice Hall (1995).

Wan, Y. and B. K. Parsons, Factors Relevant to Utility Integration of Intermittent Renewable Technologies, REL/TP-463-4953 (1993). 
Weinberg, C. J., J. J. Iannucci, and M. M. Reading, "The Distributed Utility: Technology, Customer, and Public Policy Changes Shaping the Electrical Utility of Tomorrow." Energy Systems and Policy 15, 4 (1991), 307-322.

Wenger, H, J. Berdner, and C. Jennings, "Service Without the Wire: Developing a New Service Concept at PG\&E," Proceedings of the 1994 Annual Conference, American Solar Energy Society, San Jose, CA, June (1994).

Wenger, H. J., and T. E. Hoff, The Value of Photovoltaics in the Distribution System: The Kerman Grid-Support Project Pacific Gas and Electric Company R\&D Report 007.5-94-15 (1995a).

Wenger, H., and T. Hoff, "Validating QuickScreen, a Distributed Resource Planning Tool," Distributed Resources 1995: EPRI's First Annual Distributed Resources Conference, Kansas City, Missouri, August (1995b).

Wenger, H., and T. Hoff, QuickScreen: A Guide to Evaluate the Cost-Effectiveness of Distributed PV Generation Sandia National Laboratories Contract AM-5255 (1996).

Wenger, H., and T. Hoff, J. Berdner, Rooftop Photovoltaics, Pacific Gas and Electric Company, Research and Development (1996).

Wenger, H. J., T. Hoff, and R. Perez, "PV as a Demand-Side Management Option: Benefits of a Utility-Customer Partnership," World Energy Engineering Congress, Atlanta, GA (1992).

Wind Energy Weekly 14, 647 (May 22, 1995a).

Wind Energy Weekly 14, 651, (June 19, 1995b). 


\section{REPORT DOCUMENTATION PAGE}

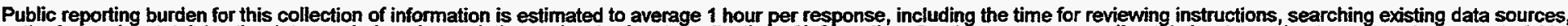

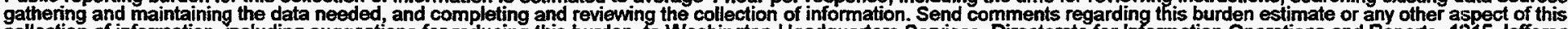

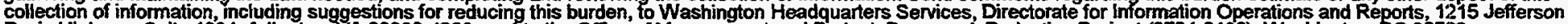

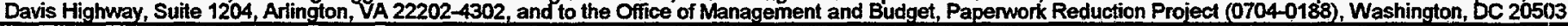

\section{AGENCY USE ONLY (Leave blank) \\ 2. REPORT DATE July 1997}

3. REPORT TYPE AND DATES COVERED Subcontractor Report

4. TITLE AND SUBTITLE

Integrating Renewable Energy Technologies in the Electric Supply Industry:

A Risk Management Approach

6. AUTHOR(S)

T.E. Hoff

7. PERFORMING ORGANIZATION NAME(S) AND ADDRESS(ES)

Pacific Energy Group

32 Valla Ct.

Walnut Creek, CA 94596

9. SPONSORINGIMONITORING AGENCY NAME(S) AND ADDRESS(ES)

National Renewable Energy Laboratory

1617 Cole Blvd.

Golden, CO 80401-3393

5. FUNDING NUMBERS

C: $X A X-6-16817-01$

TA: PV707104

8. PERFORMING ORGANIZATION REPORT NUMBER

10. SPONSORING/MONITORING AGENCY REPORT NUMEER

SR-520-23089

DE97050801

11. SUPPLEMENTARY NOTES

NREL Technical Monitor: C. Herig

12a. DISTRIBUTION/AVAILABILITY STATEMENT

12b. DISTRIBUTION CODE

UC-1320

13. ABSTRACT (Maximum 200 words)

We investigated the potential of controlling risk in the electric supply industry by owning renewable energy technologies. We idertified uncertainties that are of concern to utilities and other power producers, including fuel prices, demand, environmental regulations, capital cost, supply, and market structure. We discuss qualitatively how the attributes of renewable energy technologies are of value to various types of plant owners in light of these uncertainties. We developed methods to quantify the risk-mitigation value of each of the attributes. Explicit consideration was given to the attributes of fuel costs, environmental costs, lead-time, modularity, location flexibility, availability, initial capital costs, and investment reversibility. We demonstrated how to apply the methods. The more-detailed examples included the following four cases: The first example is a municipal utility's investment in wind; this resulted in a reduction in fuel price uncertainty, a reduction in environmental cost uncertainty, and enabled the utility to respond to demand uncertainty using the wind plant's modularity and short lead-time. The second example covers a utility's expansion of the grid- to nongrid-connected areas using customer-owned photovoltaic (PV) when there is demand uncertainty. The third example is a utility's use of distributed PV generation to respond to demand uncertainty on the transmission and distribution (T\&D) system. The last example is a renewable aggregator's use of wind technologies and the project off-ramps that they provide. In general, our research concludes that renewable energy technologies, especially modular technologies such as wind and PV, can provide decision-makers with physical risk-management investments. In particular, we provide an overview of project evaluation methods as background information, describe how renewables can be used to manage known risks faced by various types of plant owners in the electric supply industry, develop methods to calculate the risk-mitigating value of the various attributes, and apply the methods using simple examples.

14. SUBJECT TERMS photovolataics ; renewable energy technologies ; electric supply industry ; risk management

15. NUMBER OF PAGES 82

16. PRICE CODE

20. LIMITATION OF ABSTRACT OF THIS PAGE Unclassified
19. SECURITY CLASSIFICATION OF ABSTRACT Unclassified
UL
OF REPORT

Unclassified 